Aus dem Institut für Molekulare Onkologie

(Prof. Dr. med. M. Dobbelstein)

im Göttinger Zentrum für Molekulare Biowissenschaften

der Medizinischen Fakultät der Universität Göttingen

\title{
Die Interaktion von ErbB2/Her2 mit Hitzeschockproteinen in Mammakarzinomzellen
}

\author{
INAUGURAL-DISSERTATION \\ zur Erlangung des Doktorgrades \\ der Medizinischen Fakultät der \\ Georg-August-Universität zu Göttingen
}

vorgelegt von

Felix Streller

aus

Berlin 
Dekan:

I. Berichterstatter:

II. Berichterstatter/in:

III. Berichterstatter/in:

Tag der mündlichen Prüfung:
Prof. Dr. rer. nat. H. K. Kroemer

Prof. Dr. med. M. Dobbelstein 



\section{Inhaltsverzeichnis}

Inhaltsverzeichnis

Publikation der Ergebnisse

III

Abkürzungsverzeichnis

IV

Verzeichnis der Abbildungen

VII

Verzeichnis der Tabellen

VII

$1 \quad$ Einleitung

1.1 Brustkrebs

1.2 Die ErbB-Familie und der ErbB2-Rezptor als Angriffspunkt gezielter Krebstherapie

1.3 Makrophagen-Migration-inhibierender Faktor (MIF) und Brustkrebs - ein Zytokin auf Abwegen

1.4 Die zentrale Rolle der Hitzeschockproteine (HSP) als essentielle Unterstützer entarteter Zellen

1.5 Hitzeschockfaktor-Protein 1 (HSF-1) - Der Regulator der Hitzeschockantwort

1.6 Ziel dieser Arbeit: Erkenntnisgewinn bezüglich des Zusammenspiels von ErbB2-Rezeptor, HSF-1, HSP und Hsp90-Klienten in SK-BR-3-Brustkrebszellen

2 Material \& Methoden

2.1 Materialien

2.1.1 Puffer \& Lösungen

2.1.2 Antikörper

2.1.3 Reagenzien und Enzyme für RT- und qPCRReaktion

2.1.4 Primer

2.1.5 Inhibitoren

2.1.6 Zellkulturzubehör

2.1.7 Zelllinien

2.2 Methoden

2.2.1 Zellkultur

2.2.2 Zell-Behandlung

2.2.3 Hitzeschockbehandlung

2.2.4 Proteinextraktion von Zellkulturen zur WesternBlot-Analyse

2.2.5 Polyacrylamidgelelktrophorese (PAGE)

2.2.6 Western Blot \& Proteindetektion 
2.2.7 RNA-Extraktion von Zellkulturen zur qPCRAnalyse

2.2.8 Reverse Transkriptase (RT)-Reaktion

2.2.9 Quantitative real-time PCR (qPCR) 22

2.2.10 Immunfluoreszenz (IF)

2.2.11 Bestimmung des Anteils der Zellen mit granulärer Kernanfärbung

\section{Ergebnisse}

3.1 Auswahl der Zelllinien - MIF und ErbB2-Proteinlevel in MCF-7, MDA-MB-231 und SK-BR-3-Zellen

3.2 Eine Inhibition des ErbB2-Signalweges führt zu einem Absinken der MIF-Proteinlevel

3.3 Die Herabregulierung der MIF-Proteinlevel nach einer ErbB2-Inhibition wird über den PI3K-Akt-Signalweg vermittelt

3.4 Eine Inhibition des ErbB2-Rezeptors senkt die HSPLevel, die Aktivität der HSP und die Stabilität verschiedener Hsp90-Klienten

3.5 Die Aktivierung von HSF-1 durch einen Hitzeschock wird durch eine ErbB2-Inhibition eingeschränkt

3.6 Die Inhibition des ErbB2-Signalweges verändert die Transkriptionsrate HSF-1-regulierter Gene

3.7 Eine ErbB2-Inhibition verhindert die transkriptionelle Wirkung von HSF-1 auf seine Zielgene nach einem Hitzeschock

4 Diskussion

4.1 Zusammenfassung der Ergebnisse 42

4.2 Ausblick 46

4.2.1 Die fehlende Verbindung zwischen Akt und HSF-1 46

4.2.2 Das HSF-1 Transkriptionsprogramm 46

4.2.3 ErbB2, HSF-1 und Brustkrebs - Implikationen für neue Therapieansätze

5 Zusammenfassung

6 Literaturverzeichnis 


\title{
Publikation der Ergebnisse
}

Die Ergebnisse der vorliegenden Dissertation sind zu großen Teilen veröffentlicht in Cell Death and Disease (2014) 5, e980 (doi:10.1038/cddis.2013.508):

\section{HER2/ErbB2 activates HSF1 and thereby controls HSP90 clients including MIF in HER2-overexpressing breast cancer}

\author{
R Schulz ${ }^{1}$, F Streller ${ }^{1}$, A H Scheel $^{2}$, J Rüschoff ${ }^{2}$, M-C Reinert ${ }^{1}$, M Dobbelstein ${ }^{1}, \mathrm{~N}$ \\ D Marchenko $\underline{\underline{3}}$ and $\cup \mathrm{M}$ Moll $1, \underline{3}$ \\ ${ }^{1}$ Institute of Molecular Oncology, GZMB, University of Göttingen, Göttingen 37077, Germany
${ }^{2}$ Institute for Pathology Nordhessen, Kassel 34119, Germany
${ }^{3}$ Department of Pathology, Stony Brook University, Stony Brook, NY 11794, USA
}

Abstract

Overexpression of the human epidermal growth factor receptor-2 (HER2) in breast cancer strongly correlates with aggressive tumors and poor prognosis. Recently, a positive correlation between HER2 and MIF (macrophage migration inhibitory factor, a tumor-promoting protein and heat-shock protein 90 (HSP90) client) protein levels was shown in cancer cells. However, the underlying mechanistic link remained unknown. Here we show that overexpressed HER2 constitutively activates heatshock factor 1 (HSF1), the master transcriptional regulator of the inducible proteotoxic stress response of heat-shock chaperones, including HSP90, and a crucial factor in initiation and maintenance of the malignant state. Inhibiting HER2 pharmacologically by Lapatinib (a dual HER2/epidermal growth factor receptor inhibitor) or CP724.714 (a specific HER2 inhibitor), or by knockdown via siRNA leads to inhibition of phosphoactivated Ser326 HSF1, and subsequently blocks the activity of the HSP90 chaperone machinery in HER2-overexpressing breast cancer lines. Consequently, HSP90 clients, including MIF, AKT, mutant p53 and HSF1 itself, become destabilized, which in turn inhibits tumor proliferation. Mechanistically, HER2 signals via the phosphoinositide-3-kinase (PI3K)-AKT- mammalian target of rapamycin (mTOR) axis to induce activated pSer326 HSF1. Heat-shock stress experiments confirm this functional link between HER2 and HSF1, as HER2 (and PI3K) inhibition attenuate the HSF1-mediated heat-shock response. Importantly, we confirmed this axis in vivo. In the mouse model of HER2-driven breast cancer, ErbB2 inhibition by Lapatinib strongly suppresses tumor progression, and this is associated with inactivation of the HSF1 pathway. Moreover, ErbB2-overexpressing cancer cells derived from a primary mouse ErbB2 tumor also show HSF1 inactivation and HSP90 client destabilization in response to ErbB2 inhibition. Furthermore, in HER2-positive human breast cancers HER2 levels strongly correlate with pSer326 HSF1 activity. Our results show for the first time that HER2/ErbB2 overexpression controls HSF1 activity, with subsequent stabilization of numerous tumor-promoting HSP9O clients such as MIF, AKT and HSF1 itself, thereby causing a robust promotion in tumor growth in HER2-positive breast cancer. 


\begin{tabular}{|c|c|}
\hline${ }^{\circ} \mathrm{C}$ & Grad Celsius \\
\hline$\mu g$ & Mikrogramm \\
\hline$\mu l$ & Mikroliter \\
\hline$\mu \mathrm{M}$ & mikromolar $(\mu \mathrm{mol} / \mathrm{l})$ \\
\hline 36B4 & Gen für ein ribosomales Protein der 60S-Untereinheit \\
\hline APS & Ammoniumperoxodisulfat \\
\hline ATP & Adenosintriphosphat \\
\hline Bcl-xL & B-cell lymphoma-extra large \\
\hline BSA & bovines Serum Albumin \\
\hline CBX3 & Gen für das chromobox protein homolog 3 \\
\hline CDC6 & Gen für das cell division control protein 6 homolog \\
\hline cDNA & komplementäre DNA \\
\hline $\mathrm{CO}_{2}$ & Kohlenstoffdioxid \\
\hline CP724.714 & ErbB2-Inhibitor \\
\hline CTP & Cytosintriphosphat \\
\hline DAPI & 4',6-Diamidin-2-phenylindol \\
\hline DBD & DNA-Bindungs-Domäne \\
\hline DEPC & Diethyldicarbonat \\
\hline DMSO & Dimethylsulfoxid \\
\hline DNA & Desoxyribonukleinsäure \\
\hline dNTPs & Desoxynukleosidtriphosphate \\
\hline EDTA & Ethylendiamintetraessigsäure \\
\hline EGF & epidermaler Wachstumsfaktor \\
\hline EGFR (ErbB1) & epidermaler Wachstumsfaktor-Rezeptor \\
\hline ER & Östrogenrezeptor \\
\hline ErbB2 (Her2) & Bezeichnung eines Rezeptors der ErbB-Familie \\
\hline ERK & Extracellular-signal Regulated Kinases \\
\hline FASN & Gen für die Fettsäure-Synthase \\
\hline FCS & fetales Kälberserum \\
\hline g & Gramm \\
\hline GAPDH & Glycerinaldehyd-3-Phosphat-Dehydrogenase \\
\hline GTP & Guanosintriphosphat \\
\hline Her2neu & Bezeichnung eines Rezeptors der ErbB-Familie (ErbB2) \\
\hline HIF-1 $1 \alpha$ & Hypoxie-induzierter Faktor $1 \alpha$ \\
\hline HSF-1 & Heat shock factor protein 1 \\
\hline HSP & Hitzeschockprotein/e \\
\hline
\end{tabular}




\begin{tabular}{|c|c|}
\hline Hsp27/70/90/110 & heat shock protein $27 / 70 / 90 / 110$ \\
\hline $\mathrm{IHC}$ & Immunhistochemie \\
\hline IF & Immunfluoreszenz \\
\hline $\lg G$ & Immunglobulin G \\
\hline$(\mathrm{F}) \mathrm{ISH}$ & (Floureszenz)-in-situ-Hybridisierung \\
\hline $\mathrm{KCl}$ & Kaliumchlorid \\
\hline $\mathrm{kDa}$ & Kilodalton (atomare Masseneinheit) \\
\hline $\mathrm{KH}_{2} \mathrm{PO}_{4}$ & Kaliumdihydrogenphosphat \\
\hline I & Liter \\
\hline Ly294002 & Bezeichnung eines PI3K-Inhibitors \\
\hline M & molar (mol/l) \\
\hline MCF7 & (Michigan Cancer Foundation - 7) \\
\hline & Bezeichnung einer Brustkrebszelllinie \\
\hline MDA-MB-231 & (M.D. Anderson - metastatic breast) \\
\hline & Bezeichnung einer Brustkrebszelllinie \\
\hline MEK & Mitogen-aktivierte Protein Kinase Kinase \\
\hline $\mathrm{mg}$ & Milligramm \\
\hline MIF & Makrophagen-Migration-inhibierender Faktor \\
\hline $\min$ & Minute/n \\
\hline $\mathrm{ml}$ & Milliliter \\
\hline $\mathrm{mM}$ & millimolar (mmol/l) \\
\hline M-MuLV & moloney murine leukemia virus \\
\hline mRNA & messenger Ribonucleinsäure \\
\hline mTOR & mammalian-target-of-rapamycin \\
\hline mut & mutiert \\
\hline$n$ & Anzahl (der Experimente) \\
\hline n.s. & nicht signifikant \\
\hline $\mathrm{Na}_{2} \mathrm{HPO}_{4} \times 2 \mathrm{H}_{2} \mathrm{O}$ & Dinatriumhydrogenphosphat Dihydrat \\
\hline $\mathrm{NaCl}$ & Natriumchlorid (Kochsalz) \\
\hline NEB & New England Biolabs \\
\hline $\mathrm{nm}$ & Nanometer \\
\hline nSBs & nukleäre Stresskörperchen \\
\hline pAkt & Serin(473)-phosphorylierte Form von Akt \\
\hline PBS & phosphatgepufferte Salzlösung \\
\hline PBST & PBS mit Zusatz von Tween20 \\
\hline pERK & Tyrosin(204)-phosphorylierte Form von ERK \\
\hline pHSF-1 & Serin(326)-phosphorylierte Form von HSF-1 \\
\hline
\end{tabular}




\begin{tabular}{|c|c|}
\hline PI3K & Phosphoinositid-3-Kinase \\
\hline pmol & Pikomol \\
\hline PR & Progesteron-Rezeptor \\
\hline qPCR & quantitative Polymerasekettenreaktion \\
\hline qRT-PCR & quantitative Reverse-Transkriptions-Polymerasekettenreaktion \\
\hline Raf & (rapidly accelerated fibrosarcoma) eine Proteinkinase \\
\hline Ras & (rat sarcoma) ein kleines G-Protein \\
\hline $\mathrm{RD}$ & regulatorische Domäne \\
\hline RIPA & Radioimmunopräzipitations-Assay \\
\hline RNA & Ribonukleinsäure \\
\hline RNase & Ribonuklease \\
\hline RPMI & Roswell Park Memorial Institute \\
\hline RT-PCR & Reverse-Transkriptions/real-time-Polymerasekettenreaktion \\
\hline s & Sekunde \\
\hline S & Serin \\
\hline SDS & Natriumdodecylsulfat \\
\hline SDS-PAGE & Natriumdodecylsulfat-Polyacrylamid-Gelelektropherese \\
\hline siRNA & small interfering RNA \\
\hline SIRS & septic inflammatory response syndrome \\
\hline \multirow[t]{2}{*}{ SK-BR-3 } & (Sloan-Kettering HER2 3+ Breast Cancer) \\
\hline & Bezeichnung einer Brustkrebszelllinie \\
\hline TAD & Transaktivierungsdomäne \\
\hline TBS(T) & trisgepufferte Salzlösung (mit Zusatz von Tween20) \\
\hline TEMED & Tetramethylethylendiamin \\
\hline TGF & transformierender Wachstumsfaktor \\
\hline TNM & Tumor, Node, Metastasis \\
\hline Tris & Tris(hydroxymethyl)-aminomethan \\
\hline TTP & Thymidintriphosphat \\
\hline U0126 & Bezeichnung eines MEK1/2-Inhibitors \\
\hline VEGF & vaskulärer endothelialer Wachstumsfaktor \\
\hline wt & Wildtyp \\
\hline$\times g$ & $x$-faches der Erdbeschleunigung \\
\hline $\mathrm{Y}$ & Tyrosin \\
\hline zVAD & N-Benzyloxycarbonyl-Val-Ala-Asp(O-Me) fluoromethyl ketone \\
\hline
\end{tabular}




\section{Verzeichnis der Abbildungen}

Abbildung 1 - ErbB2-Signalwege-modulierende Pharmaka................................... 5

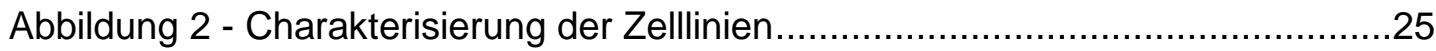

Abbildung 3 - MIF-Proteinlevel nach einer ErbB2-Inhibition ................................27

Abbildung 4 - MIF-Herabregulierung durch ErbB2-Inhibition via Akt-Signalweg ......30

Abbildung 5 - ErbB2-Inhibition bewirkt eine Inhibition der HSP-Maschinerie ............32

Abbildung 6 - ErbB2-Inhibition verringert HSF-1-Aktivierung...............................34

Abbildung 7 - ErbB2-Inhibition reprimiert HSF-1-Aktivierung .................................36

Abbildung 8 - ErbB2-Inhibition alterniert die Transkription des HSF-1-

Programms ..... .39

Abbildung 9 - ErbB2-Inhibition behindert HSF-1-Wirkung auch nach Hitzeschock

Abbildung 10 - Veranschaulichung der Hypothesen

\section{Verzeichnis der Tabellen}

Tabelle 1 - Hsp90-Funktionen \& Eigenschaften .................................................... 9

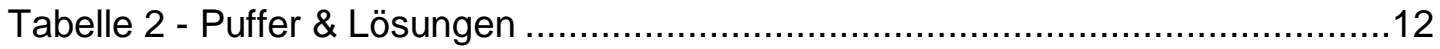

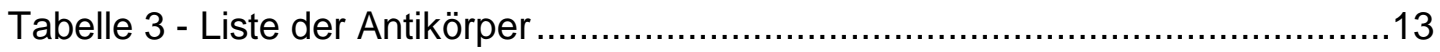

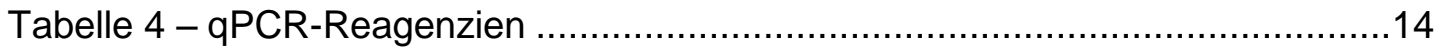

Tabelle 5 - Liste der Primer für die qPCR ….................................................... 14

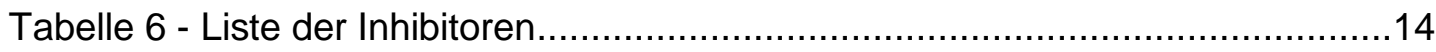

Tabelle 7 - Zellkulturzubehör.................................................................... 15

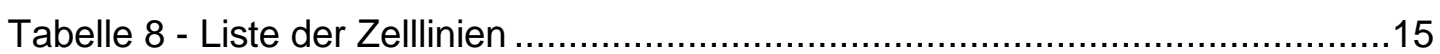

Tabelle 9 - Verdünnungsverhältnisse beim Passagieren........................................16

Tabelle 10 - Zellzahl bei Aussaat .....................................................................16

Tabelle 11 - DMSO-Gehalt im Kulturmedium behandelter Zellen ...........................16

Tabelle 12 - Zusammensetzung der Polyacrylamidgele .....................................19

Tabelle 13 - Inkubation der Western-Blot-Membranen mit Antikörpern ...................20

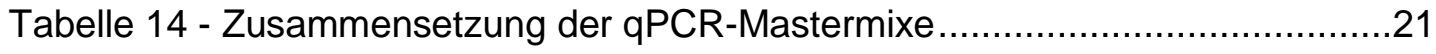

Tabelle 15 - Einzelschritte der Immunfluoreszenzfärbung ...................................23 


\section{Einleitung}

\subsection{Brustkrebs}

Neoplasien der Brustdrüse gehören mit 71660 Neuerkrankungen im Jahr 2008 in Deutschland zu den häufigsten Tumoren der Frau überhaupt. Männer erkranken nur sehr selten an Brustkrebs (Ravandi-Kashani und Hayes 1998), daher beziehen sich die folgenden Ausführungen auf Brustkrebs bei Frauen. Das mittlere Erkrankungsalter liegt bei etwa 65 Jahren, und das Lebenszeitrisiko, an einem Mammakarzinom, also Brustkrebs, zu erkranken wird auf ca. $13 \%$ geschätzt. Diese Zahlen variieren international etwas, zeigen aber für die Industrienationen ein vergleichbares Bild.

Die 5-Jahresüberlebensrate gemittelt über alle Brustkrebstypen liegt in Deutschland mit den heutigen Therapieansätzen bei etwa $80 \%$ und damit besser als bei vielen anderen Malignomen wie z.B. Speiseröhren- oder Lungenkrebs (unter $20 \%$ ) (Kaatsch et al. 2012), allerdings bestimmt der Subtypus des Brusttumors die Prognose erheblich. Karzinome der Brustdrüse werden klinisch und histopathologisch nach Tumorgröße, Lymphknotenbefall und dem Vorhandensein von Fernmetastasen klassifiziert (TNM-Klassifikation) und anhand dessen in Stadien eingeteilt (Sobin et al. 2010). Eine besonders schlechte Prognose und nahezu keine Heilungschance haben Patientinnen im metastasierten Stadium (Stadium IV) mit nur 18 - 30 Monaten durchschnittlicher Überlebenszeit (Mariani 2005). Es besteht also trotz der Erfolge und Fortschritte in der Therapie des Mammakarzinoms weiterhin Bedarf an einer Vertiefung des Verständnisses dieser Erkrankung mit dem Ziel, dadurch bessere und gezieltere Therapien zu entwickeln.

Neben der TNM-Klassifikation wird auch der sogenannte Hormonrezeptorstatus zur Einteilung unterschiedlicher Brustkrebsentitäten verwendet. Dabei wird immunhistochemisch die Expression des Östrogen- (ER) und Progesteronrezeptors (PR) bestimmt und zwischen ER-postitiv/negativ sowie PR-positiv/negativ unterschieden. Ebenso wird die Expression des Wachstumsfaktorrezeptors ErbB2 bestimmt klinisch häufig als Her2neu-Rezeptor bezeichnet - dieses Merkmal ist für das Verständnis dieser Arbeit besonders wichtig und soll daher noch näher erläutert werden. Die verschiedenen Merkmale des jeweiligen Brusttumors (TNM-Klassifikation, Hormon- sowie ErbB2-Rezeptrostatus) und das Alter der Patientin werden im klinischen Alltag zur Einteilung der betroffenen Patientinnen in Behandlungsgruppen 
gemäß der Konsensuskonferenz von St. Gallen genutzt, um sie einem optimalen Therapieregime zuordnen zu können (Goldhirsch et al. 2007).

Zur Ermittlung des ErbB2-Rezeptorstatus kommen zwei unterschiedliche Verfahren zum Einsatz, deren Ergebnisinterpretation von der Armerican Society of Clincal Oncology in den 2007 erschienenen Leitlinien beschrieben ist (Wolff et al. 2006): Zum einen die Immunhistochemie (IHC), bei der Tumorschnitte mit einem farbstoffmarkierten ErB2-Antikörper gefärbt, anschließend unter dem Mikroskop untersucht und Ausprägung der Farbintensität sowie die Anzahl positiver Zellen und die Vollständigkeit ihrer Anfärbbarkeit beurteilt werden. Daraus ergibt sich ein vierstufiger Score zwischen 0 und $3+.0$ und $1+$ werden dabei als negatives Testergebnis gewertet, 3+ als sicher positiv. Die zweite Methode ist die sog. in-situ-Hybridisierung (ISH), bei der nicht auf dem Proteinlevel der ErbB2-Rezeptor selbst, sondern auf zytogenetischer Ebene Ampflifikationen, also Mehrfachkopien, des ErbB2-Gens nachgewiesen werden. Ergibt eine Untersuchung ein nicht eindeutig positives Ergebnis (z.B. IHC-Score 2+), wird empfohlen, das bisher nicht genutzte Verfahren ebenfalls zu nutzen. Völlig diskordante Ergebnisse beider Verfahren sind mit $4 \%$ eher selten. Eine Proteinüberexpression geht also in der überwiegenden Zahl der Fälle mit einer Genamplifikation einher (Reddy et al. 2006). Bei etwa $20 \%$ der Patientinnen mit Brustkrebs lässt sich eine Amplifikation des ErbB2-Gens in den Tumorzellen nachweisen, dies korreliert mit einer schlechteren Prognose (Slamon et al. 1987).

Das Ergebnis der Untersuchung des ErbB2-Rezeptorstatus entscheidet heutzutage darüber, ob eine Patientin mit dem seit dem Jahre 2000 in der EU zugelassenen monoklonalen Antikörper Trastuzumab, der sich gegen den ErbB2-Rezeptor richtet, behandelt wird. Dieser Antikörper, der unter dem Namen Herceptin® von der Firma Roche vertrieben wird, war zunächst nur zur Behandlung des metastasierten Her2positiven Brustkrebses zugelassen, später auch zur Behandlung in kurativer Absicht (Europäische Arzeneimittelagentur 2012). Trastuzumab in Kombination mit vorheriger systemischer Chemotherapie erweist sich dabei als wirksam (Hudis 2007). Das durchschnittliche Gesamtüberleben der Patientinnen, die zusätzlich mit Trastuzumab behandelt werden, verlängert sich auf 25,1 Monate gegenüber 20,3 Monate bei Patientinnen, die Chemotherapie allein erhalten (Slamon et al. 2001). 


\subsection{Die ErbB-Familie und der ErbB2-Rezptor als Angriffs- punkt gezielter Krebstherapie}

Yarden und Pines liefern mit ihrem 2012 erschienenen Nature Review „The ERBB network: at last, cancer therapy meets systems biology“ (Yarden und Pines 2012) einen sehr gelungenen Überblick über die über 50jährige Geschichte der Entdeckung des Epidermalen Wachstumsfaktor Rezeptor (EGFR/ErbB)-Netzwerkes und dessen herausragende Bedeutung bei der Entstehung vieler Krebsarten. Sie zeigen dabei Meilensteine in der Erforschung pharmakologisch anwendbarer Substanzen in der Krebstherapie auf, wie z.B. des ErbB2-Antikörpers Trastuzumab oder des gegen ErbB2 und ErbB1 gerichteten Tyrosinkinaseinhibitors Lapatinib. Auf die bereits erforschten Details dieses komplexen biologischen Netzwerkes einzugehen, würde den Rahmen dieser Einleitung überstrapazieren, daher soll hier nur auf einige, für das Verständnis der vorliegenden Arbeit wichtige Aspekte näher eingegangen werden.

Die ErbB-Rezeptorfamilie besteht aus vier Mitgliedern: ErbB1/EGFR, ErbB2/Her2, ErbB3 und ErbB4. Alle sind transmembranäre Rezeptortyrosinkinasen, d.h. sie enthalten einen Liganden-bindenden, extrazellulären Teil, eine die Zellmembran durchspannende Transmembrandomäne und einen intrazellulären Teil, der Tyrosinkinaseaktivität besitzt und die Übertragung des extrazellulären Signals nach intrazellulär vermittelt. ErbB3 weist nur eine sehr geringe Tyrosinkinaseaktivität auf, und für ErbB2 ist bisher kein Ligand bekannt. Für die übrigen Rezeptoren sind bisher 13 verschiedene Liganden bekannt, die ErbB-Rezeptoren jeweils in unterschiedlichem Maße aktivieren können. Dazu gehören der epidermale Wachstumsfaktor EGF und der transformierende Wachstumsfaktor TGFa. Zur Aktivierung der Tyrosinkinasedomänen der ErbB-Rezeptoren muss zunächst ein Ligand gebunden werden, danach folgt die Dimerisierung zweier Moleküle der ErbB-Familie. Dabei können Homo- sowie Heterodimere gebildet werden. ErbB2, der einzige Rezeptor ohne bekannten Liganden in der Familie, ist jedoch für alle anderen ErbB-Rezeptoren der bevorzugte Dimerisierungspartner. Die Dimerisierung des ErbB2-Rezeptors mit einem weiteren Rezeptor (auch einem weiteren ErB2-Rezeptor) und darauf folgende gegenseitige Phosphorylierung der intrazellulären Domänen zieht die Rekrutierung verschiedener signaltransduzierender Proteine zum aktivierten Rezeptor nach sich. Die wichtigsten dadurch aktivierten Signalwege sind der den Phosphoinositid-3Kinasen (PI3K) nachgeschaltete Proteinkinase B- oder Akt-Signalweg und der RasRaf-MEK-ERK- Signalweg (Eccles 2011). Diese Signalwege regulieren eine Vielzahl 
zellulärer Vorgänge. Insbesondere werden Zellüberleben (Akt) und Proliferation der Zelle (MEK-ERK) mitreguliert (Alimandi et al. 1995). Eine Beobachtung von herausragender Wichtigkeit für ErB2-überexprimierende Tumorzellen machten bereits 1987 Di Fiore et al.: Bei starker Überexpression des Wachstumshormonrezeptors ErbB2 benötigt dieser keinerlei durch eine Ligandenbindung aktivierten Dimerisierungspartner mehr, um aktiviert zu werden. In ErbB2-überexprimierenden Zellen findet demnach eine ligandenunabhängige Aktivierung des ErbB2-Signalweges statt (Di Fiore et al. 1987).

Das gewonnene Verständnis über die große Bedeutung, die übermäßig aktive ErbBRezeptorsignalkaskaden in Tumorzellen spielen, führte zur Entwicklung einer groBen Anzahl an Antikörpern und Inhibitoren, die auf verschiedene Art und Weise und auf unterschiedlichen Ebenen in die ErbB-Signalwege eingreifen. Dort führen sie einheitlich zu einer Herabsenkung der Aktivierung dieser Signalwege. In Abbildung 1 findet sich eine Veranschaulichung der Angriffspunkte dieser Substanzen, von denen inzwischen einige bereits erfolgreich Einzug in die Klinik gefunden haben (z.B. Trastuzumab, Cetuximab, Erlotinib, Lapatinib) (Yarden und Pines 2012) oder sich in der klinischen Erprobung finden wie beispielsweise der Hsp90-Inhibitor 17AAG (Modi et al. 2011).

Die molekularbiologischen Wirkungsmechanismen von Trastuzumab sind seit seiner Markteinführung Gegenstand intensiver Forschung. Zwei der gut belegten Wirkungen sind die Herabsenkung der Aktivität des Ras-Raf-MEK-ERK- und des PI3K-AktSiganlweges (Vu und Claret 2012). Diese Wirkung wird auch mit dem ErbB2Tyrosinkinaseinhibitor CP724.714 erzielt (Jani et al. 2007), der in der vorliegenden Arbeit viel zum Einsatz kam. CP724.714 wäre als Chemotherapeutikum sicher eine Bereicherung in der Therapie Her2-positiven Brustkrebses, da im Gegensatz zu Trastuzumab auch oral applizierbar, allerdings wurde die klinische Erprobung aufgrund hepatotoxischer Effekte abgebrochen (Feng et al. 2009).

Als problematisch in der Trastuzumab-Therapie stellen sich primäre und sekundäre (also unter der Behandlung entstehende) Resistenzen der Tumorzellen gegen die Behandlung dar. Ein Großteil der Patientinnen, deren Brusttumoren zunächst auf eine Trastuzumabbehandlung ansprechen, zeigt im Laufe eines Jahres eine Resistenzentwicklung der Tumorzellen, die ein Voranschreiten der Erkrankung sowie den Abbruch der Trastuzumabtherapie bedeuten (Europäische Arzeneimittelagentur 2012). Es werden diverse Mechanismen diskutiert, die eine solche Resistenz bedingen könnten - viele haben jedoch gemeinsam, dass der ausbleibende Effekt der Trastuzumabbehandlung auf tiefer in der ErbB2-Signalkaskade liegende Verände- 
rungen zurückzuführen ist. Diese bedingen trotz Trastuzumabeinwirkung eine Daueraktivierung des ErbB2-Signalweges oder zumindest eines Signalwegzweiges davon (Nahta et al. 2006).

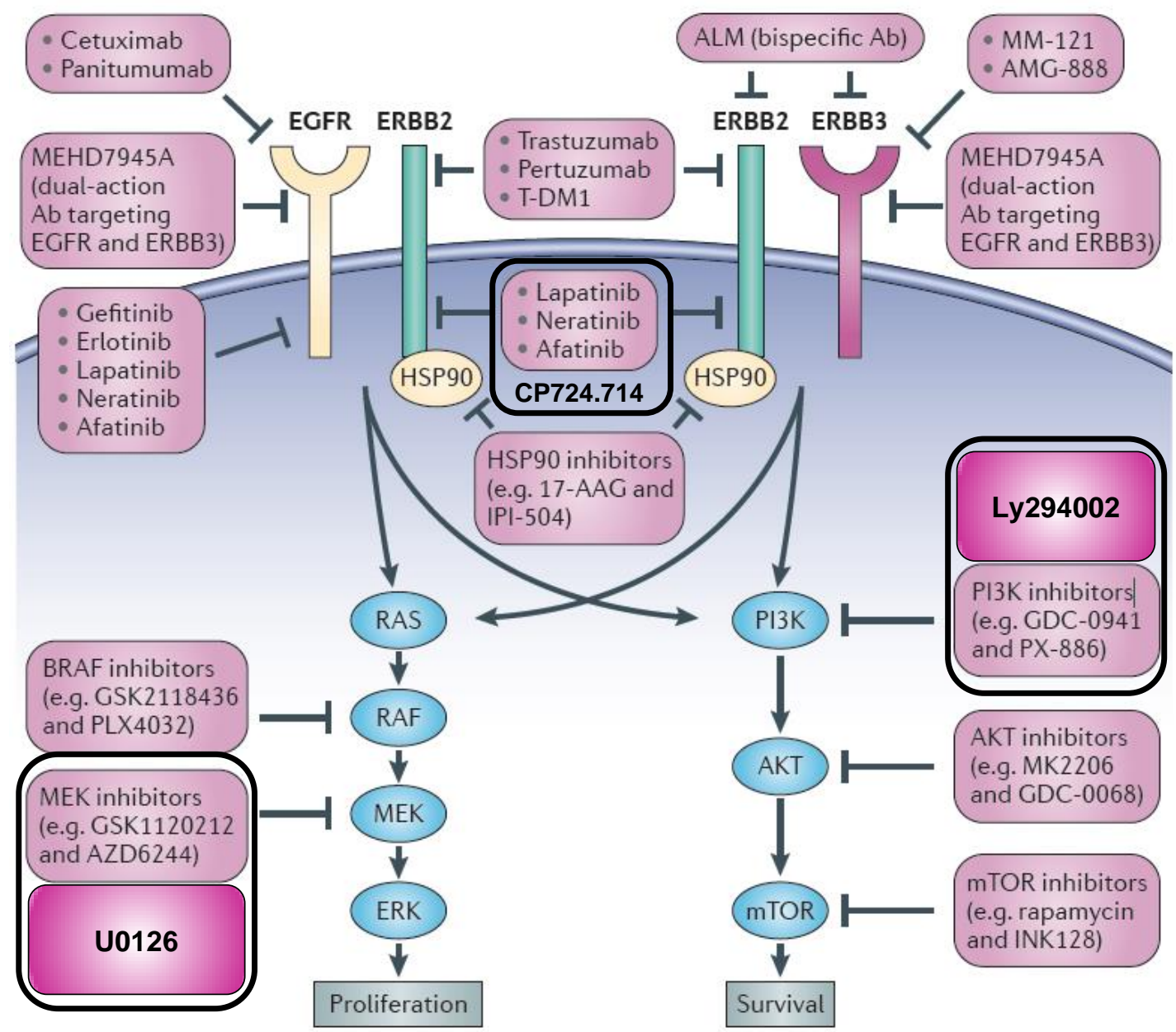

Abbildung 1: Veranschaulichung der Angriffspunkte einer Auswahl an ErbBSignalwege-modulierenden Pharmaka.

Von besonderem Interesse für diese Arbeit sind die Tyrosinkinaseinhibitoren Lapatinib (dualer Inhibitor des EGF- und ErbB2-Rezeptors) und CP724.714 (spezifischer Inhibitor des ErbB2-Rezeptors), die jeweils die intrazelluläre Kinasedomäne der ErbB-Rezeptoren inhibieren. Außerdem der MEK1/2 Inhibitor U0126 und der PI3Kinase-Inhibitor Ly294002, die jeweils nur einen der stromabwärts des ErbBRezeptors gelegenen Signalwegäste inhibieren. Die Abbildung ist Yarden und Pines 2012 erschienenem Review (Yarden und Pines 2012, S. 559) entnommen und modifiziert worden.

Dieser Umstand verdeutlicht die Notwendigkeit weitergehender Forschung, die die Mechanismen, mittels derer die ErbB2-Inhibtion eine Anti-Tumorwirkung erzielt, weiter ergründet. Ziel sollte das Aufdecken sinnvoller Angriffspunkte für eine mögliche Kombinationstherapie, beispielsweise von Trastuzumab mit anderen auf den 
ErbB2-Signalweg einwirkenden Substanzen sein, um Resistenzentwicklungen unwahrscheinlicher zu machen sowie ein tieferes Verständnis der in Tumorzellen fehlregulierten zellulären Abläufe und deren Vernetzung zu erlangen.

\subsection{Makrophagen-Migration-inhibierender Faktor und Brustkrebs - ein Zytokin auf Abwegen}

Ursprünglich wurde das Protein MIF wegen seiner Funktion als immunmodulatorisches Zytokin entdeckt und hat binnen kurzer Zeit auf diesem Feld an Bedeutung gewonnen (Calandra und Roger 2003). Unter anderem im Zusammenhang mit klinischen Krankheitsbildern wie dem septic inflammatory response syndrome (SIRS) (Larson und Horak 2006). Neben der Funktion als in die Blutbahn sezerniertes Zytokin hat MIF jedoch auch bisher nur unzureichend untersuchte, intrazelluläre Funktionen, die inn in Zusammenhang mit einer Vielzahl an Tumorerkrankungen bringen. MIF-Überexpression korreliert mit schlechterer Prognose, gesteigerter Vaskularisierung, höherer Invasivität und größerem Tumorvolumen (Conroy et al. 2010). Auch für Brustkrebszelllinien (Xu et al. 2008) und im MMTVErbB2-Mausmodell für ErbB2-überexprimierenden Brustkrebs (Schulz et al. 2012) konnte für MIF eine eindeutig pro-onkogene Wirkung nachgewiesen werden. AuBerdem konnten Choi, Jung und Koo in der Untersuchung von 276 Brustkrebsproben eine Korrelation $(p<0.05)$ zwischen erhöhter MIF-Expression und gleichzeitigem Vorliegen einer ErbB2-Überexpression zeigen (Choi et al. 2013).

Unsere Arbeitsgruppe konnte zeigen, dass MIF speziell in Tumorzellen, sowohl in vivo als auch in vitro, durch das Chaperon Hsp90 stabilisiert wird - MIF ist damit also ein neu entdeckter Hsp90-Klient (s. Kapitel 1.4, S. 7). Die Behandlung mit dem Hsp90-Inhibitor 17-AAG führte zu einem deutlichen Absinken der MIF-Level in Tumorzellen, verlangsamte in vivo die Progression von Brusttumoren und MIF knock-down mittels siRNA senkte in vitro die Proliferation von HCT116-Zellen und induzierte Apoptose (Schulz et al. 2012). Diese Erkenntnisse zeigen den hohen Stellenwert, den MIF in einigen Krebszellen einnimmt, deutlich auf.

Zwei der bislang schon untersuchten Mechanismen über die MIF seine tumorfördernde Wirkung ausübt, sind die Aktivierung des PI3K-Akt-Signalweges, dessen Stimulation der Zelle essentielle Überlebenssignale liefert und somit Apoptose verhindert (Lue et al. 2007) und auch des Ras-Raf-MEK-ERK- Signalweges (Lue et al. 2006). MIF beeinflusst also u.a. genau die Signalwege, die auch eine Schlüsselrolle in den Signalkaskaden der ErbB-Rezeptoren, insbesondere ErbB2, einnehmen. 
Außerdem verstärkt MIF die Wirkung des hypoxieinduzierten Faktors HIF-1 $\alpha$ und führt damit zu erhöhter Gefäßneubildung in Tumoren. HIF-1a ist ein Transkriptionsfaktor und bisher der einzige, für den eine induzierbare, regulatorische Wirkung auf die Transkription des MIF-Gens bekannt ist. HIF-1a induziert die Expression von MIF, und MIF wiederum verstärkt die Aktivität von HIF-1a, was z.B. in einer gesteigerten Expression des vaskulär-endothelialen Wachstumsfaktors (VEGF) zum Ausdruck kommt (Rendon et al. 2009).

Für die Regulation der intrazellulären MIF-Level sind also bisher zwei Mechanismen bekannt: Die Regulation auf Transkriptionsebene mittels HIF-1a sowie die Stabilisierung des Proteins MIF durch die Hsp90-Maschinerie.

\subsection{Die zentrale Rolle der Hitzeschockproteine (HSP) als essentielle Unterstützer entarteter Zellen}

Die Entdeckung der Hitzeschockantwort, damals observiert als massiv erhöhte Transkriptionsaktivität in Zellen von Drosophila melanogaster, die bei zu hoher Temperatur kultiviert wurden, geht auf den Italiener Ferruccio Ritossa zurück. Dies ist nun über 50 Jahre her und seitdem hat sich aus der so entdeckten Hitzeschockantwort ein riesiges Forschungsgebiet entwickelt (Maio et al. 2012). Wie sich herausstellte führte die beobachtete hohe Transkriptionsaktivität zur Synthese einiger Proteine, die Hitzeschockproteine getauft wurden. Insbesondere das Hitzeschockprotein von 90 kDa (Hsp90) ist hochkonserviert und in sehr ähnlicher Form in Bakterien- wie auch Hefe-, Tier- und menschlichen Zellen gefunden worden. Die HSP bzw. strukturell sehr nahe Verwandte davon werden allerdings auch unter Normalbedingungen, nicht nur unter Einwirkung von Stress (wie Hitze, Nährstoffmangel, Hypoxie oder pH-Änderungen), ubiquitär exprimiert. So macht z.B. Hsp90 etwa 1-2 \% des Gesamtproteingehaltes einer ungestressten Zelle aus (Whitesell und Lindquist 2005). Es existiert also sowohl eine basale HSP-Expression, wie auch eine stressinduzierte und durch den Transkriptionsfaktor HSF-1 vermittelte (s. Kapitel 1.5, S. 9).

Hitzeschockproteine werden oft auch als Chaperone (=Anstandsdame, Leibwächter) bezeichnet, was sich von ihrer biologischen Funktion ableitet: Sie „bewachen“ und ermöglichen die korrekte Faltungsweise von Proteinen, was ebenfalls erklärt weshalb unter Stressbedingungen eine Hochregulierung dieser HSP notwendig wird. Höhere Temperaturen oder $\mathrm{pH}-$ Änderungen führen zu einer größeren Anzahl fehlgefalteter Proteine, die wieder in den nativen Zustand zurückversetzt werden müs- 
sen, um nicht zu aggregieren und ihre mit der spezifischen Faltung verbundene biologische Funktion erfüllen zu können. Ist diese Reparatur nicht möglich, werden die fehlgefalteten Proteine im Proteasom degradiert und damit unschädlich gemacht. Die Hintergründe und Mechanismen der komplexen Interaktionen von HSP, die in großen Multiproteinkomplexen zusammen mit sog. Co-Chaperonen mit ihren „Klienten“ interagieren, hier näher zu erläutern würde den Rahmen einer Einleitung sprengen. Ich verweise daher auf die Reviews aus der Arbeitsgruppe um Susan Lindquist, die auf dem Gebiet der Chaperone als führend zu bezeichnen ist (Lindquist 1986; Whitesell und Lindquist 2005; Taipale et al. 2010).

Krebszellen sind durch ihr abberantes Zellprogramm und die damit verbundene Produktion von durch Genmutationen dys- oder malfunktionalen Proteinen sowie die Überproduktion von onkogenen Proteinen konstantem, proteotoxischem Stress ausgesetzt. Daher sind viele Tumorzellen regelrecht „abhängig“ (Trepel et al. 2010, S. 537) von HSP, insbesondere Hsp90. Dies trifft sowohl auf viele Tumorzellen im Allgemeinen wie auch auf Brustkrebszellen im Speziellen zu (Calderwood und Gong 2012). Eine riesige Anzahl an Proteinen, die mit Hsp90 interagieren (Picard 2013) ist inzwischen bekannt und etliche davon sind wohlbekannte tumorfördernde und/oder häufig in Tumoren mutierte Proteine sowie "Drehscheibenproteine“ an Knotenpunkten von Signalwegen, die Zellproliferation und -überleben steuern. Dazu gehören auch einige der hier schon erwähnten Moleküle wie der ErbB2-Rezeptor (Münster et al. 2002), der Transkriptionsfaktor HIF-1a (Isaacs 2002), die mutierte Form des „Wächter des Genoms“ p53 (Li et al. 2011), die Signalkinase Akt (Basso 2002), das anti-apoptotische Bcl-xL (Caldas-Lopes et al. 2009) und MIF (Schulz et al. 2012).

Besonders interessant ist, dass Hsp90 in Krebszellen abberant gefaltete (Onko)proteine (z.B. mutiertes p53) stabilisiert, die unter normalen Umständen der Degradierung im Proteasom zugeführt werden müssten. Insgesamt werden die Funktion und Eigenschaften von Hsp90 in Tumorzellen regelrecht verdreht: Die hochdynamischen, wenig stabilen Multiproteinkomplexe, in denen Hsp90 mit seinen Co-Chaperonen und Klienten physiologischerweise interagiert, wandeln sich in Krebszellen zu hochstabilen, hochaktivierten Super-Chaperon-Komplexen, welche die mutierten, z.T. trunkierten Formen der Hsp90-Klienten stabilisieren. Damit einhergehend steigt sowohl die Aktivität der ATPase Domäne des Hsp90, sowie dessen Affinität zu Inhibitoren wie 17-AAG auf das 100fache (Kamal et al. 2003), (Whitesell und Lindquist 2005). Die Unterschiede zwischen Hsp90 in untransformierten Zellen und in Tumorzellen sind in Tabelle 1 (s.u.) veranschaulicht. 


\begin{tabular}{|c|c|c|}
\hline \multicolumn{2}{|c|}{ Hsp90-Funktionen \& Eigenschaften } \\
\hline & $\begin{array}{c}\text { Untransformierte } \\
\text { Zelle }\end{array}$ & Tumorzelle \\
\hline $\begin{array}{c}\text { Stabilität der Chaperon- } \\
\text { Multiproteinkomplexe }\end{array}$ & transient, dynamisch & stabil, starr \\
\hline ATPase Aktivität & gering & hoch \\
\hline Affinität zu Inhibitoren & niedrig & $\begin{array}{c}\text { hoch } \\
\text { (100x für 17-AAG) }\end{array}$ \\
\hline Affinität zu Klienten & gering & hoch \\
\hline
\end{tabular}

Tabelle 1 - Hsp90-Funktionen \& Eigenschaften

\subsection{Hitzeschockfaktor-Protein 1 (HSF-1) - Der Regulator der Hitzeschockantwort}

Mittels des Transkriptionsfaktors HSF-1 kann eine Zelle ihr Transkriptionsprogramm in Reaktion auf Stressfaktoren schnell und massiv abändern. In Säugetierzellen existieren 4 Isoformen dieses Proteins (HSF-1/2/3/4), allerdings ist HSF-1 wohl die am besten charakterisierte und funktional bedeutsamste für die Hitzeschockantwort. Murine embryonale HSF-1 knock-out Fibroblastenzellen verlieren die Fähigkeit auf einen Hitzeschock mit Hochregulierung von HSP zu reagieren, haben aber weiterhin eine basale HSP-Expression (McMillan 1998). HSF-1 reguliert also vorrangig die stressinduzierte HSP-Expression.

HSF-1 besteht aus vier Domänen mit unterschiedlicher Funktion: Einer DNABindungsdomäne (DBD), einer Transaktivationsdomäne (TAD), die für die Rekrutierung der Transkriptionsmaschinerie zu den HSF-1-Zielgenen sorgt, einer Oligomerisierungsdomäne, die eine Trimeriesierung dreier HSF-1-Moleküle ermöglicht und einer Regulatordomäne (RD), die die Regulierbarkeit der HSF-1-Aktivierung ermöglicht. Diese Aktivierung von HSF-1 (hin zu einem aktiven Transkriptionsfaktor) ist ein komplexer Prozess, bezüglich dessen detailierter Erörterung ich auf Anckar und Sistonen verweisen möchte (Anckar und Sistonen 2011). Einige Kernpunkte sind dabei die Interaktion von HSF-1-Monomeren mit Hsp90, die durch diese Interaktion in einem inaktiven Zustand gehalten werden. Akkumulation fehlgefalteter Proteine verdrängt in diesem Modell HSF-1-Monomere aus der Interaktion mit Hsp90 und fördert so HSF-1-Aktivierung. Die freien HSF-1-Monomere lagern sich dann zu Trimeren zusammen. Die Bildung dieser Trimere ist essentiell für die Fähigkeit von 
HSF-1 als Transkriptionsfaktor zu fungieren. Ferner geschehen vielfältige posttranslationale Modifikationen von HSF-1 an seiner RD. Besonders bedeutsam dabei ist die aktivierende Phosphorylierung von S326 (Guettouche et al. 2005).

Eine Beobachtung, deren funktionelle Bedeutung noch weitgehend ungeklärt erscheint, ist die Formierung sog. nukläerer Stresskörperchen (nSBs) (Biamonti 2004), deren Bildung mit aktivierter Transkription HSF-1-regulierter Gene einhergeht und die sich z.B. vermittels Immunfluoreszenzmikroskopie sichtbar machen lässt (Sarge et al. 1993) - ein Verfahren, welches auch in dieser Arbeit Anwendung findet.

HSF-1 hat wegen seines Zusammenhanges mit der Produktion der für viele Krebszellen unentbehrlichen stressinduzierten HSP auch im Bereich der Krebsforschung große Bedeutung erlangt. Beispielsweise hat HSF-1-knock-out in Mäusen einen protektiven Effekt bezüglich der Entwicklung von Tumoren unterschiedlicher Genese (Dai et al. 2007).

Um HSF-1 bezüglich des Einflusses auf Brustkrebs zu untersuchen, haben Santanaga et al. 1841 Tumorproben von Brustkrebspatientinnen aus der Nurses's Health Study analysiert und konnten zeigen, dass hohe nukläere Anfärbbarkeit von HSF-1 mit größeren Tumoren, höherer Invasivität und schlechterer Prognose korreliert. Insgesamt war die Intensität der Kernanfärbung für HSF-1 in der immunhistochemischen Untersuchung in etwa 80 \% aller in situ und invasiven Karzinome höher als im gesunden Gewebe (Santagata et al. 2011). Meng, Gabai und Sherman konnten ferner in vitro zeigen, dass HSF-1 für die maligne Transformation von Brustdrüsenzellen durch ErbB2-Überexpression essentiell ist (Gabai et al. 2012).

Im Jahr 2012 veröffentlichten Mendillo et al. aus der Arbeitsgruppe um Susan Lindquist einen Artikel in Cell über die Beobachtung, dass HSF-1 in hochgradig entarteten Krebszellen - neben der physiologischen Funktion als Regulator der HSP-Level ein vom Muster her anderes Transkriptionsprogramm aktiviert als in nicht oder geringergradig entarteten Zellen. Einige der Gene, die Bestandteil des Tumor-HSF1-Programms sind, „unterstützen onkogene Prozesse: Zellzyklusregulation, Siganlwege, Metabolismus, Adhäsion und Translation“ (Mendillo et al. 2012, S.549).

Dass ein Fehlen von HSF-1 onkogene Prozesse verlangsamt oder ganz einschränkt, zeigt sich in vivo im MMTV-ErbB2-Mausmodell des ErbB2überexprimierenden Brustkrebses - knock-out von HSF-1 in diesen Tieren verringert die Invasivität, Metastasierung und Proliferation von Mammakarzinomen (Xi et al. 2012). 
Unabhängig von deren Funktion wurden für die vorliegende Arbeit einige Gene, die sich in Mendillos Arbeit als besonders stark HSF-1-reguliert gezeigt haben, für qPCR-Analysen ausgewählt.

\subsection{Ziel dieser Arbeit: Erkenntnisgewinn bezüglich des Zusammenspiels von ErbB2-Rezeptor, HSF-1, HSP und Hsp90-Klienten in SK-BR-3-Brustkrebszellen}

ErbB2-überexprimierender oder klinisch Her2-positiver Brustkrebs ist bereits seit 1987, dem Jahr der Entdeckung des Zusammenhanges der ErbB2-Genamplifikation mit der schlechteren Prognose für die Patientinnen (Slamon et al. 1987), Gegenstand intensiver Forschung. Angesichts der Tatsache, dass statistisch gesehen ca. 2,6 \% aller Frauen in Deutschland, also mehr als jede 40. Frau, in ihrem Leben von dieser Erkrankung betroffen sein werden, ist es nicht vermessen, von einer schon rein zahlenmäßig relevanten Erkrankung zu sprechen.

Zur Findung neuer und fortschrittlicher Therapieansätze ist ein tiefes Verständnis der molekularbiologischen Vorgänge, die innerhalb dieser spezifischen Tumorentität ablaufen, unabdingbar. Durch tieferes Verständnis ist die Ableitung besonders geeigneter Angriffspunkte für solche Therapieansätze überhaupt erst möglich. Der derzeitige Kenntnisstand liefert auch vielversprechende Vorschläge in dieser Richtung, allerdings beschränken sich die meisten Arbeiten nur auf kleinere Teilaspekte der Funktion von ErbB2.

Ziel dieser Arbeit soll es sein zu prüfen, ob die Expression des tumorfördernden Proteins MIF vom Subtyp des Brustkrebses, speziell von einer Überexpression des ErbB2-Rezeptors, abhängt. Ferner soll der Mechanismus einer etwaigen Korrelation untersucht und verstanden werden. Dabei soll durch Verknüpfen der „Iosen Fadenenden“, die sich in der Literatur über die Funktion des ErbB2-Rezeptors in Zusammenhang mit HSF-1, Hitzeschockproteinen und Hsp90-Klienten wie MIF finden, ein „roter Faden“ geschaffen werden, der ein klareres Bild der Abläufe in einer ErbB2überexprimierenden Brustkrebszelle liefert. Die daraus resultierenden Hypothesen sollen anhand von Zellkulturexperimenten geprüft werden, um am Ende dieser Arbeit ein vervollständigtes Bild dieses roten Fadens darstellen zu können. 


\section{Material \& Methoden}

\subsection{Materialien}

\subsubsection{Puffer \& Lösungen}

\begin{tabular}{|c|c|}
\hline RIPA-Puffer & $\begin{array}{l}20 \mathrm{mM} \text { Tris } \mathrm{pH} 7,5 \\
1 \% \text { TritonX-100 } \\
1 \% \text { Desoxycholat } \\
0,1 \% \text { SDS } \\
150 \mathrm{mM} \mathrm{NaCl} \\
10 \mathrm{mM} \mathrm{EDTA} \\
100000 \mathrm{KIE} / \mathrm{L} \text { Trasylol }\end{array}$ \\
\hline Laemmli Puffer & $\begin{array}{l}\text { 0,35 M Tris pH 6,8 } \\
30 \% \text { Glycerin } \\
10 \% \text { SDS } \\
\text { 9,3\% Dithiotreit } \\
\text { 0,02\% Bromphenolblau }\end{array}$ \\
\hline Laufpuffer & $\begin{array}{l}25 \mathrm{mM} \text { Tris pH 8,3 } \\
0,1 \% \text { SDS } \\
192 \mathrm{mM} \text { Glycin }\end{array}$ \\
\hline Transferpuffer & $\begin{array}{l}25 \text { mM Tris pH 8,3 } \\
192 \text { mM Glycin } \\
5 \text { mM SDS } \\
20 \% \text { Methanol }\end{array}$ \\
\hline $\begin{array}{l}\text { Waschpuffer } \\
\text { (TBST) }\end{array}$ & $\begin{array}{l}0,1 \mathrm{M} \text { Tris } \mathrm{pH} 7,5 \\
0,15 \mathrm{M} \mathrm{NaCl} \\
0,05 \% \text { Tween20 }\end{array}$ \\
\hline Blockier-Puffer & $50 \mathrm{~g} / \mathrm{L}$ Milchpulver oder bovines Serum-Albumin in TBST \\
\hline $\begin{array}{l}\text { Rotiphorese }{ }^{\circledR} \\
\text { Gel } 30(37,5: 1)\end{array}$ & $\begin{array}{l}30 \text { \% Acrylamid/Bisacrylamid im Mischungsverhältnis 37,5:1 } \\
\text { Best.-Nr. 3029.1(1 I) }\end{array}$ \\
\hline $\begin{array}{l}\text { Phosphatgepufferte } \\
\text { Salzlösung (PBS) } \\
\text { pH 7,4 }\end{array}$ & $\begin{array}{l}150 \mathrm{mM} \mathrm{NaCl} \\
2,7 \mathrm{mM} \mathrm{KCl} \\
1,5 \mathrm{mM} \mathrm{KH}_{2} \mathrm{PO}_{4} \\
4,3 \mathrm{mM} \mathrm{Na}_{2} \mathrm{HPO}_{4} \times 2 \mathrm{H}_{2} \mathrm{O}\end{array}$ \\
\hline PBST & PBS $+0,05 \%$ Tween20 \\
\hline
\end{tabular}




\subsubsection{Antikörper}

Die Antikörper sind in den angegebenen Verdünnungen in Blockier-Puffer nach Herstellerangaben entweder auf Milchpulverbasis oder bovinem Serum-Albumin (BSA)-Basis gelöst worden - Phospho-Antikörper wurden immer in BSA-BlockierPuffer gelöst. Inkubation der Membranen für Western Blots erfolgte jeweils bei $4^{\circ} \mathrm{C}$ über Nacht in verschlossenen 50-ml-Falcon-Röhrchen auf einem automatischen Roller. Die Peroxidase-gekoppelten Sekundärantikörper wurden für $30 \mathrm{~min}$ bei Raumtemperatur mit den Membranen in Schälchen auf einem Schüttler inkubiert.

Antikörper für die Ladekontrollen ( $\beta$-Aktin und GAPDH) sind gemeinsam mit dem Sekundärantikörper für 30 min bei Raumtemperatur zur Inkubation auf die Membranen gegeben worden.

\begin{tabular}{|c|c|c|c|c|c|}
\hline Zielstruktur & Wirtstier & KIonalität & Hersteller & $\begin{array}{l}\text { Katalog- } \\
\text { Nr. }\end{array}$ & $\begin{array}{l}\text { Verdün- } \\
\text { nung }\end{array}$ \\
\hline Akt & Kaninchen & polyklonal & Cell Signaling & \#9272 & $1: 1000$ \\
\hline Bcl-xL & Kaninchen & monoklonal & Cell Signaling & \#2764 & $1: 1000$ \\
\hline ErbB2 & Kaninchen & monoklonal & Cell Signaling & \#2165 & $1: 500$ \\
\hline GAPDH & Maus & monoklonal & abcam & ab8245 & $1: 10000$ \\
\hline HSF-1 & Kaninchen & polyklonal & Cell Signaling & \#4356 & $1: 1000$ \\
\hline Hsp27 & Maus & monoklonal & Cell Signaling & \#2402 & $1: 1000$ \\
\hline Hsp70 & Maus & monoklonal & Santa Cruz & sc-24 & $1: 500$ \\
\hline Hsp90 & Kaninchen & polyklonal & Santa Cruz & sc-7947 & $1: 2000$ \\
\hline Hsp90a & Kaninchen & monoklonal & Milipore & \#07-2174 & $1: 4000$ \\
\hline $\begin{array}{l}\text { Kaninchen- } \\
\text { IgG (Fluo- } \\
\text { reszenzmar } \\
\text { kiert) }\end{array}$ & Ziege & Monoklonal & $\begin{array}{l}\text { Life Technolo- } \\
\text { gies }\end{array}$ & $A-11008$ & $1: 600$ \\
\hline $\begin{array}{l}\text { Kaninchen- } \\
\text { IgG (Peroxi- } \\
\text { dase- } \\
\text { gekoppelt) }\end{array}$ & Esel & monoklonal & Jackson & $\begin{array}{l}711-036- \\
152\end{array}$ & $1: 10000$ \\
\hline $\begin{array}{l}\text { Maus-IgG } \\
\text { (Peroxidase- } \\
\text { gekoppelt) }\end{array}$ & Esel & monoklonal & Jackson & $\begin{array}{l}715-036- \\
150\end{array}$ & $1: 10000$ \\
\hline MIF & Kaninchen & monoklonal & Sigma & $\begin{array}{l}\text { HPA0038 } \\
68\end{array}$ & $1: 2000$ \\
\hline p53 & Maus & monoklonal & Santa Cruz & sc-126 & $1: 2000$ \\
\hline pAkt (S473) & Kaninchen & polyklonal & Cell Signaling & \#9271 & $1: 500$ \\
\hline pAkt (S473) & Kaninchen & monoklonal & Cell Signaling & $\# 4060$ & $1: 2000$ \\
\hline pERK (Y204) & Kaninchen & monoklonal & Santa Cruz & sc-7383 & $1: 500$ \\
\hline $\begin{array}{l}\text { pHSF-1 } \\
\text { (S326) }\end{array}$ & Kaninchen & polyklonal & enzo & $\begin{array}{l}\text { ADI-SPA- } \\
902\end{array}$ & $1: 1000$ \\
\hline$\beta$-Aktin & Maus & monoklonal & abcam & ab6276 & $1: 10000$ \\
\hline
\end{tabular}




\subsubsection{Reagenzien und Enzyme für RT- und qPCR-Reaktion}

\begin{tabular}{|l|l|l|}
\hline Produkt & Hersteller & Katalog-Nr. \\
\hline dNTPs (ATP, TTP, CTP, GTP) 100mM & Primetech & $1202-1205$ \\
\hline M-MuLV Reverse Transkriptase & NEB & M0253 \\
\hline NEB-Puffer für M-MuLV, 10x & NEB & B0253 \\
\hline $\begin{array}{l}\text { Primer-Mix für RT-PCR = zufällige Nonamere } \\
\text { und dT }{ }_{23} \text { VN }\end{array}$ & Metabion & \\
\hline RNase Inhibitor & NEB & M0307 \\
\hline Taq DNA Polymerase & Primetech & 1800 \\
\hline SYBR Green & Invitrogen & S-7563 \\
\hline PCR-Reaktionsgefäß 0,2 ml & Sarstedt & $1202-1205$ \\
\hline
\end{tabular}

\subsubsection{Primer}

Alle Primer wurden bei metabion international AG, Martinsried, bestellt. Die lyophilisierten Primer wurden nach Herstellerangaben in sterilisiertem Wasser gelöst und so auf eine Konzentration von $100 \mathrm{pmol} / \mu \mathrm{l}$ eingestellt und bei $-20^{\circ} \mathrm{C}$ gelagert.

\begin{tabular}{|l|l|l|}
\hline Gen & Vorwärtsprimer 5‘ nach 3‘ & Rückwärtsprimer 5‘ nach 3‘ \\
\hline 36B4 & $\begin{array}{l}\text { GCAGATCGGGTAC- } \\
\text { CCAACTGTTG }\end{array}$ & CAGCAGCCGCAAATGCAGATG \\
\hline CBX3 & GTTGAAGAGGCAGAGCCTGA & TCTTTGCCAGCTTTCTGAGAGT \\
\hline CDC6 & TCCTCGTGTAAAAGCCCTGC & TCTTGCCTTGCTTTGGTGGA \\
\hline FASN & GTGCCCATCCTGGAGAAGTT & GGTCACCTTGGTCTGCAGTG \\
\hline HSP110* & $\begin{array}{l}\text { ACTGCTTGTTCA- } \\
\text { AGAGGGCTGTGA }\end{array}$ & $\begin{array}{l}\text { AACATCCACACCCACACACAT- } \\
\text { GCT }\end{array}$ \\
\hline HSP70 & TCAAGGGCAAGATCAGCGAG & TGATGGGGTTACACACCTGC \\
\hline MIF & AGCAGCTGGCGCAGGCCAC & CTCGCTGGAGCCGCCGAAGG \\
\hline SPTAN1 & GGATGAAGTGGCAGCTCGTA & CTGGAGGTTCTGCACATTGG \\
\hline
\end{tabular}

*aus der Arbeit von Chou et al. entnommen (Chou et al. 2012)

\subsubsection{Inhibitoren}

\begin{tabular}{|l|l|l|}
\hline Inhibitorbezeichnung & Hersteller & Katalog-Nr. \\
\hline Lapatinib Ditosylate (Tykerb) & Selleck Chemicals & S1028 \\
\hline LY294002 & Cell Signaling & $\# 9901$ \\
\hline U0126 & Cell Signaling & $\# 9903$ \\
\hline Z-VAD-FMK & Sigma-Aldrich & V116 \\
\hline CP-724.714 & Selleck Chemicals & S1167 \\
\hline
\end{tabular}




\subsubsection{Zellkulturzubehör}

\begin{tabular}{|l|l|}
\hline Produkt & Hersteller \\
\hline fetales Kälberserum (FCS) & GIBCO, Invitrogen \\
\hline RPMI 1640 Medium & GIBCO, Invitrogen \\
\hline Penicillin/Streptomycin & GIBCO, Invitrogen \\
\hline L-Glutamin & GIBCO, Invitrogen \\
\hline Zellkulturpetrischalen & Greiner \\
\hline Multiwellplatten 6er / 12er & Greiner \\
\hline
\end{tabular}

Tabelle 7 - Zellkulturzubehör

\subsubsection{Zelllinien}

\begin{tabular}{|l|l|c|c|c|}
\hline Zelllinie & Quelle & $\begin{array}{c}\text { p53 } \\
\text { Status }\end{array}$ & $\begin{array}{c}\text { ER / PR - } \\
\text { Expression }\end{array}$ & $\begin{array}{c}\text { ErbB2- } \\
\text { Überexpression }\end{array}$ \\
\hline MCF-7 & \multirow{2}{*}{$\begin{array}{l}\text { Brustkrebszellen } \\
\text { aus Pleuraerguss- }\end{array}$} & wt & $+/+$ & - \\
\cline { 3 - 5 } MDA-MB-231 & flüssigekeit & mut & $-/-$ & - \\
\cline { 3 - 5 } SK-BR-3 & & $-/-$ & + \\
\hline
\end{tabular}

Tabelle 8 - Liste der Zelllinien

Kulturmedium: RPM1640 Medium (10 \% FCS, Glutamin und Penicillin/Streptomycin)

\subsection{Methoden}

\subsubsection{Zellkultur}

Alle Zellinien (Tabelle 8, S.15) wurden in RPM1640 Medium (10 \% FCS, Glutamin und Penicillin/Streptomycin) adhärent auf Kunststoffpetrischalen wachsend, im Brutschrank bei $37^{\circ} \mathrm{C}$ und $5 \% \mathrm{CO}_{2}$ kultiviert. Sämtliche Zellkulturarbeiten sind unter der Sterilbank durchgeführt worden. Zum Anzüchten größerer Zellzahlen für die Experimente wurden zunächst in 20\% DMSO / 80 \% FCS kryokonservierte Zellen aufgetaut und mit dem 10-fachen Volumen Medium in ein Falcon-Röhrchen übertragen. Nach Zentrifugieren bei Raumtemperatur und 900 x g für 5 min wurde der Überstand aspiriert und das Zellpellet mit frischem Medium resuspendiert. Die Zellen wurden dann in Petrischalen (10 cm - 10 ml Medium) bis zu 80 \%iger Konfluenz kultiviert. Nach dem Auftauen wurden die Zellen zunächst für 3 Passagen in Kultur gehalten, ehe sie für Experimente verwendet wurden. Passagieren erfolgte nach den in Tabelle 9, S.16, angegebenen Verhältnissen. Dazu wurde zunächst das Zellkulturmedium aspiriert und die Zellen mit autoklaviertem PBS (Tabelle 2, S.12) gewaschen um eine Inaktivierung des im Folgenden zugegebenen Trypsins durch FCS-Reste zu verhindern. Durch Zugabe von $2 \mathrm{ml}$ Trypsin-Lösung auf eine $10 \mathrm{~cm}-$ Kulturschale, kurze Inkubation ( $<5 \mathrm{~min}$ ) und vorsichtiges Klopfen wurden die Zellen von der Petrischalen gelöst, das Trypsin durch Zugabe von frischem Medium inaktiviert und die Zellen darin suspendiert. Die Zellsuspension wurde dann auf neue 
Kulturschalen verteilt und diese mit frischem Medium auf $10 \mathrm{ml}$ aufgefüllt. Mediumwechsel erfolgte alle $2-3$ Tage.

\begin{tabular}{|l|l|}
\hline Zelllinie & $\begin{array}{l}\text { Verdünnung beim Passagieren (Zell- } \\
\text { suspension : Medium) }\end{array}$ \\
\hline MCF-7 & $1: 4$ \\
\hline MDA-MB-231 & $1: 10$ \\
\hline SK-BR-3 & $1: 6$ \\
\hline
\end{tabular}

\subsubsection{Zell-Behandlung}

Für die Zellkulturexperimente wurde die beim Passagieren gewonnene Zellsuspension nicht gleich ausplattiert, sondern bei Raumtemperatur und $900 \times \mathrm{g}$ für $5 \mathrm{~min}$ zentrifugiert, der Überstand verworfen und das Zellpellet in $2-3 \mathrm{ml}$ Medium resuspendiert. Nach Zellzahlerfassung mithilfe des automatischen Zellzählers Countess ${ }^{\circledR}$, Invitrogen, wurden die Zellen in entsprechender Anzahl (Tabelle 10, S. 16) für Experimente auf 6er (2 ml Medium / Mulde) oder 12er (1 ml Medium / Mulde) Multiwellplatten ausplattiert. Vor Beginn einer Behandlung wurden die Zellen immer für 24 Stunden unter Normalbedingungen kultiviert. Alle Inhibitoren wurden in DMSO gelöst. Zellen der Kontrollgruppen wurden immer der höchsten DMSOKonzentration ausgesetzt, die im jeweiligen Experiment genutzt wurde. Der jeweilig resultierende DMSO-Gehalt im Medium für jeden Inhibitor ist Tabelle 11, S.16 zu entnehmen.

\begin{tabular}{|c|c|c|}
\hline Zelllinie & $\begin{array}{l}\text { Zellzahl / ml Medium } \\
\text { für } 24 \mathrm{~h} \text { Behandlung }\end{array}$ & $\begin{array}{l}\text { Zellzahl / ml Medium } \\
\text { für } 48 \mathrm{~h} \text { Behandlung }\end{array}$ \\
\hline MCF-7 & $1,25 * 10^{5}$ & $0,9 * 10^{5}$ \\
\hline MDA-MB-231 & $0,7 * 10^{5}$ & $0,5 * 10^{5}$ \\
\hline SK-BR-3 & $1,5 * 10^{5}$ & $1,0 * 10^{5}$ \\
\hline
\end{tabular}

\begin{tabular}{|l|l|}
\hline Inhibitor & DMSO-Gehalt im Medium [\%] \\
\hline CP 724.714 & $\begin{array}{l}0,1-0,2 \\
(1,0 \text { in Experimenten mit weiteren Inhibitoren) }\end{array}$ \\
\hline Lapatinib & 0,2 \\
\hline Ly294002 & 1,0 \\
\hline Rapamycin & 1,0 \\
\hline U0126 & 1,0 \\
\hline Z-VAD-FMK & 1,25 \\
\hline
\end{tabular}




\subsubsection{Hitzeschockbehandlung}

Für die Hitzeschockbehandlung wurden die Zellen vor Ernte eine Stunde lang in einem auf $43^{\circ} \mathrm{C}$ vorgeheizten Brutschrank inkubiert und darauffolgend wieder für drei Stunden unter Normalbedingungen $\left(37^{\circ} \mathrm{C}\right)$ in einem anderen Inkubator gehalten.

\subsubsection{Proteinextraktion von Zellkulturen zur Western-Blot-Analyse}

Die Zellkulturschalen wurden auf Eis gestellt, das Kulturmedium vorsichtig aspiriert und in einem Reaktionsgefäß gesammelt. Die Zellen wurden mit etwa der gleichen Menge PBS (Tabelle 2, S.12) wie vorher auch für das Nährmedium verwendet wurde gewaschen, das PBS wieder aspiriert und zum bereits entnommenen Kulturmedium ins Reaktionsgefäß hinzugesetzt. Das Reaktionsgefäß wurde dann für 5 $\min$ bei $800 \times \mathrm{g}$ und $4^{\circ} \mathrm{C}$ zentrifugiert. Der erhaltene Überstand wurde verworfen und das entstandene Pellet zur Weiterverwendung behalten. Als Lysispuffer kam RIPA-Puffer zum Einsatz (Tabelle 2, S.12). Das eingesetzte Volumen richtete sich dabei nach Größe der Kulturschale und Konfluenz der Zellen. Für die meisten Versuche wurden $2 \mathrm{~cm}$ 6er-Kulturschalen benutzt. Waren diese zu $100 \%$ konfluent bewachsen, wurden $250 \mu \mathrm{l}$ RIPA-Puffer benutzt, bei nur $50 \%$ Konfluenz entsprechend die Hälfte. Der Grad der Konfluenz wurde jeweils kurz vor Ernte der Zellen unter dem Mikroskop abgeschätzt. Der RIPA-Puffer wurde direkt auf die gewaschenen Zellen gegeben und diese mit einem Zellschaber von der Kulturschale gekratzt. Durch Auf- und Abpipettieren wurden die Zellen anschließend in RIPA-Puffer lysiert und homogenisiert. Die erhaltene Lösung wurde nun noch zur Resuspendierung des Pellets aus dem ersten Zentrifugationsschritt benutzt, für 30 min auf Eis inkubiert und in einem Reaktionsgefäß für 10 min bei $13000 \times \mathrm{g}$ und $4^{\circ} \mathrm{C}$ abzentrifugiert. Der Überstand (das fertige Proteinlysat) wurde nun aliquotiert und bei $-80^{\circ} \mathrm{C}$ gelagert.

\subsubsection{Polyacrylamidgelelktrophorese (PAGE)}

Zum Einsatz kam die erstmals von Ulrich Laemmli beschriebene Methode der diskontinuierlichen SDS-Polyacylamidgelektrophorese (SDS-PAGE) (Laemmli 1970).

Für die PAGE wurde das miniVE Vertical Electrophoresis System von GE Healthcare verwendet. Es wurden Gele eingesetzt, die in einer Rahmenkonstruktion gegossen wurden. Diese bestand aus Teilen, die in der unserm Labor angegliederten Werkstatt gefertigt wurden. Ein Gel wurde dabei jeweils zwischen zwei Glasplatten mit einem Abstand von $1 \mathrm{~mm}$ gegossen, Trenn- und Sammelgel wurden nacheinander gegossen. Nach Gießen des Trenngels wurde dieses mit Isopropanol über- 
schichtet, die Polymerisierung des Gels abgewartet (15 - $60 \mathrm{~min}$ ) und das Isopropanol durch Abgießen und mithilfe von Filterpapier vollständig entfernt. Anschließend wurde darauf das Sammelgel gegossen und 10 Geltaschen (etwa $35 \mu$ Volumen) durch Einbringen eines 10er Kammes geformt. Zum Einsatz kamen $10-15 \%$ Acrylamid enthaltende Gele, Zusammensetzung s. Tabelle 12, S.19.

Als Proteinstandard wurde PageRuler Plus Prestained Protein Ladder, Thermo Fisher Scientific, in den beiden äußeren Geltaschen verwendet. Jeweils $25 \mu$ eines Proteinlysats wurden mit $5 \mu \mathrm{l}$ Laemmli-Puffer in einem 1,5-ml-Reaktionsgefäß gemischt, für 5 min bei $95^{\circ} \mathrm{C}$ denaturiert, kräftig geschüttelt und anschließend in einer Tischzentrifuge kurz abzentrifugiert. Das gesamte Gemisch wurde dann in eine Geltasche geladen. Durch das Anpassen des RIPA-Puffer-Volumens (s. Kapitel 2.2.4) an die Zellkonfluenz enthielten die Lysate, später erkennbar an einer gleichmäßig erscheinenden Ladekontrolle, vergleichbare Proteingesamtmengen. Von einer vorhergehenden Bestimmung der Proteinkonzentration konnte somit abgesehen werden. Erschienen die Ladekontrollen ungleichmäßig, wurde die Menge des eingesetzten Proteinlysats in einer Wiederholung des Western Blots entsprechend angepasst.

Die Gele wurden in der Elekrophoresekammer mit konstanter Spannung von $80 \mathrm{~V}$ für das Sammelgel und $120 \mathrm{~V}$ für das Trenngel laufen gelassen. Wenn der blaue Farbstoff des Laemmli-Puffers (Bromphenolblau) etwa $1 \mathrm{~cm}$ vor der Unterkante des Trenngels angelangt war, wurde die Spannungsquelle ausgeschaltet und die Gele für den Western Blot weiter verwendet. 


\begin{tabular}{|c|c|c|}
\hline Gelbezeichnung & $\begin{array}{l}\text { Eingesetztes } \\
\text { Volumen pro } \\
\text { Gel }\end{array}$ & Reagenz \\
\hline \multicolumn{3}{|l|}{ Sammelgel $(4 \mathrm{ml})$} \\
\hline & $2,7 \mathrm{ml}$ & Wasser \\
\hline & $0,67 \mathrm{ml}$ & Rotiphorese ${ }^{\circledR}$ Gel $30(37,5: 1)$ \\
\hline & $0,5 \mathrm{ml}$ & $1 \mathrm{M}$ Tris-Puffer $(\mathrm{pH} 6,8)$ \\
\hline & $40 \mu l$ & $10 \%$ SDS \\
\hline & $40 \mu l$ & $10 \%$ APS \\
\hline & $4 \mu \mathrm{l}$ & Tetramethylethylendiamin (TEMED) \\
\hline \multicolumn{3}{|l|}{ Trenngel $10 \%(10 \mathrm{ml})$} \\
\hline & $4,0 \mathrm{ml}$ & Wasser \\
\hline & $3,3 \mathrm{ml}$ & Rotiphorese $\AA$ Gel $30(37,5: 1)$ \\
\hline & $2,5 \mathrm{ml}$ & 1,5 M Tris-Puffer $(\mathrm{pH} 8,8)$ \\
\hline & $100 \mu \mathrm{l}$ & $10 \%$ SDS \\
\hline & $100 \mu \mathrm{l}$ & $10 \%$ APS \\
\hline & $4 \mu \mathrm{l}$ & Tetramethylethylendiamin (TEMED) \\
\hline \multicolumn{3}{|l|}{ Trenngel $12 \%(10 \mathrm{ml})$} \\
\hline & $3,3 \mathrm{ml}$ & Wasser \\
\hline & $4,0 \mathrm{ml}$ & Rotiphorese $\AA$ Gel $30(37,5: 1)$ \\
\hline & $2,5 \mathrm{ml}$ & 1,5 M Tris-Puffer (pH 8,8) \\
\hline & $100 \mu \mathrm{l}$ & $10 \%$ SDS \\
\hline & $100 \mu \mathrm{l}$ & $10 \%$ APS \\
\hline & $4 \mu \mathrm{l}$ & Tetramethylethylendiamin (TEMED) \\
\hline \multicolumn{3}{|l|}{ Trenngel $15 \%(10 \mathrm{ml})$} \\
\hline & $2,3 \mathrm{ml}$ & Wasser \\
\hline & $5,0 \mathrm{ml}$ & Rotiphorese $\AA$ Gel $30(37,5: 1)$ \\
\hline & $2,5 \mathrm{ml}$ & 1,5 M Tris-Puffer $(\mathrm{pH} 8,8)$ \\
\hline & $100 \mu \mathrm{l}$ & $10 \%$ SDS \\
\hline & $100 \mu \mathrm{l}$ & $10 \%$ APS \\
\hline & $4 \mu \mathrm{l}$ & Tetramethylethylendiamin (TEMED) \\
\hline
\end{tabular}

\subsubsection{Western Blot \& Proteindetektion}

Es wurde mit dem Tankblotverfahren gearbeitet. Dabei wurden bis zu 3 Gele gleichzeitig in einer mit eiskaltem Transferpuffer gefüllten Kammer bei konstanter Spannung von $100 \mathrm{~V}$ und $4^{\circ} \mathrm{C}$ für 90 min geblottet. Zwischen 2 Plastikhaltern wurde für das Blot-Sandwich immer folgender Aufbau für den Transfer der Proteine aus einem PAGE-Gel auf eine Nitrozellulose-Membran (Millipore) benutzt: Anode, 1 transferpuffergetränkter Schwamm, 3 Whatman-Papiere, die auf das Gel zugeschnittene 
Membran, das Gel selbst, 3 Whatman-Papiere und wieder ein Schwamm, Kathode. Es wurde auf blasenfreies Aufbringen der Membran auf das Gel geachtet sowie zwischen den Filterpapieren vorhandene Luftblasen durch Ausstreichen entfernt.

Die Membranen wurden nach Entnahme aus dem Tank zur Entfernung des Transferpuffers dreimal kurz in TBST (Tabelle 2, S.12) gewaschen, danach noch einmal für 5 min, dann erfolgte die Blockierung der noch unbesetzten Proteinbindekapazität der Membran durch Inkubation mit Blockierpuffer ( $5 \%$ Milch in TBST) für 30 min bei Raumtemperatur auf dem Schüttler. Die Membranen wurden nun wieder dreimal kurz in TBST gewaschen und für die Proteindetektion verwendet.

Inkubation mit Primär- und Sekundärantikörper erfolgte nach folgendem Schema (Tabelle 13, S. 20), für Konzentrationsangaben s. Tabelle 3, S. 13:

\begin{tabular}{|l|l|}
\hline Arbeitsschritt & Bedingungen \\
\hline Inkubation mit Primärantikörper & $\begin{array}{l}4^{\circ} \text { C, über Nacht, in Falcon-Röhrchen auf } \\
\text { automatischem Roller (s. Tabelle 3, S. 13) }\end{array}$ \\
\hline $1 \times$ Waschen & in TBST, Raumtemperatur, kurz \\
\hline $3 \times$ Waschen & $\begin{array}{l}\text { in TBST, Raumtemperatur, jeweils 5 min, in } \\
\text { Schälchen auf dem Schüttler }\end{array}$ \\
\hline Inkubation mit Sekundärantikörper & $\begin{array}{l}\text { Raumtemperatur, 30 min, in Schälchen auf } \\
\text { dem Schüttler (s. Tabelle 3, S. 13) }\end{array}$ \\
\hline $1 \times$ Waschen & in TBST, Raumtemperatur, kurz \\
\hline $3 \times$ Waschen & $\begin{array}{l}\text { in TBST, Raumtemperatur, jeweils 5 min, in } \\
\text { Schälchen auf dem Schüttler }\end{array}$ \\
\hline
\end{tabular}

Tabelle 13 - Inkubation der Western-Blot-Membranen mit Antikörpern

Zur Detektion der gebundenen Sekundärantikörper wurden das SuperSignal West Femto Chemiluminescent Substrat, Thermo Scientific oder das Immobilon Western Chemiluminescent HRP Substrat, Millipore, genutzt. Bei beiden Kits wurden die zwei Komponenten 1: 1 gemischt und auf die Membran gebracht und durch Schwenken selbiger homogen verteilt. Nach kurzer Inkubation wurde diese blasenfrei in Plastikfolie eingeschlagen und zur Detektion der Lumineszenz im Molecular Imager® VersaDoc ${ }^{\mathrm{TM}}$ Imaging System analysiert.

\subsubsection{RNA-Extraktion von Zellkulturen zur qPCR-Analyse}

Die RNA-Extraktion wurde mithilfe der Trizoß-Reagenzien und unter Benutzung des vom Hersteller mitgelieferten Protokolls durchgeführt, welches sich an der Arbeit von Chomczynski orientiert (Chomczynski 1993). Für RNA Untersuchungen erfolgten die Zellkulturversuche immer in $12 \times 1 \mathrm{~cm}-$ Kulturschalen. Das am Ende 
der Extraktion entstehende RNA Pellet wurde in $30 \mu$ DEPC-Wasser (Diethyldicarbonat zur RNasen-Inaktivierung) gelöst und bei $-80^{\circ} \mathrm{C}$ gelagert.

Die RNA-Konzentration wurde mithilfe des NanoDrop-Spektrophotometers bestimmt. Dazu wurde die Extinktion bei $260 \mathrm{~nm}$ von $1 \mu \mathrm{l}$ des gewonnen Extraktes in der Maschine gemessen und aus dem bestimmten Koeffizienten durch die NanoDrop-Software direkt in die RNA-Konzentration umgerechnet.

\subsubsection{Reverse Transkriptase (RT)-Reaktion}

Für die RT-Reaktion, mit der mRNA in cDNA umgeschrieben werden kann, wurde das virale Enzym M-MuLV-RT verwendet sowie ein Mix aus poly-dT-Primern und Zufalls-dNTP-Nonamern (vgl Tabelle 4, S. 14). Durch die Wahl dieses Primermixes werden auch RNA-Moleküle ohne poly-A-Schwanz und weit vom 3'-Ende entfernte Bereiche zuverlässiger in cDNA umgeschrieben.

Alle nun beschriebenen Arbeiten sind in verschließbaren PCR-Reaktionsgefäßen auf Eis durchgeführt worden, sofern nicht anders angegeben.

Pro Reaktionsgefäß wurde ein Volumen der RNA-Extrakte zugesetzt, das $1 \mu \mathrm{g}$ RNA entsprach. Dieses wurde dann mit DEPC-Wasser auf $10 \mu \mathrm{l}$ Gesamtvolumen aufgefüllt. Die qPCR-Reagenzien wurden als zwei Mastermixe (Zusammensetzung s. Tabelle 14, S. 21) vorbereitet und wie folgt eingesetzt: Nach Zugabe von $6 \mu$ RTMix 1 wurden die Proben für 5 min auf $70^{\circ} \mathrm{C}$ erwärmt und danach $4 \mu \mathrm{l}$ RT-Mix 2 (mit RT-Enzym bzw. ohne, als Negativkontrolle) hinzugesetzt und die RT-Reaktion für eine Stunde bei $42^{\circ} \mathrm{C}$ durchgeführt. Durch kurzes Erhitzen auf $95^{\circ} \mathrm{C}$ wurde das RTEnzym inaktiviert und die RT-Reaktion damit gestoppt. Nach Verdünnen der gewonnenen cDNA-Lösungen durch Zugabe von $30 \mu$ LEPC-Wasser, wurden diese bei $-20^{\circ} \mathrm{C}$ gelagert und für die quantitative PCR-Analyse verwendet.

\begin{tabular}{|l|r|}
\hline & $\boldsymbol{\mu l}$ / Reaktionsgefäß \\
\hline RT - Mix 1 & $\mathbf{6 . 0}$ \\
\hline Primer-Mix $(100 \mu \mathrm{M})$ (Zufallsnonamere und $\left.\mathrm{dT}_{23} \mathrm{VN}\right)$ & 2.0 \\
\hline dNTPs $(2.5 \mathrm{mM})$ & 4.0 \\
\hline & $\mathbf{4 . 0}$ \\
\hline RT - Mix 2 & 2.0 \\
\hline NEB-Puffer für M-MuLV-RT, 10x & 0.25 \\
\hline RNase Inhibitor (10U) & 0.125 \\
\hline M-MuLV-RT(25U) & 1.625 \\
\hline DEPC Wasser & \\
\hline \multicolumn{2}{|r}{} \\
\hline
\end{tabular}




\subsubsection{Quantitative real-time PCR (qPCR)}

Der Gehalt an genspezifischer mRNA der RNA-Extrakte wurde aus den cDNALösungen mittels qPCR bestimmt. Zur Quantifizierung diente die Fluoreszenz des interkalierenden Farbstoffes SYBR Green. Erreicht die Fluoreszenz erstmals einen Wert, der über dem gemessenen Grundwert liegt, markiert dies den Beginn der exponentiellen Amplifizierung eines spezifischen cDNA-Fragments. Dieser sogenannte cycle threshold oder Ct-Wert ist bei einem hohen Gehalt an spezifischer cDNA in der Probe niedrig. Bei einem niedrigen Gehalt steigt erst nach einer größeren Anzahl abgelaufener PCR-Zyklen die Fluoreszenz über das Hintergrundrauschen an, der Ct-Wert liegt also höher. Um die Ergebnisse zu normalisieren, wurde das weitgehend unabhängig von den Kultur- und Behandlungsbedingungen regulierte Gen 36B4, welches für ein ribosomales Protein kodiert, herangezogen. Als Negativkontrollen wurden DNA-freie Proben (Wasser) sowie no-RT-Proben, die aus einer RT-Reaktion ohne Zugabe der reversen Transkriptase resultierten, geführt. Die zu 36B4 relativierten mRNA-Expressionsraten wurden nach der $\Delta \Delta$ Ct-Methode bestimmt, dazu wurde folgende Formel verwendet:

$2^{-(C t(G e n X ~-~ 36 B 4) ~ B e h a n d l u n g s g r u p p e) ~-~(C t(G e n ~ X ~-~ 36 B 4) ~ K o n t r o l l g r u p p e) ~}$

Zur Untersuchung der einzelnen Gene wurden Primer designed (Tabelle 5, S. 14), die Intron-Sequenzen überspannend gestaltet waren und PCR-Produkte mit einer Länge zwischen 100 und 300 Basenpaaren ergaben. Dadurch konnte die Gefahr einer Fehlbestimmung durch die Ampflifizierung von eventuell noch vorhandener genomischer DNA oder nachträglich in die Probe gelangter DNA-Kontaminationen minimiert werden. Diese enthalten im Gegensatz zur cDNA Intronsequenzen und wären damit zu lang, um ein effizientes Ablaufen der PCR-Reaktion zu gestatten. Jede Probe wurde pro qPCR-Analyse als Triplikat geführt.

Folgendes Protokoll wurde für die Amplifikation im Cycler genutzt: Vorerhitzen der Proben für 2 min bei $95^{\circ} \mathrm{C}$, danach 40 Zyklen bei $95^{\circ} \mathrm{C}$ für $15 \mathrm{~s}$, gefolgt von einer einminütigen Elongationsphase bei $60^{\circ} \mathrm{C}$, an deren Ende jeweils die Detektion des Fluoreszenzsignals stand. Am Ende wurden unter kontinuierlicher Temperaturerhöhung Schmelzkurven als Qualitätskontrolle erstellt. Anhand dieser Kurven ließen sich Hinweise auf unspezifische PCR-Produkte finden, die für suboptimal gewählte Primer oder Fehler im Ablauf der qPCR sprächen. 


\subsubsection{Immunfluoreszenz (IF)}

Für die IF-Färbung wurden Zellen, wie beschrieben (s. Kapitel 2.2.2), in 12er Multiwellplatten kultiviert und 48 Stunden lang behandelt. Auf den Boden der einzelnen Mulden wurde vor Aussaat der Zellen jeweils ein rundes, gelatineüberzogenes Deckgläschen eingebracht, auf dem die Zellen anwachsen und mithilfe dessen die Zellen entnommen werden konnten. Die bewachsenen Deckplättchen wurden für die einzelnen Schritte der Färbung auf einer beschrifteten Plastikfolie in einer Feuchtkammer platziert. Zum Waschen wurden die Deckplättchen mit einer Pinzette vorsichtig in PBS (Tabelle 2, S.12) getaucht. Zur Inkubation wurde jeweils etwa 200 $\mu l$ Lösung als Tropfen auf die Plastikfolie gegeben und die Deckplättchen mit der bewachsenen Seite nach unten auf die Tropfen gelegt und die Feuchtkammer geschlossen.

IF-Färbung der Zellen folgte dem folgenden Schema, alle Schritte bei Raumtemperatur, wenn nicht anders angegeben:

\begin{tabular}{|l|l|}
\hline Arbeitsschritt & Bedingungen \\
\hline $2 \times$ Waschen & in PBS, kurz \\
\hline Fixieren der Zellen & $4 \%$ Paraformaldehyd in PBS, 10 min \\
\hline $2 \times$ Waschen & in PBS, kurz \\
\hline Permeabilisieren der Zellen & $0,1 \%$ TritonX100 in PBS, 5 min \\
\hline $2 \times$ Waschen & in PBS, kurz \\
\hline Blockieren & $10 \%$ FCS in PBST (Tabelle 2, S.12), 1 Stunde \\
\hline $\begin{array}{l}\text { 1 } x \text { Waschen } \\
\text { Inkubation mit HSF-1-Antikörper } \\
(\text { Sabelle 3, S. 13) }\end{array}$ & in PBST, kurz \\
\hline $2 \times$ Waschen & in $\%$ FCS in PBST, über Nacht, 4 ${ }^{\circ}$ C \\
\hline $\begin{array}{l}\text { Inkubation mit Fluoreszenz- } \\
\text { Sekundär-Antikörper } \\
(\text { s. Tabelle 3, S. 13) }\end{array}$ & in PBST, kurz \\
\hline $2 \times$ Waschen & in $\%$ FCS in PBST, 30 min \\
\hline Zellkernfärbung & in PBST, kurz \\
\hline $2 \times$ Waschen & DAPI in PBST, 10 min \\
\hline
\end{tabular}

Die, wie in Tabelle 15, S. 23, beschrieben, gefärbten Zellen wurden anschließend auf einen Objektträger für die Mikroskopie aufgebracht. Dazu wurden die bewachsenen, gefärbten Deckgläschen mit der zellbewachsenen Seite nach unten auf einen Tropfen Fluoromount-G (SouthernBiotech) auf den Objektträger gelegt, vorsichtig angedrückt und die Seiten des Deckgläschens schließlich mit handelsübli- 
chem Nagellack versiegelt. Nach Aushärten über Nacht bei $4^{\circ} \mathrm{C}$ wurden die Proben für die IF-Mikroskopie verwendet und stets dunkel bei $4^{\circ} \mathrm{C}$ aufbewahrt.

\subsubsection{Bestimmung des Anteils der Zellen mit granulärer Kernanfärbung}

Die fertig gefärbten Präparate wurden unter dem Fluoreszenzmikroskop (Carl Zeiss $A G$, Jena) untersucht. Es wurden je elf Gesichtsfelder pro Präparat mit dem $10 \mathrm{x}$ Objektiv ausgewertet. Die Gesichtsfelder lagen dabei immer etwa auf einer dem Kreisdurchmesser der Deckgläschen folgenden Linie, sodass in jedem Präparat der gleiche Streifen untersucht und verglichen werden konnte. In jedem Gesichtsfeld wurden zunächst die Zellkerne fotografiert (Fluoreszenz der DAPI-Zellkernfärbung $364 / 454 \mathrm{~nm}$ ), um sie später automatisch auszuzählen. Daraufhin wurde die Wellenlänge des anregenden Lichtes geändert, so dass die grüne Fluoreszenz $(488 / 546 \mathrm{~nm})$ des Sekundärantikörpers sichtbar wurde. Nun wurden alle Zellen mit einem granulären Farbsignal im Zellkern von Hand ausgezählt.

Die automatische Erfassung der Zellkernanzahl pro Gesichtsfeld erfolgte aus den Fotografien des blauen DAPI-Fluoreszenzsignals mithilfe des Programms ImageJ. Dazu wurden die Bilder in ein 8 bit Graustufenbild umgewandelt, dann in ein reines Schwarz-Weiß-Bild, wobei die Erfassung des Grenzwertes für die Entscheidung schwarz oder weiß vom Programm automatisch getroffen wurde und bei Bedarf manuell so nachjustiert wurde, dass sich die Zellkerne deutlich abzeichneten und keine artifiziellen Schatten als große Objekte das Bild verdeckten. So entstand ein Bild, auf dem die vorher blauen Zellkerne nun mit maximalem Kontrast als schwarze Objekte auf weißem Grund erkennbar waren. Dieses ist einer Partikelanalyse zugänglich und lieferte so die Anzahl der sichtbaren Zellkerne.

Die Zellkernzahl sowie die Ergebnisse der manuellen Auszählung wurden über alle Gesichtsfelder eines Präparates aufaddiert - so sind jeweils mindestens 3000 Zellen pro untersuchtem Präparat in die Auswertung eingeflossen. Die Summe der manuell ausgezählten granulär angefärbten Zellkerne konnte so ins Verhältnis zur automatisch bestimmten Gesamtzahl der Zellkerne gesetzt werden und wird in dieser Arbeit als prozentualer Anteil angegeben. 


\section{Ergebnisse}

\subsection{Auswahl der Zellinien - MIF und ErbB2-Proteinlevel in MCF-7, MDA-MB-231 und SK-BR-3-Zellen}

Zunächst wurden in einem Vorversuch verschiedene Brustkrebszelllinien auf ihren Gehalt an den Proteinen MIF und ErbB2 untersucht. Zur Prüfung der Hypothesen bezüglich funktioneller Zusammenhänge zwischen diesen Proteinen wurde eine Zelllinie als Negativkontrolle mit sehr niedriger MIF- und ErbB2-Expression gewählt: MDA-MB-231-Zellen. Als Positivkontrolle (sehr hohe MIF- und ErbB2-Expression) sollten SK-BR-3-Zellen dienen sowie eine Zelllinie mit Intermediärstellung, MCF-7Zellen. Mithilfe von Western-Blot-Analysen wurden diese Zelllinien mit einem Proteinlysat eines murinen, ErbB2-überexprimierenden Brusttumors verglichen.

MDA-MB-231-Zellen (Abb. 2) enthalten im Vergleich am wenigsten MIF. MCF-7und SK-BR-3-Zellen enthalten jeweils ähnliche Mengen dieses Proteins. SK-BR-3Zellen zeigen zudem eine starke Expression des ErbB2-Rezeptors, vergleichbar der Menge, die im Proteinlysat der Tumorprobe \#25 (ErbB2-überexprimiernder, muriner Brusttumor, freundlich zur Verfügung gestellt von R. Schulz, Göttingen) zu finden ist.
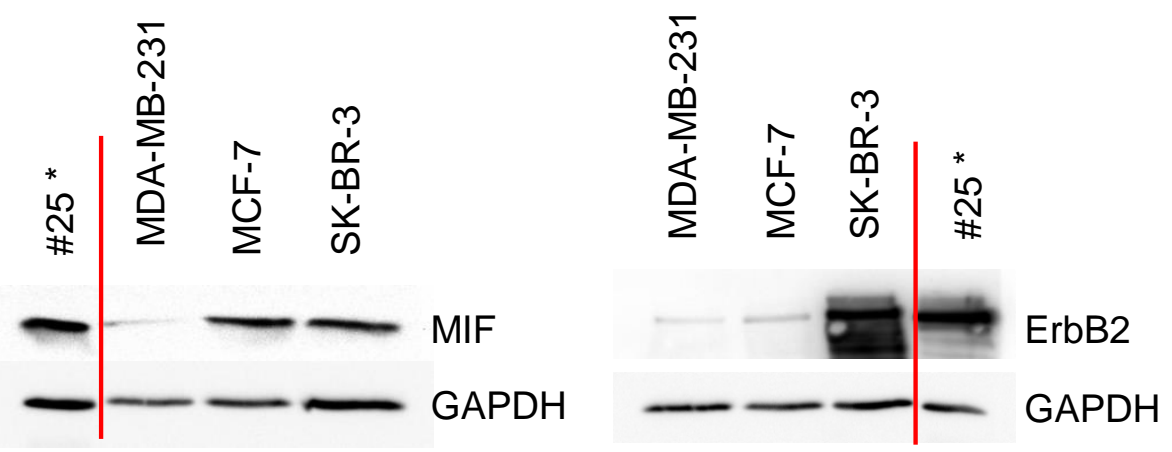

\footnotetext{
Abbildung 2: Proteinlevel der Proteine MIF und ErbB2 in MDA-MB231-, MCF-7- und SK-BR-3-Zellen.

Die Zellen wurden unbehandelt für 48 Stunden kultiviert und anschlieBend in RIPA-Puffer geerntet. Darauf folgte die Western-Blot-Analyse mit MIF bzw. ErbB2-Antikörpern.

*als Vergleichsprobe wurde ein Proteinlysat, gewonnen aus einem ErbB2-positiven Brusttumor murinen Ursprungs, verwendet (\#25) Anzahl der unabhängigen Experimente $n=3$, repräsentatives Ergebnis dargestellt.
} 


\subsection{Eine Inhibition des ErbB2-Signalweges führt zu einem Absinken der MIF-Proteinlevel}

Um die Frage zu beantworten, welchen Einfluss der ErbB2-Signalweg auf die MIFProteinlevel hat, wurden Zellkulturversuche zunächst unter Einsatz des EGF- und ErbB2-Rezeptorinhibitors Lapatinib, dann mit dem spezifischen ErbB2-Inhibitor CP724.714 durchgeführt. Die Ergebnisse der Zeit- und Konzentrationsreihen sind Abbildung $3 \mathrm{zu}$ entnehmen. Nach Inhibitorgabe zeigt sich in SK-BR-3- (Abb. 3 A) und MCF-7-Zellen (Abb. $3 \mathrm{C}$ ) eine deutlichen Abnahme der MIF-Proteinlevel. In der Negativkontrollzelllinie MDA-MB-231 kann dieser Effekt nicht gezeigt werden (Abb. $3 \mathrm{C})$. Das Absinken des Zellgehaltes an phosphoryliertem Akt bzw. ERK unter Inhibitoreinfluss demonstriert die effektive Behandlung in den responsiven Zelllinien. Beide Kinasen sind stromabwärts des ErbB2-Rezeptors gelegene Proteine im ErbB2-Signalweg und werden bei dessen Aktivierung phosphoryliert (Xia et al. 2002). Hier zeigen sich auch Unterschiede in der Responsivität der Zellen auf den Inhibitor. Die ErbB2-überexprimierenden SK-BR-3-Zellen reagieren mit einer deutlichen Reduktion der ERK und Akt Phosphorylierung nach ErbB2-Inhibitorbehandlung (Abb. $3 \mathrm{~A}$ ), wohingegen MCF-7 Zellen auf dieselbe Inhibitorkonzentration nur moderat und MDA-MB-231 gar nicht reagieren (Abb. $3 \mathrm{C}$ ).

Um zu überprüfen, auf welcher Ebene die Expression reprimiert ist, wurden die MIFmRNA-Level DMSO-behandelter SK-BR-3-Zellen mit denen CP724.714behandelter Zellen verglichen (Abb. 3 B). Die Transkription des MIF-Gens unter einer Inhibition des ErbB2-Rezeptors bleibt unverändert (0,92 $\pm 0,04$, Standardfehler, $n=3$, Unterschied nicht signifikant, Student'scher t-Test, $p=0,11)$.

Die Inhibition des ErbB2-Rezeptors senkt also den MIF-Gehalt in MCF-7- und SKBR-3-Zellen, nicht in MDA-MB-231-Zellen. Ferner bleibt die Expression des MIFGens unter der Inhibitorbehandlung in ErbB2-überexprimierenden SK-BR-3-Zellen unverändert. Demzufolge kann das Abfallen der MIF-Proteinlevel nicht auf Veränderungen auf Transkriptionsebene beruhen, sondern könnte auf Proteinebene vermittelt werden. 
A

SK-BR-3

$\frac{\text { Lapatinib, 48 h }}{*} \frac{\text { CP724.714, 48 h }}{[\mu \mathrm{M}]} \frac{\text { CP724.714 }[2 \mu \mathrm{M}]}{[\mu \mathrm{M}]} \frac{\mathrm{h}}{}$

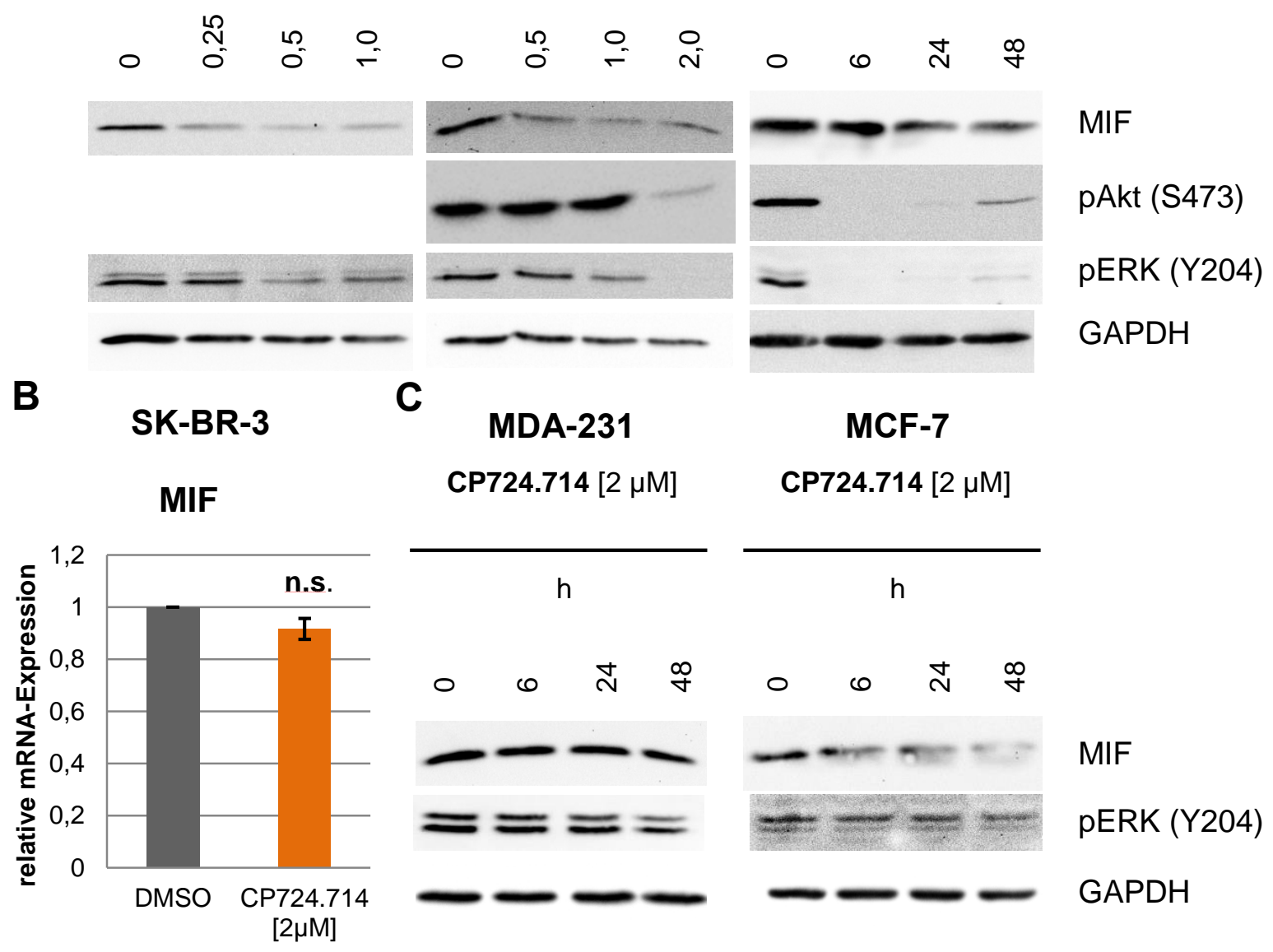

\section{Abbildung 3: Eine Inhibition des ErbB2-Signalweges führt zu einem Herabsinken der MIF-Proteinlevel in SK-BR-3- und MCF-7-Zellen.}

(A) Zeit- und Konzentrationsreihen - Humane SK-BR-3-Brustkrebszellen wurden für jeweils 48 Stunden, sonst wie angegeben, mit dem EGFR/ErbB2-Inhibitor Lapatinib oder dem selektiven ErbB2-Inhibitor CP724.714 behandelt. DMSO-behandelte Zellen dienten als Kontrolle. Mittels Immunoblot wurde ihr MIF-Proteingehalt untersucht. pERK und pAkt dienten als Kontrolle der Inhibitorbehandlung, GAPDH als Ladekontrolle. Anzahl der unabhängigen Experimente $n \geq 3$, repräsentatives Ergebnis dargestellt. (B) Die Transkription des MIF-Gens in SK-BR-3-Zellen bleibt durch die ErbB2-Inhibition unverändert. MIFmRNA-Analyse mittels qRT-PCR - SK-BR-3-Zellen wurden für 48 Stunden mit dem

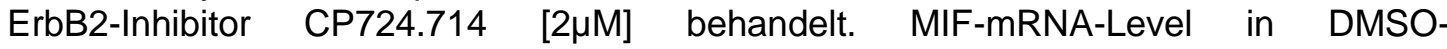
kontrollbehandelten Zellen diente als Referenzwert und wurde gleich 1 gesetzt. Anzahl der unabhängigen Experimente $n=3$. Fehlerbalken zeigen den Standardfehler. Student'scher t-Test, $p=0,11$, n.s. = nicht signifikant. (C) Zeitreihe in humanen MDA-MB-231und MCF-7-Brustkrebszellen - Die Zellen wurden mit dem ErbB2-Inhibitor CP724.714 $[2 \mu \mathrm{M}]$ für die angegebenen Zeiten behandelt und als Kontrolle je eine Gruppe DMSObehandelter Zellen geführt. Im Western Blot wurden die MIF-Proteinlevel untersucht. pERK als Kontrolle der erfolgreichen ErB2-Inhibition, GAPDH als Ladekontrolle. Anzahl der unabhängigen Experimente $n=2$, repräsentatives Ergebnis dargestellt.

*bei der Lapatinibbehandlung handelt es sich um einen Vorversuch, der nur einmal durchgeführt wurde 


\subsection{Die Herabregulierung der MIF-Proteinlevel nach einer ErbB2-Inhibition wird über den PI3K-Akt-Signalweg vermittelt}

Der ErbB2-Signalweg moduliert das Verhalten einer Zelle hauptsächlich über den PI3K-Akt- und den MEK-ERK-MAPK-Signalweg (Xia et al. 2002). Es stellte sich also die Frage, ob der beobachtete Effekt auf die MIF-Level primär über einen der beiden Wege vermittelt wird oder nicht. Um dieser Frage zu beantworten, wurde ein weiteres Zellkulturexperiment entworfen, in welchem Inhibitoren dieser zwei Signalwegzweige zum Einsatz kamen: Ly294002 als Inhibitor der PI3Kinase und somit des Akt-Signalweges, U0126 als Inhibitor der Kinasen MEK1/2 und damit des MEKERK-MAPK-Signalweges. Zugleich wurde in diesem Experiment durch Verwendung des Caspasen-Inhibitors zVAD überprüft, ob das Absinken der MIF-Proteinlevel mit einer Caspasenaktivierung in Zusammenhang steht. Die Inhibition der Caspasen müsste dieser Hypothese nach das Absinken der MIF-Level unter einer ErbB2Inhibitorbehandlung verhindern.

In Abbildung 4 sind die Ergebnisse der auf den Zellkulturversuch folgenden Western-Blot-Analyse dargestellt. Sowohl der ErbB2-Inhibitor CP724.714 (Abb. 4 A \& B, Spur 2) als auch der PI3K-Inhibitor Ly294002 allein (Abb. 4 A, Spur 4) führen zum Absinken der MIF-Proteinlevel. Eine Kombination aus beiden Inhibitoren (Abb. 4 A, Spur 3) hat denselben Effekt, bewirkt aber keine Verstärkung dessen. Der MEK1/2 Inhibitor U0126 (Abb. 4 A, Spur 6; B, Spur 3) führt zu keiner Veränderung der MIFLevel verglichen mit DMSO-behandelten Zellen (Abb. 4 A \& B, je Spur 1).

Das Absinken der MIF-Level in SK-BR-3-Zellen lässt sich unter einer ErbB2Inhibition und auch bei einer Inhibition des PI3K-Akt-, aber nicht des MEK-ERKMAPK-Signalweges beobachten. Die MIF-Herabregulierung ist also abhängig vom PI3K-Akt-Signalweg. Eine kombinierte Inhibition von ErbB2 und PI3K verstärkt den Effekt auf MIF nicht.

Ferner verhindert die Behandlung mit zVAD (Abb. 4 A, Spur 7; B, Spur 6) nicht die durch CP724.714 bewirkte Verringerung des zellulären MIF- Gehaltes. Die Verringerung des MIF-Proteingehaltes ist folglich unabhängig von einer etwaigen Caspasenaktivität.

Die Färbung für pERK bzw. pAkt demonstrieren den Erfolg der verschiedenen Inhibitorbehandlungen: Sowohl alleinige CP724.714-Behandlung (Abb. 4 A \& B, je Spur 2) als auch Kombinationsbehandlungen mit CP724.714 (Abb. 4 A, Spur 3, 5 und 7; 
B, Spur 4 und 6) führen zu verringerter Phosphorylierung beider Kinasen, Akt und ERK. Behandlung mit dem PI3K-Inhibitor Ly294002 (Abb. 4 A, Spur 4) lässt die ERK-Phosphorylierung unverändert. Die MEK1/2-Inhibiton mit U0126 bewirkt verringerte pERK-Level (Abb. 4 A, Spur 6), aber keine Änderung der pAkt-Level (Abb. 4 B, Spur 3).

Die Inhibitoren Ly294002 und U0126 wirken demnach wie gewünscht nur auf einen - dem ErbB2-Rezeptor nachgeschalteten - Signalwegast. Die MIF-Herabregulierung unter einer ErbB2-Inhibition ist PI3K-abhängig und unabhängig von Caspasenaktivität. 
A

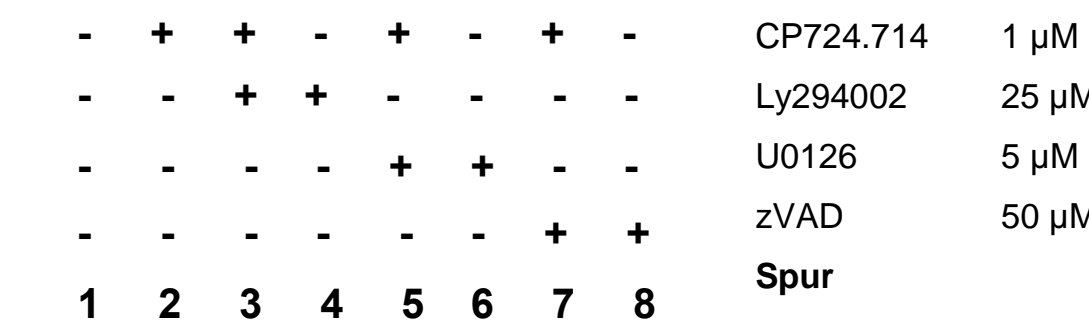

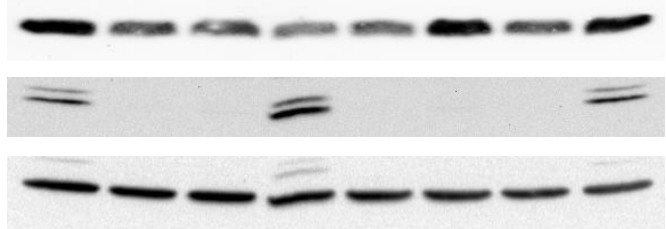

MIF

pERK (Y204)

GAPDH

B

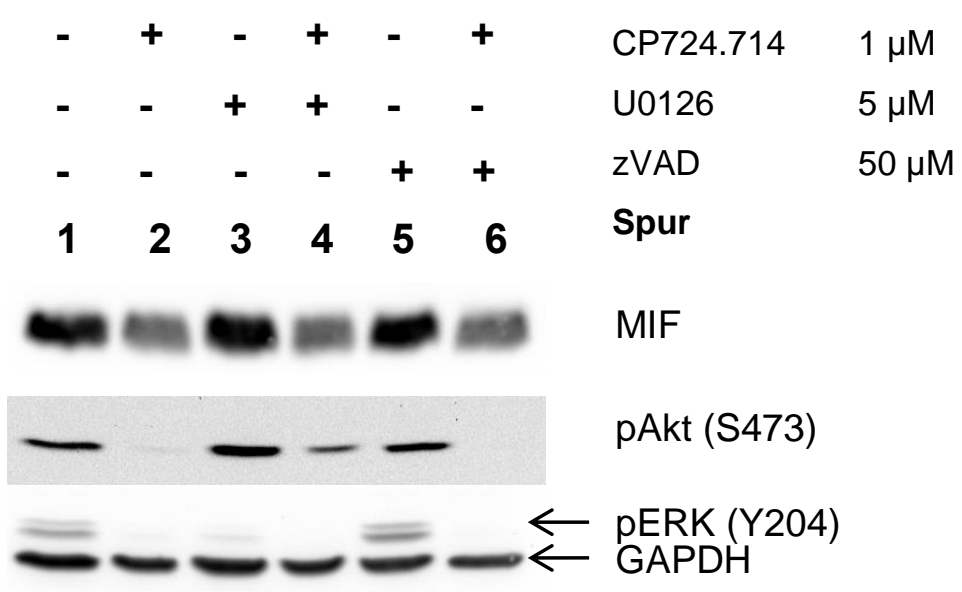

Abbildung 4: Die Herabregulierung der MIF-Proteinlevel durch eine ErbB2Inhibition wird über den ErbB2-PI3K-Akt-Signalweg und unabhängig von einer etwaigen Caspasenaktivität vermittelt.

(A) Nur Behandlungen mit Beteiligung der Inhibitoren CP724.714 oder Ly294002 führen zu einer Herabregulierung der MIF-Proteinlevel. SK-BR-3-Zellen wurden für 48 Stunden mit folgenden Inhibitoren einzeln oder in Kombination behandelt (vgl. Abbildung): CP724.714 [1 $\mu \mathrm{M}]$ - ErbB2-Inhibitor; Ly294002 [25 $\mu \mathrm{M}]$ - PI3K-Inhibitor; U0126 [5 $\mu \mathrm{M}]$ - MEK1/2-Inhibitor; zVAD [50 $\mu \mathrm{M}]$ - Caspaseninhibtor. Als Kontrolle dienten DMSO-behandelte Zellen. Im Immunoblot wurden die MIF-Proteinlevel und als read-out der Inhibitoraktivitäten die Phosphoproteine pAkt und pERK untersucht. GAPDH fungierte als Ladekontrolle. (B) Wiederholung des Experimentes für die Inhibitoren CP724.714 [1 $\mu \mathrm{M}]$, U0126 [5 $\mu \mathrm{M}]$ und zVAD [50 $\mu \mathrm{M}]$. Anzahl der unabhängigen Experimente: $n \geq 3$ für die CP724.714 Behandlung, $n=2$ für die Ly294002Behandlung (jeweils repräsentatives Ergebnis dargestellt), für alle anderen Inhibitoren und Kombinationen $\mathrm{n}=1$. 


\subsection{Eine Inhibition des ErbB2-Rezeptors senkt die HSP- Level, die Aktivität der HSP und die Stabilität ver- schiedener Hsp90-Klienten}

Wie in Kapitel 3.2 (S. 26, Abb. 3 B) gezeigt, bleibt die MIF-mRNA-Expression unter ErbB2-Inhibition in SK-BR-3-Zellen unverändert. Unsere Arbeitsgruppe konnte zeigen, dass MIF in Brustkrebszellen durch das Chaperon Hsp90 stabilisiert wird (Schulz et al. 2012). Es ist also denkbar, dass das Absinken der MIF-Proteinlevel nach ErB2-Inhibition durch ein Absinken der Konzentration an HSP, verringerte HSP Aktivität, und damit sinkender Stabilisierung des Hsp90-Klienten MIF bedingt ist. Um diese Hypothese zu überprüfen wurde eine weitere Zeitreihe einer CP724.714 Behandlung im Zellkulturversuch an SK-BR-3-Zellen durchgeführt.

Wie vorab beobachtet, sinken die MIF-Proteinlevel im zeitlichen Verlauf der 48stündigen Behandlung (Abb. 3, S. 27; Abb. 5, S. 32). Parallel dazu ist in Abbildung 5 A ein Absinken der Konzentrationen der Hitzeschockproteine Hsp70 und Hsp27 sowie der induzierbaren Form des Hsp90, Hsp90- $\alpha$, zu beobachten. Jedes der Proteine ist Bestandteil der sog. Hitzeschockproteinmaschinerie (Whitesell und Lindquist 2005), die u.a. MIF stabilisiert (Schulz et al. 2012). Eine weitere, wichtige Beobachtung ist die bereits nach 6 Stunden CP724.714 Behandlung eintretende verminderte Phosphorylierung von S326 an HSF-1. Diese Phosphorylierung führt zu einer Aktivierung des Transkriptionsfaktors der HSP (Guettouche et al. 2005).

Unter der ErbB2-Inhibitorbehandlung sinken die Level einiger weiterer Hsp90Klienten, wie in Abbildung $5 \mathrm{~B}$ zu sehen ist. Neben (in SK-BR-3-Zellen mutiertem) p53, MIF und Bcl-xL, auch die Kinase Akt und der Transkriptionsfaktor des Hitzeschockprogrammes HSF-1. Vergleicht man die HSF-1-Level (Abb. 5 B) mit den pHSF-1-Leveln (Abb. $5 \mathrm{~A}$ ) fällt auf, dass die Abnahme der Phosphorylierung früher im zeitlichen Verlauf der Behandlung und insgesamt prominenter auftritt, als die Abnahme des totalen zellulären Gehaltes an HSF-1.

S473-Phosphorylierung an Akt diente hier wieder als Kontrolle der erfolgreichen Inhibitorbehandlung.

Die Behandlung mit dem ErbB2-Inhibitor CP724.714 bewirkt in SK-BR-3-Zellen also eine verminderte HSF-1-Aktivierung, gefolgt von einem Absinken des Gehalts an Hitzeschockproteinen. Damit einhergehend kommt es zur Destabilisierung von Hsp90-Klienten. 
Die Aktivierung von HSF-1 durch S326-Phosphorylierung unterbleibt zeitlich deutlich bevor die HSF-1-Proteinlevel sinken. Erst ändert sich also die Regulation des Transkriptionsfaktors unter der Inhibitorbehandlung, dann zeigt sich der Effekt auf die HSP-Level und HSF-1 (selbst ein Hsp90-Klient) wird destabilisiert.

A

$$
\text { CP724.714 }[2 \mu \mathrm{M}]
$$

h

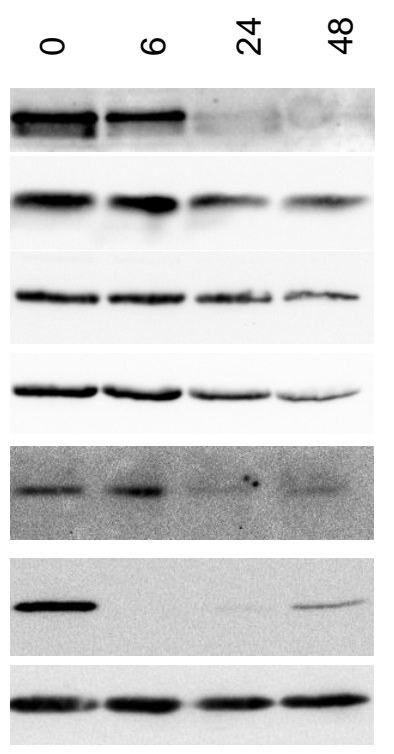

B

$$
\text { CP724.714 }[2 \mu \mathrm{M}]
$$

$\mathrm{h}$

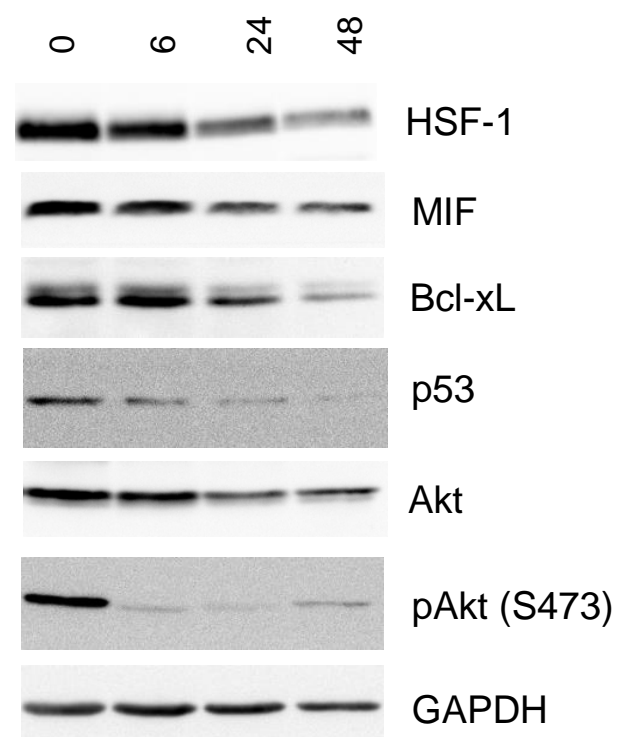

\begin{abstract}
Abbildung 5: Die ErbB2-Inhibition bewirkt eine Inhibition der HSPMaschinerie und destabilisiert Hsp90-Klienten.

(A) Die aktivierende S326-Phosphorylierung an HSF-1 sowie anschließend der Gehalt an Hitzeschockproteinen in SK-BR-3-Brustkrebszellen nehmen im zeitlichen Verlauf der Behandlung mit CP724.714 [2 $\mu \mathrm{M}$ ] deutlich ab. Eine Kontrollgruppe wurde nur mit DMSO behandelt. Die in der Zeitreihe erhaltenen Proteinlysate sind im Western Blot analysiert worden. Dabei wurden Färbungen für den aktivierten Transkriptionsfaktor pHSF-1, MIF, sowie die Hitzeschockproteine Hsp90-a, Hsp70 und Hsp27 durchgeführt. pAkt als Erfolgskontrolle der Inhibitorbehandlung und GAPDH als Ladekontrolle. (B) Die Klientenproteine der Hitzeschockmaschinerie erfahren durch die ErbB2-Inhibiton eine Destabilisierung. Experimentelles Vorgehen wie in (A), immunochemische Analyse der Proteinlevel von monomerem HSF-1 und den Hsp90-stabilisierten Proteinen MIF, Bcl-xL, mutiertes p53 sowie Akt. Zur Erfolgskontrolle der Behandlung diente pAkt und als Ladekontrolle GAPDH. Anzahl der unabhängigen Experimente $n=2$ (Ausnahme Hsp27, n=1), repräsentatives Ergebnis dargestellt.
\end{abstract}




\subsection{Die Aktivierung von HSF-1 durch einen Hitzeschock wird durch eine ErbB2-Inhibition eingeschränkt}

Wie im vorangegangen Kapitel gezeigt, schränkt eine ErbB2-Inhibition die aktivierende S326-Phosphorylierung an HSF-1 ein und senkt so die HSP-Level. Eine Hitzeschockbehandlung führt zur Aktivierung des Transkriptionsfaktors HSF-1 (Guettouche et al. 2005). Um eine funktionelle Verbindung zwischen dem ErbB2Signalweg und der Hitzeschockantwort zu zeigen, wurden SK-BR-3-Zellen in einem weiteren Experiment für 48 Stunden kultiviert und währenddessen, neben DMSO als Kontrolle, mit den bereits beschriebenen Inhibitoren CP724.714 und Ly294002 behandelt. Jeweils eine Untergruppe der verschieden behandelten Zellen wurde vor Ernte einem einstündigen Hitzeschock bei $43^{\circ} \mathrm{C}$ ausgesetzt, gefolgt von einer dreistündigen Erholungsphase bei Normalbedingungen. Die gewonnen Zelllysate wurden mithilfe von Western Blots untersucht (Abb. 6).

In der DMSO-behandelten Untergruppe (Abb. 6, Spur 1 und 2) erkennt man die ohne Inhibitoreinfluss stattfindenden Veränderungen an HSF-1 nach einem Hitzeschock (Abb. 6, Spur 2): Der Gehalt an S326-phosphoryliertem HSF-1 nimmt zu. Ebenso steigt das Molekulargewicht von HSF-1, durch seine zahlreichen posttranslationalen Modifikationen. Dies wird erkennbar an der leicht verringerten Wandergeschwindigkeit in der SDS-PAGE und der damit etwas höher liegenden Bande im Western Blot. Sowohl die Veränderungen des Molekulargewichtes als auch die S326-Phosphorylierung verschwinden nahezu vollständig in den CP724.714- (Abb. 6, Spur 3 und 4) und Ly294002-behandelten Untergruppen (Abb. 6, Spur 5 und 6).

Folglich verhindert die Inhibition des ErbB2-Signalweges die aktivierende S326Phosphorylierung nach einem Hitzeschock. Dieser Effekt wird mindestens zum Teil über den PI3K-Akt-Signalweg bewirkt oder ist abhängig von diesem. 


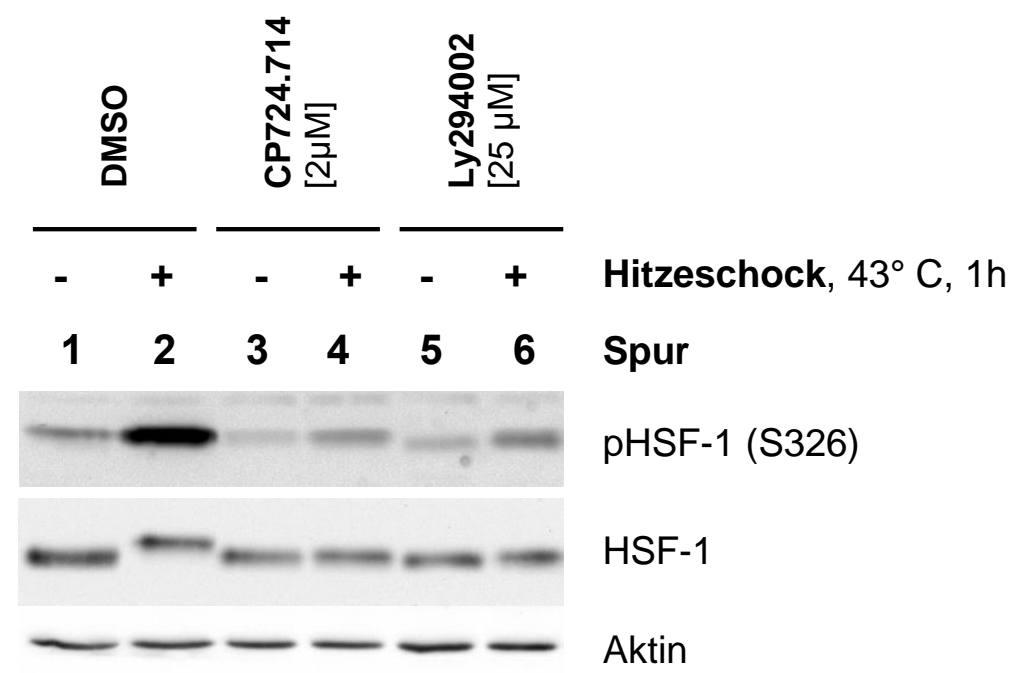

\begin{abstract}
Abbildung 6: Die ErbB2-Inhibition bewirkt eine über PI3K-Akt vermittelte verringerte Aktivierung des Transkriptionsfaktors HSF-1 durch einen Hitzeschock.

Der Effekt der ErbB2-Inhibition auf die HSF-1-Aktivierung wird sowohl bei Betrachtung der pHSF-1-Banden als auch der Änderung im Molekulargewicht von HSF-1 deutlich, die durch vielfältige posttranslationale Modifikationen entsteht. Humane SK-BR-3Brustkrebszellen wurden für 48 Stunden mit dem ErbB2-Inhibitor CP724.714 [2 $\mu \mathrm{M}]$, dem PI3K-Inhibitor Ly294002 [25 $\mu \mathrm{M}$ ] oder DMSO als Kontrolle behandelt. Hitzeschockbehandlung erfolgte für eine Stunde bei $43^{\circ} \mathrm{C}$. Anschließend folgte eine dreistündige Erholungsphase im Inukubator bei Normalbedingungen. Die gewonnen Lysate wurden im Western Blot auf den HSF-1-Gehalt bzw. dessen transkriptionell aktive Form pHSF-1 untersucht, Aktin diente als Ladekontrolle. Bis auf die Ergebnisse für CP724.714 ( $n=2$, repräsentatives Bild gezeigt) handelt es sich um einen Einzelversuch.
\end{abstract}

Abbildung 6 - ErbB2-Inhibition verringert HSF-1-Aktivierung

Ein analoges, funktionelles Experiment wurde zusätzlich durchgeführt, um den Einfluss der Inhibition des ErbB2-Signalweges auf HSF-1 weiter zu untersuchen. Dazu wurde ein in der Literatur beschriebenes immunfluoreszenzmikroskopisch darstellbares Korrelat der Aktivierung von HSF-1 herangezogen. Mit HSF-1Antikörpern gefärbte, fixierte Zellen zeigen verstärkt eine granuläre Musterung im Zellkern. Diese so genannten nukleären Stresskörperchen (nSBs) (Biamonti 2004) entstehen, wenn HSF-1 zuvor z.B. durch einen Hitzeschock aktiviert wurde (Sarge et al. 1993). Inaktivierter HSF-1 korreliert mit einer homogenen Kernanfärbung. 48 Stunden mit DMSO, CP724.714 bzw. Ly294002 behandelte SK-BR-3-Zellen wurden, wie oben beschrieben, einem Hitzeschock ausgesetzt, fixiert und mit einem HSF-1- Antikörper und fluoreszenzmarkiertem Sekundärantikörper gefärbt. Eine DAPI-Kernfärbung diente als Gegenfärbung. Die Ergebnisse der Auswertung der erhaltenen Immunfluoreszenzbilder sind in Abbildung 7 zu finden. 
Auch in der Immunfluoreszenzanalyse zeigt sich eine deutliche Abnahme der HSF1-Aktivierung nach dem Hitzeschock in den inhibitorbehandelten Zellgruppen. DMSO-behandelte Zellen zeigen zu 18,3 \% eine granuläre Kernanfärbung, CP724.714-behandelte nur zu 8,1\% und Ly294002 behandelte zu 6,0 \% (Abb. 7 B).

Beide Experimente zeigen übereinstimmend eine verringerte Aktivierung von HSF-1 durch Hitzeschock unter der ErbB2-Inhibition, mindestens zum Teil PI3K-vermittelt. 
A
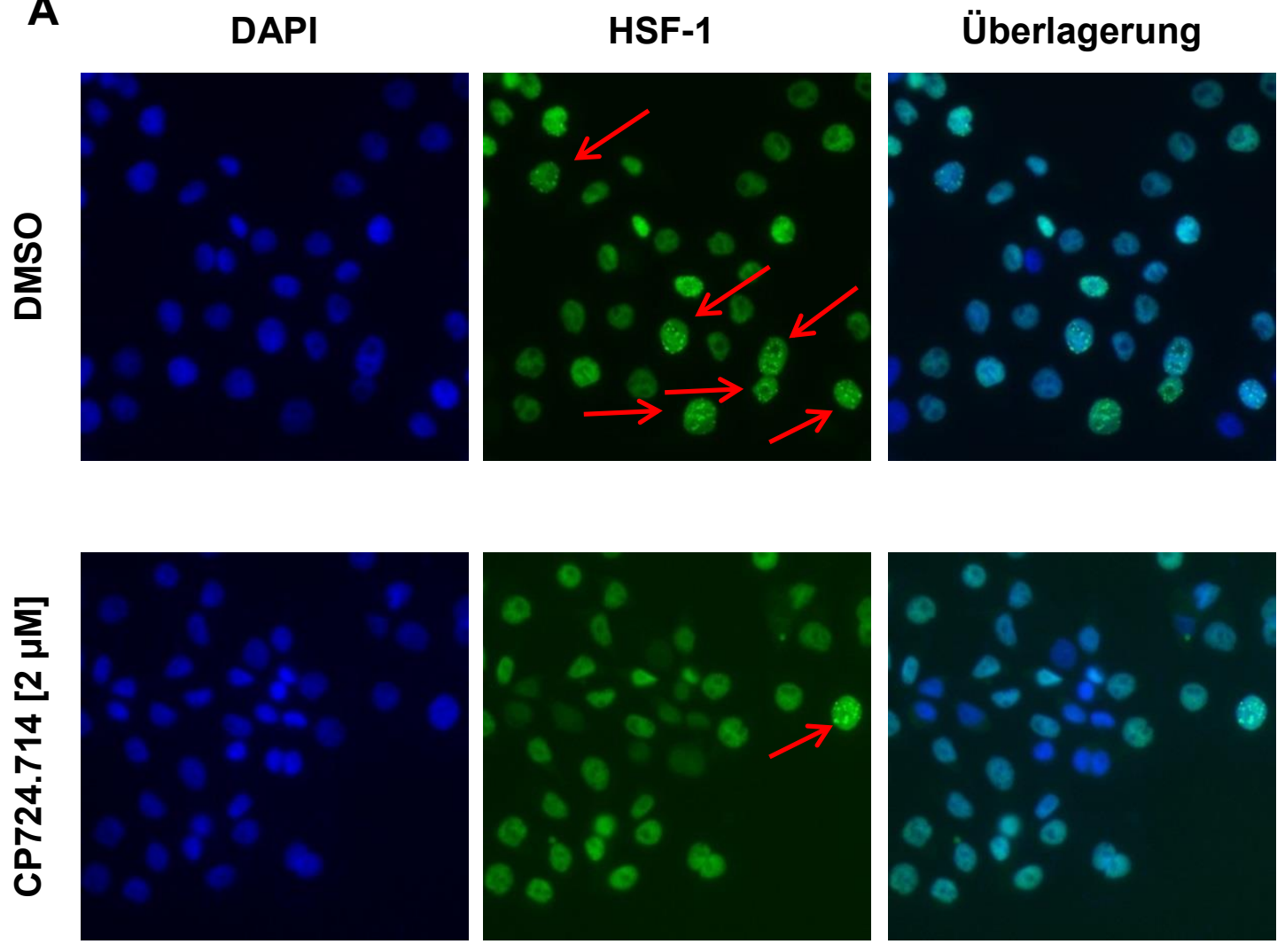

B

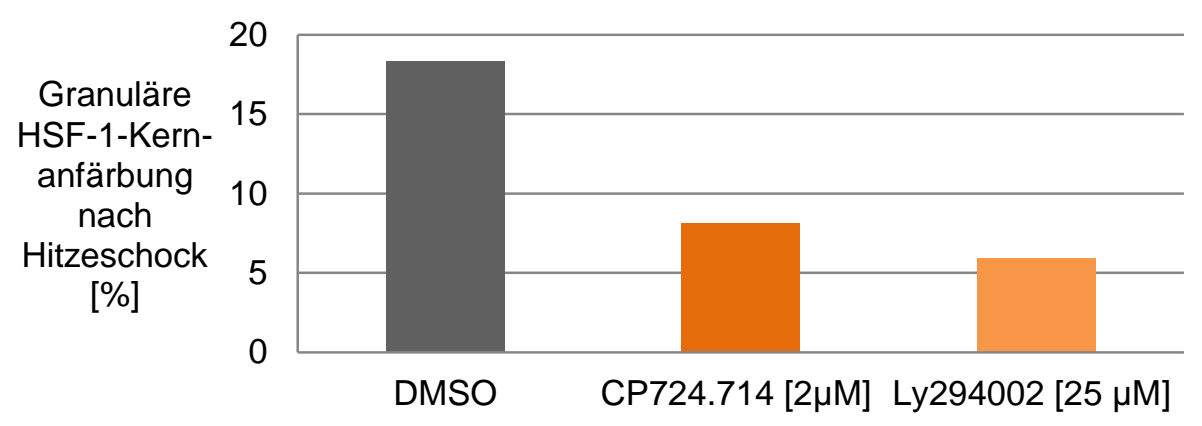

Abbildung 7: Sowohl eine ErbB2- als auch eine PI3K-Inhibition reprimieren die Aktivierung von HSF-1 durch einen Hitzeschock.

(A) CP724.714-behandelte Zellen zeigen nach einem Hitzeschock deutlich seltener ein granuläres Muster in der HSF-1-Anfärbung als kontrollbehandelte Zellen. Einige repräsentative Gesichtsfeldausschnitte sind hier dargestellt. Pfeile markieren Zellen mit granulärer HSF-1-Kernanfärbung, 40x-Objektiv. (B) Diagrammdarstellung der Ergebnisse der quantitativen Analyse. Die CP724.714- und Ly294002-Behandlung verringern beide drastisch den prozentualen Anteil an Zellen, die eine granuläre HSF-1-Anfärbung nach Hitzeschock im Kern zeigen. Pro untersuchter Zellgruppe wurden für die Quantifizierung jeweils mindestens 3000 Zellen im Hinblick auf granuläre, nukleäre HSF-1-Anfärbung unter dem Fluoreszenzmikroskop ausgezählt. Humane SK-BR-3-Brustkrebszellen wurden nach 48-stündiger Behandlung mit dem ErbB2-Inhibtor CP724.714 [2 $\mu \mathrm{M}$ ], dem PI3K-Inhibitor Ly294002 $[25 \mu \mathrm{M}]$ oder DMSO als Kontrolle, für eine Stunde einem Hitzeschock bei $43^{\circ} \mathrm{C}$ ausgesetzt. Nach drei weiteren Stunden unter Normalbedingungen wurden die Zellen für die Immunfluoreszenzanalyse fixiert und HSF-1 gefärbt (grün). Eine Zellkernfärbung erfolgte mit DAPI (blau). Es handelt sich um einen Einzelversuch. 


\subsection{Die Inhibition des ErbB2-Signalweges verändert die Transkriptionsrate HSF-1-regulierter Gene}

Die bisherigen Ergebnisse, die eine verminderten Aktivierung von HSF-1 unter Blockierung des ErbB2-Signalweges zeigen, werfen die Frage auf, inwieweit sich dies auf die Transkription von HSF-1-Zielgenen auswirkt. Zu erwarten wären eine gesteigerte Transkriptionsrate negativ regulierter Gene und eine herabgesenkte Transkriptionsrate positiv regulierter Gene. Um dies zu ergründen wurden SK-BR-3Zellen erneut für 48 Stunden mit dem ErbB2-Rezeptor-Inhibitor CP724.714 behandelt, DMSO-behandelte Zellen als Kontrollgruppe geführt und eine qRT-PCR Analyse der mRNA-Level einer Auswahl an HSF-1-Zielgenen durchgeführt. Gewählt wurden dazu die positiv regulierten Gene der HSP Hsp70 und Hsp110, als Vertreter der Hitzeschockantwort (Lindquist 1986) und die Gene CDC6, CBX3, FASN und SPTAN1, welche als Bestandteil des in Tumorzellen alternierten HSF-1Programmes beschrieben sind (Mendillo et al. 2012), vgl. auch Kapitel 1.5, S. 9.

CDC6 kodiert für das cell division cycle 6 protein, steht im Zusammenhang mit der Regulation des Zellzyklus (Liu et al. 2000) und wird positiv durch HSF-1 reguliert. CBX3 kodiert für das chromoboxprotein homolog 3, dem eine Funktion in der Organisation des Heterochromatin und dessen Anbindung an die innere Zellkernmembran zugeordnet wird (Ye and Worman 1996). CBX3 wird positiv durch HSF-1 reguliert. FASN kodiert für die Fettsäure-Synthase, ein Protein des Fettstoffwechsels (Witkowski et al. 1991) und wird negativ reguliert. SPTAN1 kodiert für das Protein spectrin alpha chain, non-erythrocytic 1, welches Bestandteil des Zytoskeletts in nicht erythrocytären Zellen ist (Moon and McMahon 1990) und ebenfalls negativ durch HSF-1 reguliert wird (Abbildung 8 A, S. 39).

Die Ergebnisse der qPCR-Analyse finden sich in Abbildung 8. Die mRNA-Level sind jeweils relativ zu denen in DMSO-behandelten Zellen gefundenen angegeben. Einen Überblick über die jeweilige Regulationsrichtung der Gene liefert Teil A der Abbildung.

Die Expression der untersuchten Gene wird durch Behandlung mit CP724.714 verändert. Alle Gene zeigen dabei eine Alternierung ihrer Expressionsrate, die entgegengesetzt zur HSF-1-Regulierung ausfällt. Die drei durch HSF-1 positiv regulierten Gene für die Proteine Hsp70 (0,82 \pm 0,09), Hsp110 (0,68 $\pm 0,06)$ und CDC6 $(0,68 \pm 0,07$, jeweils Angabe des Standardfehlers, $n=3)$ zeigen eine gesenkte Expressionsrate (Abb. 8 B und C). Die negativ regulierten Gene FASN $(1,99 \pm 0,29)$ 
und SPTAN1 (1,40 $\pm 0,20$, je Angabe des Standardfehlers, $n=3)$ weisen eine gesteigerte Expressionsrate auf (Abb. $8 \mathrm{C}$ ). Die Ergebnisse sind dabei mindestens auf dem $5 \%$-Niveau signifikant ( $p$-Werte aus den durchgeführten, zweiseitigen Student'schen t-Tests finden sich in der Abbildungsunterschrift). Für CBX3, das positiv durch HSF-1 reguliert wird, konnte ebenfalls eine Reprimierung der Expressionsrate $(0,79 \pm 0,13$, Standardfehler, $n=2)$ unter der ErbB2-Inhibition gezeigt werden (Abb. $8 \mathrm{C})$, das Ergebnis ist allerdings nicht signifikant.

Eine Behandlung mit dem ErbB2-Inhibitor CP724.714 bewirkt in SK-BR-3-Zellen folglich eine Alternierung der Transkriptionsrate HSF-1-regulierter Gene. Positiv regulierte Gene werden unter einer ErbB2-Inhibition reprimiert, negativ regulierte hingegen werden vermehrt transkribiert. Dieser Zusammenhang trifft sowohl für Gene der HSP Hsp70 und Hsp110 zu als auch für die Gene des HSF-1Tumorprogramms, das von Mendillo et al. beschrieben wurde. 
A

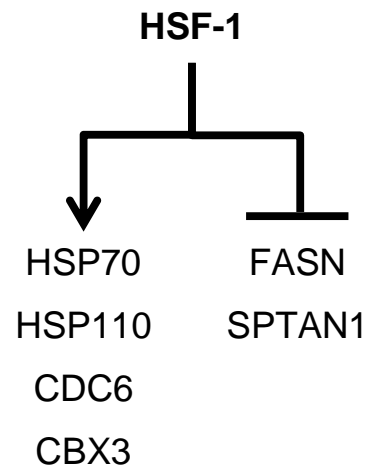

C
FASN

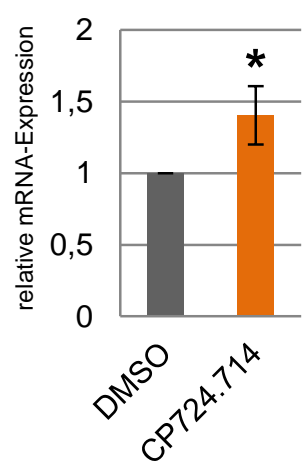

\section{SPTAN1}

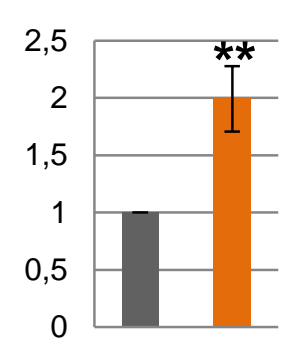

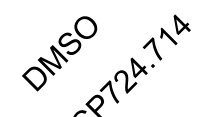

B

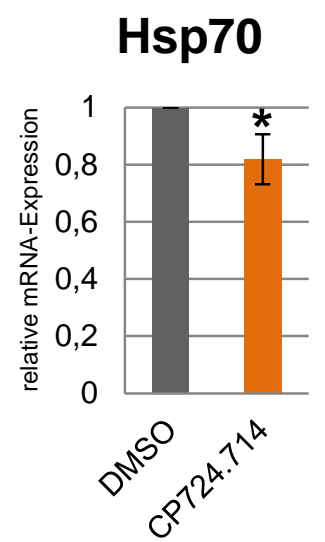

\section{Hsp110}

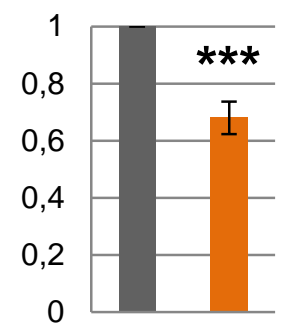

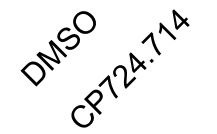

CDC6

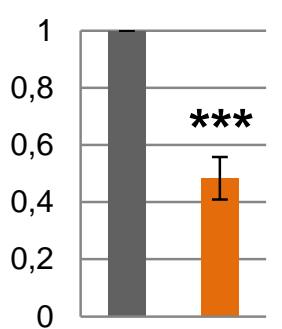

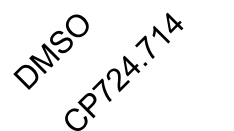

CBX3

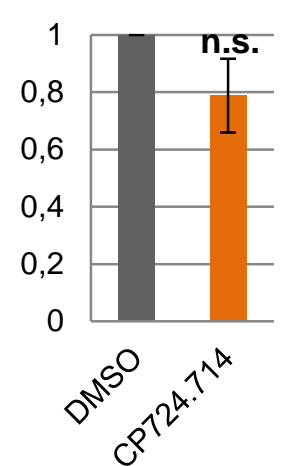

\begin{abstract}
Abbildung 8: Eine Inhibition des ErbB2-Signalweges verändert die Transkription von HSF1- regulierten Genen.

(A) Übersicht über die untersuchten, durch HSF-1 aktivierten bzw. reprimierten Gene. Humane SK-BR-3-Brustkrebszellen wurden 48 Stunden lang mit dem ErbB2-Inhibtior CP724.714 [2 $\mu \mathrm{M}]$ bzw. zur Kontrolle mit DMSO behandelt. Anschließend wurde der mRNA-Gehalt in den erhaltenen Extrakten vermittels qRT-PCR untersucht: (B) Die HSF1-regulierten Gene für die HSP Hsp70 $(p=0.0396)$ und Hsp110 ( $p=0.001)$ werden durch die ErbB2-Inhibition herunterreguliert. (C) Die Transkription der Gene des für Tumorzellen spezifischen HSF-1-Programms wird durch die ErbB2-Inhibition alterniert: SPTAN1 $(p=0.0362)$, FASN $(p=0.0069), \operatorname{CDC6}(p=0.001)$ und CBX3 $(p=0.067)$. Als Haushaltsgen wurde 36B4 benutzt. Die Expression ist jeweils relativ zu den kontrollbehandelten Zellen angegeben. Fehlerbalken zeigen den Standardfehler. Anzahl unabhängiger Experimente $n=3$, außer SPTAN1 $n=2$. qPCR jeweils in Triplikaten. Student'scher $t-T e s t ~{ }^{*} p<0.05$, ${ }^{* *} p<0.01$ und ${ }^{* *} p<0.001$, n.s. $=$ nicht signifikant.
\end{abstract}




\subsection{Eine ErbB2-Inhibition verhindert die transkriptionelle Wirkung von HSF-1 auf seine Zielgene nach einem Hitzeschock}

Wie in Kapitel 3.6 (S. 37) gezeigt wurde, alterniert eine ErbB2-Inhibition die Transkription HSF-1-kontrollierter Gene. Es sollte nun mithilfe eines weiteren Zellkulturexperimentes ergründet werden, ob die Inhibition des ErbB2-Rezeptors - auch bei gleichzeitiger Einwirkung eines Hitzeschockes - die transkriptionsregulierende Wirkung von HSF-1 verhindern kann. SK-BR-3-Zellen wurden dazu 48 Stunden entweder mit DMSO als Kontrolle oder dem ErbB2-Inhibitor CP724.714 behandelt und je eine Untergruppe einem einstündigen Hitzeschock bei $43^{\circ} \mathrm{C}$ ausgesetzt. Nach dreistündiger Erholungsphase wurden alle Zellen geerntet und deren Gehalt an Hsp110-, CDC6-, FASN- und SPTAN1-mRNA untersucht.

Die gemessenen mRNA-Level sind jeweils relativ zu DMSO-behandelten, nicht hitzegeschockten Zellen angegeben (Abb. 9, S. 41). Der Hitzeschock bewirkt eine Hochregulierung der Transkription der positiv durch HSF-1 regulierten Gene für das Hsp110 (Abb. 9 A, 7,32 \pm 0,38) und CDC6 (Abb. 9 B, 1,54 \pm 0,31, jeweils Säule 1 vs. 3). Eine Herunterregulierung der Expression bewirkt der Hitzeschock bei den negativ durch HSF-1 regulierten Genen FASN (Abb. 9 C, 0,86 $\pm 0,04$ ) und SPTAN1 (Abb. 9 D, 0,67 $\pm 0,04$, jeweils Säule 1 vs. 3). Jeweils Angabe des Standardfehlers, $\mathrm{n}=2$. Dies veranschaulicht die durch Hitzeschock erzielte Aktivierung von HSF-1 auf Ebene der Transkription.

Für das Gen des Hsp110 (Abb. 9 A, 11,33 \pm 4,40) zeigt sich, dass die nach einer ErbB2-Inhibition beobachtete Herabregulierung unter normalen Temperaturbedingungen (Abb. 8 B, S. 39) durch einen Hitzeschock überwunden wird. Das Ergebnis in Bezug auf die hitzeschockbehandelte DMSO-Kontrolle ist nicht signifikant. Bei den tumorspezifischen HSF-1-Zielgenen führt die Behandlung mit dem ErbB2Inhibitor CP724.714 einheitlich, auch nach einem Hitzeschock, zu einer Alternierung der Expressionsrate. Im Falle des positiv regulierten Gens CDC6 (0,79 $\pm 0,05$, Abb. 9 B) wird die Transkription reprimiert. Bei den negativ durch HSF-1 regulierten Genen des HSF-1-Tumorprogrammes, FASN (1,75 \pm 0,08, Abb. 9 C) und SPTAN1 $(1,28 \pm 0,1$, Abb. 9 D) steigt die Transkriptionsrate. Als Vergleich diente hier die DMSO-behandelte, hitzegeschockte Zellgruppe. Jeweils Angabe des Standardfehlers, $n=2$. Die Ergebnisse sind mindestens auf $5 \%$-Niveau signifikant ( $p$-Werte aus den durchgeführten, zweiseitigen, Student'schen t-tests finden sich in der Abbildungsunterschrift). 
Als Ergebnis für die Gene des tumorspezifischen HSF-1-Programms (CDC6, FASN und SPTAN1) lässt sich also festhalten, dass die ErbB2-Inhibitorbehandlung mit CP724.714 die HSF1-typische-Regulation der Expressionsraten auch nach einem Hitzeschock, also massiver HSF-1-Aktivierung, verhindert.
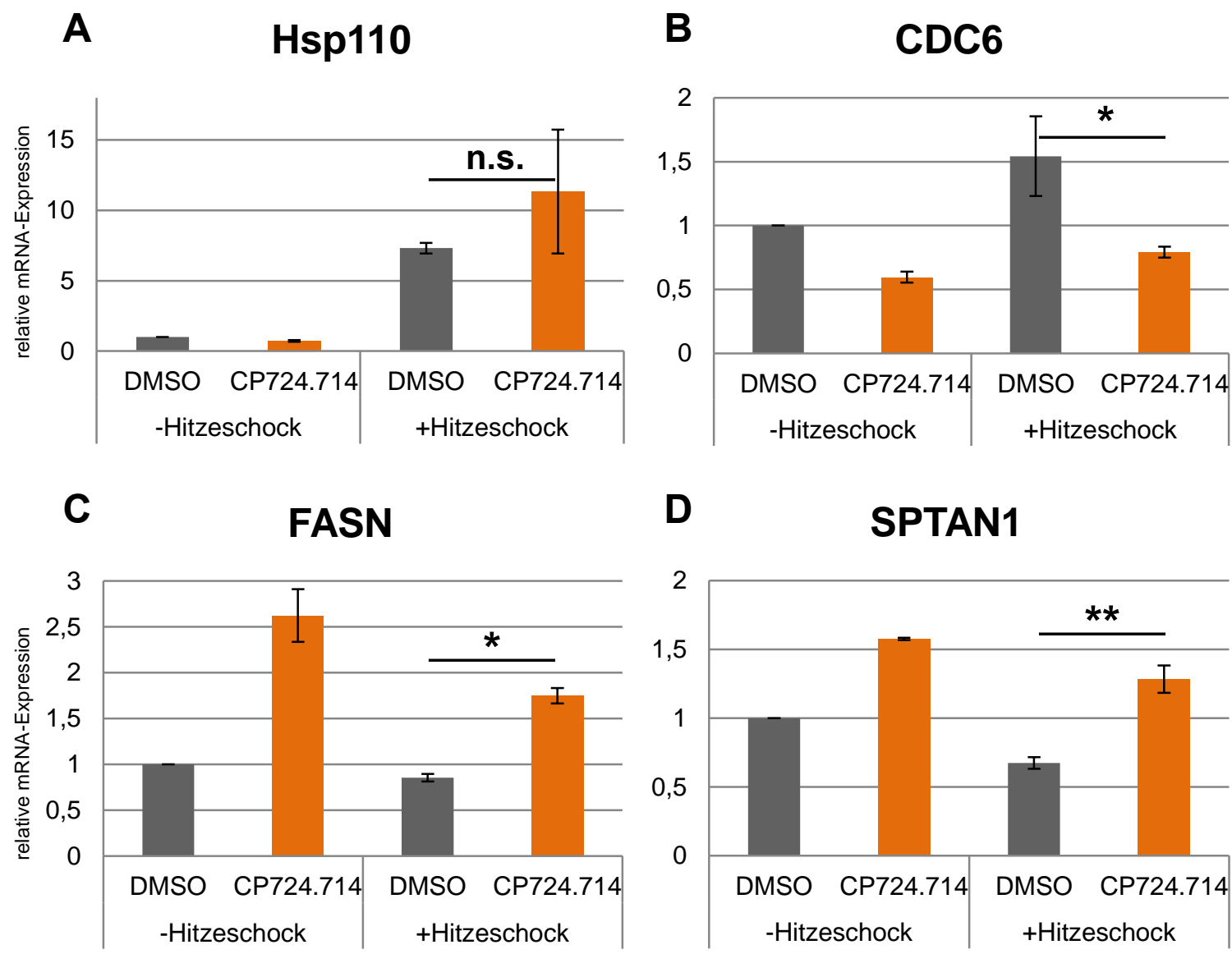

Abbildung 9: Die Inhibition des ErbB2-Rezeptors verhindert die Wirkung von HSF-1 auf einige seiner Zielgene, auch nach einem Hitzeschock.

SK-BR-3-Zelllen wurden für 48 Stunden unter einer Behandlung mit DMSO bzw. CP724.714 [2 $\mu \mathrm{M}]$ kultiviert. Eine Untergruppe wurde des Weiteren für eine Stunde bei $43^{\circ} \mathrm{C}$ einem Hitzeschock ausgesetzt und abschließend für 3 Stunden wieder bei $37^{\circ} \mathrm{C}$ inkubiert. Die Expression der HSF-1-Zielgene für Hsp110 (A) sowie CDC6 (B), FASN (C) und SPTAN1 (D) wurde durch qPCR untersucht. Die Inhibitorbehandlung vermag es, auch unter der Hitzeschockeinwirkung, die HSF-1-Gen-Regulation zu verhindern. Dies trifft allerdings nur auf die Gene des tumorspezifischen HSF-1-Programms (CDC6 $(p=0,0373)$, FASN $(p=0,0161)$, SPTAN1 $(p=0,0048))$, nicht auf das Gen für Hsp110 $(p=0,4142)) z u$. Als Haushaltsgen diente 36B4. Der mRNA-Gehalt ist jeweils relativ zu DMSO-kontrollbehandelten, nicht hitzegeschockten Zellen angegeben. Anzahl der unabhängigen Experimente $n=2$, qPCR jeweils in Triplikaten. Fehlerbalken indizieren den Standardfehler. Student'scher t-Test ${ }^{*} p<0.05,{ }^{* *} p<0.01$, n.s. $=$ nicht signifikant. 


\section{Diskussion}

Fragestellung dieser Dissertation war, ob der zelluläre Gehalt des pro-onkogenen Proteins MIF in Brustkrebszellen vom Subtyp des Brustkrebses, in Bezug auf eine Überexpression des ErbB2-Rezeptors, abhängt. Die Ergebnisse dieser Arbeit weisen eindeutig darauf hin, dass eine ErbB2-Überexpression mit hohen MIF-Leveln einhergeht (s. Abb. 2, S. 25). Ferner war eine Zielsetzung die Zusammenführung bekannter Einzelzusammenhänge zwischen den dem ErbB2-Rezeptor nachgeschalteten Signalwegen, dem Regulator der Hitzeschockantwort HSF-1, den HSP, insbesondere Hsp90 und dessen Klientenproteinen, vorrangig MIF. Die herausragende pro-onkogene Bedeutung von MIF für ErbB2-positiven Brustkrebs ist von unserer Arbeitsgruppe bereits gezeigt worden. Erstmals konnte in der vorliegenden Arbeit eine klare Signalachse vom ErbB2-Rezeptor über die Akt-Kinase zum Transkriptionsfaktor HSF-1 gezeigt werden. Über diese wird auch die Expression der HSP reguliert, die viele bekannte tumorwachstumfördernde Proteine wie Akt, HSF-1 selbst, mutiertes p53 und MIF stabilisieren.

\subsection{Zusammenfassung der Ergebnisse}

Die folgenden Aussagen beziehen sich auf Ergebnisse, gewonnen aus Zellkulturexperimenten in der ErbB2-überexprimierenden Zelllinie SK-BR-3 (s. Abb. 2, S. 25).

Es konnte erstmalig gezeigt werden, dass die Inhibition des ErbB2-Rezeptors in ErbB2-überexprimierenden Zellen ein Absinken der MIF-Protein-Level bewirkt, welches nicht auf Transkriptionsebene vermittelt wird (s. Abb. 3, S. 27). Eine Destabilisierung auf Proteinebene war als Erklärung denkbar. Zunächst wurde geprüft, ob eine Caspasenaktivierung die sinkenden MIF-Level erklärt und über welchen Signalweg die beobachteten Effekte vermittelt werden. Die beiden bedeutsamsten, stromabwärts des ErbB2-Rezeptors gelegenen Signalwegäste sind der MEK-ERKMAPK-Signalweg und der PI3K-Akt-Signalweg (Eccles 2011). Durch eine Behandlung mit für diese Signalwege spezifischen Inhibitoren konnte der Effekt auf die MIFLevel eindeutig dem PI3K-Akt-Signalwegast zugeordnet werden und durch KoBehandlung mit dem Caspaseninhibitor zVAD eine Beteiligung der Caspasen ausgeschlossen werden (s. Abb. 4, S. 30). MIF wird in Brustkrebszellen durch Hsp90 stabilisiert (Schulz et al. 2012). Wir konnten hier zeigen, dass eine ErbB2-Inhibition die HSP-Maschinerie, inklusive Hsp90, inhibiert (s. Abb. 5 A, S. 32). Als Ausdruck dessen kann die von uns gezeigte Abnahme der Level der Proteine Akt, HSF-1, mutiertes p53, Bcl-xL und MIF gewertet werden (Abb. 5 B), welche allesamt als 
Hsp90-Klienten gelten (Basso 2002, Li et al. 2011, Caldas-Lopes et al. 2009, Picard 2013). Diese Beobachtungen lenkten die Aufmerksamkeit auf den Transkriptionsfaktor der HSP: HSF-1.

HSF-1 ist von außerordentlicher Bedeutung im Zusammenhang mit Brustkrebs. Brusttumoren mit höherem HSF-1-Gehalt in den Zellkernen der Krebszellen sind im Schnitt größer, invasiver und mit einer schlechteren Prognose für die Patientinnen vergesellschaftet (Santagata et al. 2011). Auch im Mausmodell konnte eine Steigerung von Invasivität, Metastasierung und Proliferationsgeschwindigkeit durch HSF-1 beim Brustkrebs gezeigt werden (Xi et al. 2012). Wichtig ist, dass es sich dabei ebenfalls um durch ErbB2-Überexpression induzierte Tumoren handelte. Wir konnten zeigen, dass die Aktivierung des Transkriptionsfaktors HSF-1 durch einen Hitzeschock unter der Behandlung mit dem ErbB2-Inhibitor CP724.714 deutlich herabgesenkt wird. Dies ließ sich anhand verminderter S326-Phosphorylierung und Änderung des Molekulargewichts durch posttranslationale Modifikationen von HSF-1 auf der Proteinebene (Abb. 6, S. 34) zeigen. Außerdem in einem funktionellen Experiment anhand der verringerten Bildung nukleärer Stresskörperchen in der Immunfluoreszenz (Abb. 7, S. 36). Es konnte zusätzlich demonstriert werden, dass dieselben Effekte auch mit dem PI3K-Inhibitor Ly294002 erzielbar waren (Abb. 6 und 7, S. 34f), was ihre Vermittlung über den PI3K-Akt-Signalweg nahelegt.

Mendillo et al. beschrieben 2012, dass HSF-1 in Krebszellen ein distinktiv anderes Genprogramm reguliert als in nicht entarteten Zellen. Einige dieser in Tumorzellen unterschiedlich regulierten Gene „unterstützen onkogene Prozesse: Zellzyklusregulation, Signalwege, Metabolismus, Adhäsion und Translation“ (Mendillo et al. 2012, S. 549). Zur Untersuchung der Auswirkungen einer ErbB2-Inhibition in ErbB2überexprimierenden Brustkrebszellen auf der Transkriptionsebene wählten wir einige der besonders präferenziell in Tumorzellen durch HSF-1 regulierten Gene aus: CDC6, CBX3, FASN und SPTAN1. Zusätzlich untersuchten wir als Gene der klassischen Hitzeschockantwort die HSP-Gene für Hsp70 und Hsp110. Wir konnten zeigen, dass letztere durch eine ErbB2-Inhibition reprimiert werden (Abb. 8 B, S. 39). Die Expressionsraten der Gene des HSF-1-Tumorprogramms wurden durch die ErbB2-Inhibition jeweils in die der HSF-1-Regulierung entgegengesetzte Richtung verändert. Positiv regulierte Gene wurden reprimiert, negativ regulierte verstärkt transkribiert (Abb. 8 C, S. 39). Dieser Effekt konnte für CDC6, SPTAN1 und FASN auch nach zusätzlicher Stimulierung der HSF-1-Aktivität durch einen Hitzeschock noch aufrechterhalten werden. Unbehandelte Zellen reagierten darauf mit Regulation der Transkriptionsraten in die Richtung, die jeweils von Mendillo et al. für HSF-1 
beschrieben wurde. Eine ErbB2-Inhibitorbehandlung hingegen bewirkte eine Regulation in die entgegengesetzte Richtung (Abb. 9 B - C, S. 41).

Die hier erarbeiteten Ergebnisse sprechen für eine konstitutive Überaktivierung von HSF-1 in ErbB2-überexprimierenden Brustkrebszellen. Diese wird über die ErbB2PI3K-Akt-HSF-1-Achse, welche hier erstmalig beschrieben ist, vermittelt.

Insgesamt führen die gewonnenen Evidenzen zu der in Abbildung 10 A (S. 45) schematisch dargestellten Modellvorstellung der Abläufe in ErbB2überexprimierenden Brustkrebszellen: Die Dimerisierung des ErbB2-Rezeptors, für die wegen der ErbB2-Überexpression kein Ligand notwendig ist (Di Fiore et al. 1987, vgl. auch Kapitel 1.2, S. 3), führt zur Aktivierung des PI3K-Akt-Signalweges (repräsentiert durch die Akt-Kinase). Die Akt-Kinase liegt dann vermehrt in ihrer aktiven, phosphorylierten Form (pAkt) vor. pAkt führt nun über einen in dieser Arbeit nicht überprüften Mechanismus zur Aktivierung von HSF-1, erkennbar an dessen S326-Phosphorylierung. Eines der Hauptziele der Signalkinase Akt ist die Kinase mammalian target of rapamycin (mTOR). Chou et al. beschrieben mTOR in HeLaZellen als „essentiell für die (...) HSF-1-Aktivierung“ (Titel der Arbeit) und als die Kinase, die eben jenen S326-Rest phosphoryliert (Chou et al. 2012). Die S326Phosphorylierung führt zu Änderungen der Expression von HSF-1-regulierten Genen, unter anderem werden HSP-Gene transkribiert. Die HSP, insbesondere Hsp90, wiederum stabilisieren ihre Klienten, neben HSF-1 auch viele Onkoproteine, hier exemplarisch MIF, mutiertes p53 und den ErbB2-Rezeptor. Eine weitreichende Auflistung von Hsp90-Interaktoren liefert Picard (Picard 2013).

In Abbildung 10 B soll die Situation unter einer ErbB2-Inhibitorbehandlung (z.B. CP724.714) bildlich verdeutlicht werden: Die Behandlung verhindert die Aktivierung des stromabwärts des ErbB2-Rezeptors liegenden PI3K-Akt-Signalweges. Dadurch kommt es zu keiner S326-Phosphorylierung von HSF-1, es sinkt die Transkriptionsrate der HSP-Gene und anderer positiv HSF-1-regulierter Gene. Zugleich steigt die Transkriptionsrate HSF-1-reprimierter Gene. Der sinkenden HSP-Gen-Transkription folgt ein Absinken der zellulären HSP-Level und folglich kommt es zu einer Destabilisierung der HSP-Klienten, deren Proteinlevel somit ebenfalls sinken. 
A

ErbB2-überxprimierende Tumorzelle

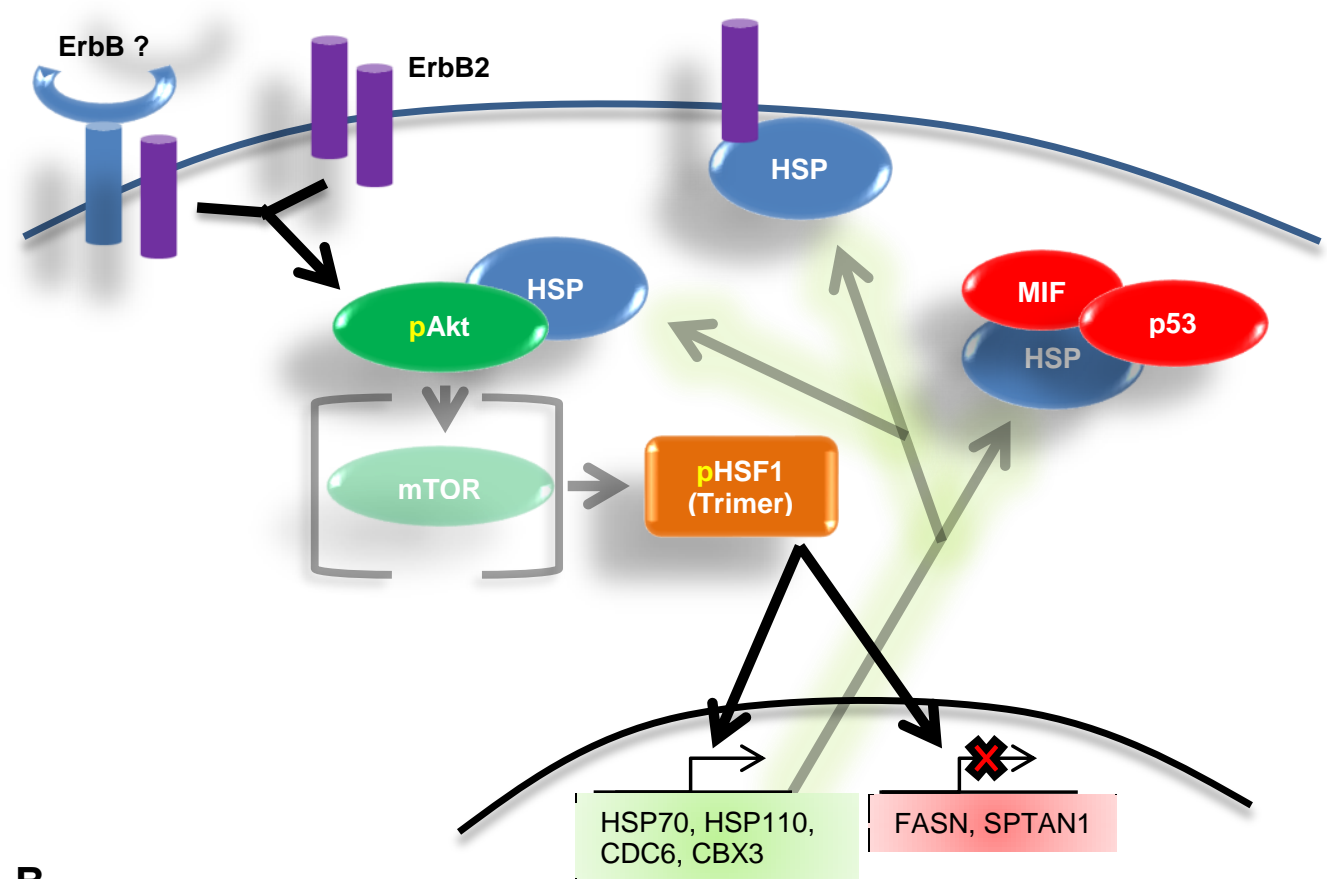

B

...unter einer ErbB2-Inhibition

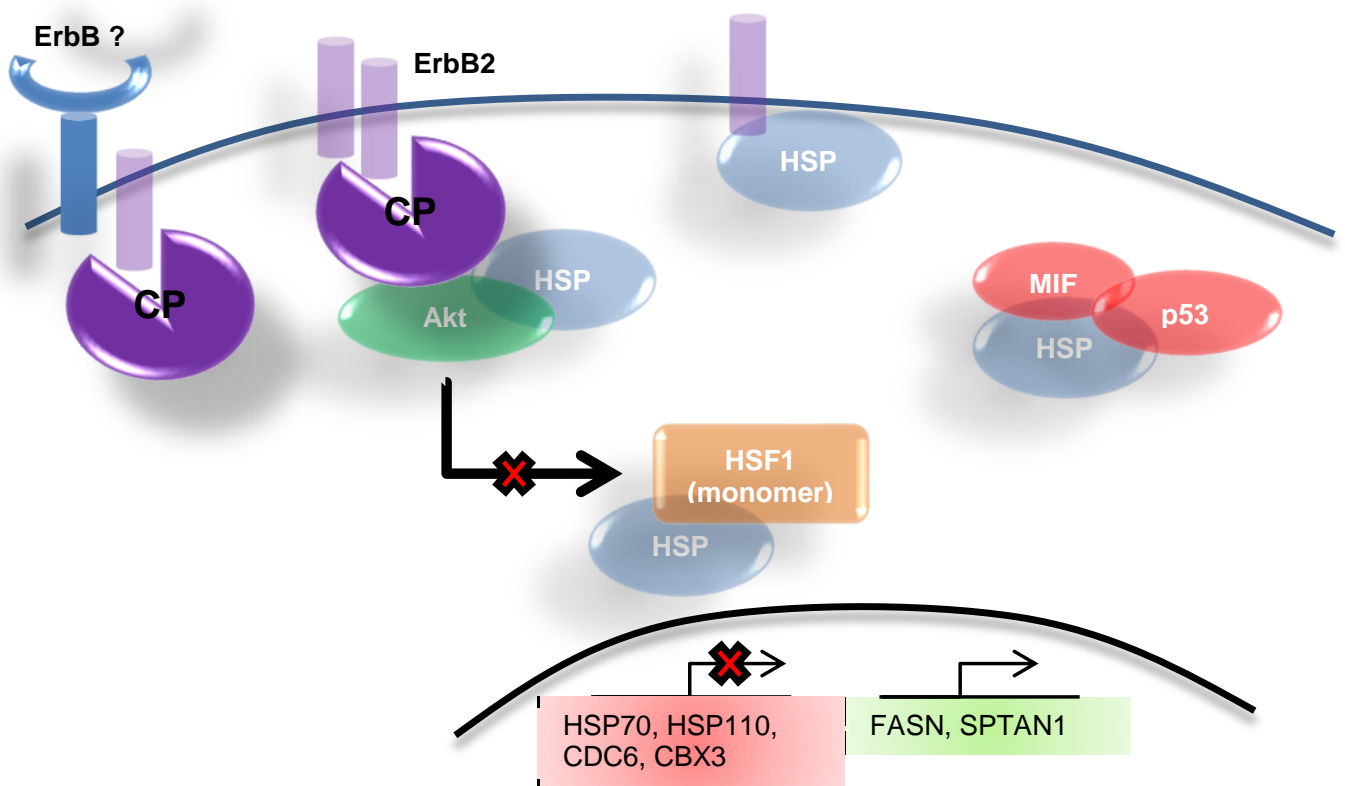

Abbildung 10: Hypothesen zur Interaktion von ErbB2, HSF-1 und seinen Zielgenen sowie den HSP in einer ErbB2-überexprimierenden Tumorzelle.

(A) Hoch aktive ErbB2-Akt-HSF-1-Achse, aktive Transkriptionsregulierung durch HSF-1, aktive Stabilisierung von Hsp90-Klienten (B) Inhibition der ErbB2-AktHSF-1-Achse z.B. durch CP724.714, Destabilisierung von Hsp90-Klienten. 


\subsection{Ausblick}

\subsubsection{Die fehlende Verbindung zwischen Akt und HSF-1}

In der Literatur findet sich eine Vielzahl von Forschungsergebnissen über posttranslationale Modifikationen des Transkriptionsfaktors HSF-1 wie Phosphorylierung, Sumoylierung und Acetylierung. Den wenigsten konnte bisher eine eindeutige Rolle bei der Regulation der Funktion von HSF-1 zugeordnet werden (Anckar und Sistonen 2011). Die Mutationsanalyse der 12 gefundenen Serinreste, die nach einem Hitzeschock phosphoryliert vorgefunden werden, zeigte, dass mit Ausnahme von S326 kein anderer Serinrest für die Funktionalität von HSF-1 essentiell ist (Guettouche et al. 2005). S326-Phosphorylierung gilt somit als die am effizientesten stimulatorisch wirkende bekannte Modifizierung an HSF-1. In Übereinstimmung mit diesen Ergebnissen konnte in dieser Arbeit gezeigt werden, dass die durch eine ErbB2Inhibition vermittelte Verringerung der S326-Phosphorylierung mit einer gesenkten HSF-1 Aktivierung einhergeht (Abb. 6 und 7, S. 34f). Chou et al. beschrieben mTOR als die für diese Phosphorylierung verantwortliche Kinase in HeLa-Zellen (Chou et al. 2012). Neuere, auf der vorliegenden Arbeit aufbauende Ergebnisse unserer Arbeitsgruppe konnten dies in ErbB2-überexprimierenden Brustkrebszellen bestätigen. Eine mTOR-Inhibition mit Rapamycin führte genau wie die ErbB2- und die AktInhibition zu erniedrigter HSF-1Aktivierung, einer Inhibition der HSP-Maschinerie und einer Destabilisierung des Hsp90-Klienten MIF (Schulz et al. 2014). Die beschriebene ErbB2-Akt-Achse konnte somit also um einen weiteren Schritt stromabwärts vervollständigt werden zur ErbB2-Akt-mTOR-HSF-1-Achse (Abb. 10 A).

\subsubsection{Das HSF-1 Transkriptionsprogramm}

Für die qPCR-Analysen der Transkriptionsraten HSF-1-regulierter Gene wurden in dieser Arbeit Gene aus zwei Gruppen gewählt: Als Vertreter der klassischen Hitzeschockproteine die Gene für Hsp70 und Hsp110 und vier der von Mendillo et al. beschriebenen Gene, die nur in Tumorzellen HSF-1-reguliert sind (Mendillo et al. 2012). Die induzierbare Form von Hsp90, Hsp90- $\alpha$ (Gen HSP90AA1), ist ebenfalls untersucht worden (Daten hier nicht gezeigt), da Hsp90 zusammen mit Hsp70 wohl funktionell das bedeutendste HSP darstellt (Taipale et al. 2010; Tavaria et al. 1996). Die daraus gewonnenen Ergebnisse waren allerdings wenig einheitlich. Dem lag, wie sich retrospektiv zeigte, ein Problem mit dem Primer für die qPCR zugrunde, der auch die konstitutiv exprimierte Form von Hsp90 miterfasste. Versuche aus unserer Arbeitsgruppe mit spezifischen Hsp90- $\alpha$-Primern lieferten Ergebnisse, die sich mit den hier beschriebenen Beobachtungen für Hsp70 und Hsp110 decken (Schulz et al. 2014). 
Für Hsp110 zeigten wir, dass die Hochregulierung der Genexpression durch einen Hitzeschock, anders als bei den tumorspezifisch-HSF-1-kontrollierten Genen, durch CP724.714-Behandlung nicht unterbunden werden kann (Abb. 9 A, S. 41). Dies kann als Indiz dafür verstanden werden, dass weitere Aktivierungsmechanismen von HSF-1 oder die wenig untersuchten Isoformen HSF-2/3/4 für die Regulation der HSP-Genexpression eine Rolle spielen, die bei den tumorzellspezifischen Genen von untergeordneter Bedeutung sind.

\subsubsection{ErbB2, HSF-1 und Brustkrebs - Implikationen für neue Thera- pieansätze}

Die hier vorgestellten Ergebnisse sind gänzlich aus Zellkulturexperimenten, also in vitro gewonnen worden. Es ist unabdingbar, deren Richtigkeit und Relevanz in zukünftigen Arbeiten auch in weiteren Zellinien sowie in vivo, z.B. im Mausmodell, zu bestätigen. Erfreulicherweise ist dies unserer Arbeitsgruppe z.T. in Zusammenarbeit mit anderen, in Aufbau auf diese Arbeit, inzwischen auch gelungen. Die hier beschriebenen Ergebnisse auf Proteinebene (Abb. 3 bis Abb. 6, S. 27ff) konnten in zwei weiteren humanen sowie einer murinen, ErbB2-überexprimierenden Brustkrebszellinie bestätigt werden. Ferner wurden die Effekte auf Proteinebene dort auch durch siRNA-knockdown von ErbB2 und HSF-1 bestätigt. Besonders hervorzuheben sind die in vivo-Ergebnisse: Im Mausmodell des ErbB2-überexprimierenden Brustkrebses konnte das Tumorwachstum durch Behandlung mit dem EGF/ErbB2-Rezeptor-Inhibitor Lapatinib stark beeinträchtigt werden. Außerdem wurde in der Analyse der Tumorlysate im Western Blot die Inhibition der HSF-1Hsp90-MIF-Achse bestätigt. Zusätzlich zeigte die histopathologische Untersuchung einiger humaner, invasiver duktaler Mammakarzinome eine positive Korrelation zwischen der ErbB2-Expression und der Intensität der Serin 326-Phosphorylierung von HSF-1 (Schulz et al. 2014).

Neben der Publikation von Schulz et al. gibt es noch einige weitere Arbeiten, die bereits Daten geliefert haben, die die Ergebnisse der vorliegenden Dissertation stützen. Mir sind vier Arbeiten der letzten drei Jahre bekannt, die Hinweise darauf liefern, dass der ErbB2-Rezeptor und der Transkriptionsfaktor der Hitzeschockantwort HSF-1 bei der Entstehung, dem Wachstum, der Invasivität und der Metastasierung von Brustkrebs funktionell in Zusammenhang stehen, ohne dabei jedoch den genauen Mechanismus zu erklären. Meng und Gabai konnten zeigen, dass die neoplastische Transformation menschlicher epithelialer Brustdrüsenzellen (MCF10A), die mittels ErbB2-Überexpression herbeigeführt werden kann, durch knockout von HSF-1 verhindert wird (Meng et al. 2010). Außerdem zeigten sie im ErbB2- 
Brustkrebs-Mausmodell, dass HSF-1-knockout die Tumorentstehung in diesen Tieren stark verzögert. Zusätzlich wachsen diese Tumore langsamer und sind schlechter vaskularisiert, was sie auf die Supression des Transkriptionsfaktors HIF1a (vgl. Kapitel 1.3, S. 6) auf Translationsebene zurückführen konnten (Gabai et al. 2012). Zhao et al. haben in ihrer Arbeit zu trastuzumabresistenten Brustkrebszellen gezeigt, dass Trastuzumabbehandlung zur Inhibition der Glykolyse führt und dieser Effekt HSF-1 vermittelt ist. Sie konnten einer Herabregulierung der HSF-1-Level auf Proteinebene unter der Behandlung mit dem ErbB2-Antikörper beobachten (Zhao et al. 2011), was sich mit den Ergebnissen dieser Arbeit deckt (Abb. 5, S. 32). Xi et al. schließlich liefern weitere in vivo gewonnene Ergebnisse. Knockout von HSF-1 in Mäusen, die ErbB2 im Brustdrüsengewebe überexprimieren (Mäusestamm: FVB/N$\mathrm{Tg}(\mathrm{MMTVneu}) 202 \mathrm{Mul} / \mathrm{J}$ ), führt zu einer drastischen Abnahme der Anzahl an Tieren, die einen Tumor entwickeln verglichen mit HSF-1 wildtypischen Mäusen. Nach knapp eineinhalb Jahren hatte keines der HSF-1-knockout Tiere einen Tumor, allerdings schon $22 \%$ der HSF-1-wildtypischen Tiere. Über den gesamten Beobachtungszeitraum von über 2 Jahren entwickelte nur ein HSF-1-knockout Tier einen Tumor (7\%), aber $74 \%$ der HSF-1-Wildtypen (Xi et al. 2012). Schulz et al. konnten nun zeigen, dass eine ErbB2-Überexpression HSF-1 konstitutiv aktiviert. Dies stellt eine von vielen Möglichkeiten dar das Hsp90-System überzuaktivieren.

Auch Dai et al. aus der Arbeitsgruppe um Susan Lindquist konnten bereits 2007 für andere Krebsentitäten umfänglich zeigen, dass HSF-1-knockout in Mäusen tumorprotektiv wirkt. Im Mausmodell der chemisch induzierten Hautkrebsentstehung wurde durch knockout von HSF-1 die Gesamtanzahl an Tumoren gesenkt und die Latenz bis zum Tumorauftreten sowie das Gesamtüberleben drastisch verlängert. Ein deutlich verlängertes Gesamtüberleben hatten ebenfalls für die p53 R172H Mutation heterozygote Mäuse, die gleichzeitig den HSF-1 -/- Genotyp aufwiesen (medianes Überleben: HSF-1 +/+ 427 Tage versus HSF -/- >622 Tage) (Dai et al. 2007).

HSF-1 hat zwei für entartete Zellen essentielle Funktionen: Durch Aktivierung der Hitzeschockantwort unterstützt er die Krebszelle, indem er so einen Kompensationsmechanismus für die kumulierenden fehlgefalteten Proteine, die aufgrund des erhöhten zytotoxischen Stresses in Tumorzellen entstehen, liefert (Dai et al. 2007; Whitesell und Lindquist 2009). Außerdem steuert HSF-1 in Tumorzellen ein onkogenes Transkriptionsprogramm, das Bezüge zur Regulation des Zellüberleben und Wachstum aufweist (Mendillo et al. 2012). 
Das direkte Zusammenspiel zwischen der Überexpression des ErbB2-Rezeptors, HSF-1 und Hitzeschockproteinen in SK-BR-3-Zellen konnte in dieser Arbeit überzeugend gezeigt werden. Zusammengenommen mit den beschriebenen in vivoDaten aus den Mausmodellen spricht vieles dafür, dass dieser Zusammenhang für die ErbB2-abhängige Brustkrebserkrankung auch funktionell von großer Bedeutung ist und damit einen potentiellen Therapieangriffspunkt liefert: den gleichzeitigen Einsatz von ErbB2-Inhibitor oder -Antikörper und Inhibitoren von HSF-1 (bislang noch nicht bereit für den klinischen Gebrauch) (Whitesell und Lindquist 2009) oder Hitzeschockproteinen. Beim trastuzumabrefraktärem Brustkrebs beispielsweise ist der Hsp90-Inhibitor Tanspimycin (17-AAG) im Rahmen einer Phase II-Studie bereits erfolgreich in Kombination mit Trastuzumab eingesetzt worden (Modi et al. 2011). Daher ist, gerade im Hinblick auf primäre und sekundäre Resistenzen gegen die ErbB2-Antikörperbehandlung, die Nutzung eines weiteren Angriffspunktes in der in dieser Arbeit erstmalig beschriebenen ErbB2-Akt-HSF-1-HSP-Achse eine vielversprechende zusätzliche Therapieoption. 


\section{Zusammenfassung}

Her2-positiver Brustkrebs, der Subtyp des Mammakarzinoms, bei dem eine Überexpression des epidermalen Wachstumsfaktor-Rezeptors-2 (ErbB2/Her2) vorliegt, hat für die betroffenen Frauen eine besonders schlechte Prognose. Eine positive Korrelation zwischen der ErbB2-Expression in Brusttumoren und der Expression des Makrophagen-Migration-inhibierenden Faktors (MIF), einem inzwischen gut bekannten tumorfördernden Protein, konnte bereits gezeigt werden. Ferner konnte gezeigt werden, dass MIF durch das Hitzeschockprotein 90 (Hsp90) in einem Mausmodell des Her2-positiven Brustkrebses stabilisiert wird. Der zugrundeliegende Mechanismus war bisher unverstanden.

In dieser Doktorarbeit konnte erstmalig demonstriert werden, dass Hitzeschockfaktor-1 (HSF-1), der Transkriptionsfaktor der stressinduzierten Hitzeschockproteine (HSP), einschließlich Hsp90, in ErbB2-überexprimierenden SK-BR-3Brustkrebszellen konstitutiv durch ErbB2 aktiviert wird. Durch eine Behandlung mit dem ErbB2-Inhibitor CP724.714 konnte die aktivierende Serin326-Phosphorylierung von HSF-1 verhindert werden. Als Folge wird, wie durch Western-Blot-Analysen gezeigt, die HSP-Maschinerie inhibiert und tumorfördernde Hsp90-Klienten wie MIF, Akt, mutiertes p53, ErbB2 und HSF-1 destabilisiert. Außerdem konnte die unterbleibende HSF-1-Aktivierung durch quantitative PCR-Analysen und Immunfluoreszenzmikroskopie bestätigt werden. Die mechanistischen Untersuchungen konnten die hier erstmalig beschriebene ErbB2-Akt-HSF-1-Achse aufdecken, über die HSF-1 in SK-BR-3-Zellen reguliert wird. Ferner konnte eine ErbB2-Inhibition sogar die HSF-1-Aktivierung durch einen Hitzeschock unterbinden.

Unsere Ergebnisse zeigen zum ersten Mal, dass die ErbB-2-Überexpression in SKBR-3-Zellen eine konstitutive HSF-1-Aktivierung bewirkt, mit der Folge, dass tumorfördernde Hsp90-Klienten wie MIF, HSF-1 selbst, ErbB2 und mutiertes p53 stabilisiert werden. Die neu entdeckte ErbB2-Akt-HSF-1-Hsp90-Klienten-Achse legt möglicherweise neue Angriffspunkte für zusätzliche Pharmaka bei der Therapie Her2positiven Brustkrebses offen. 


\section{Literaturverzeichnis}

Alimandi M, Romano A, Curia MC, Muraro R, Fedi P, Aaronson SA, Di Fiore PP, Kraus MH (1995): Cooperative signaling of ErbB3 and ErbB2 in neoplastic transformation and human mammary carcinomas. Oncogene $\underline{10}$, 1813-1821

Anckar J, Sistonen L (2011): Regulation of H SF 1 Function in the Heat Stress Response: Implications in Aging and Disease. Annu Rev Biochem 80, 1089-1115

Basso AD (2002): Akt Forms an Intracellular Complex with Heat Shock Protein 90 (Hsp90) and Cdc37 and Is Destabilized by Inhibitors of Hsp90 Function. J Biol Chem 277, 39858-39866

Biamonti G (2004): Opinion: Nuclear stress bodies: a heterochromatin affair? Nat Rev Mol Cell Biol $\underline{5}, 493-498$

Calandra T, Roger T (2003): Macrophage migration inhibitory factor: a regulator of innate immunity. Nat Rev Immunol $\underline{3}, 791-800$

Caldas-Lopes E, Cerchietti L, Ahn JH, Clement CC, Robles Al, Rodina A, Moulick K, Taldone T, Gozman A, Guo Y et al. (2009): Hsp90 inhibitor PU-H71, a multimodal inhibitor of malignancy, induces complete responses in triple-negative breast cancer models. Proc Natl Acad Sci USA 106, 8368-8373

Calderwood SK, Gong J (2012): Molecular chaperones in mammary cancer growth and breast tumor therapy. J Cell Biochem 113, 1096-1103

Choi J, Jung W, Koo JS (2013): Metabolism-related proteins are differentially expressed according to the molecular subtype of invasive breast cancer defined by surrogate immunohistochemistry. Pathobiology $\underline{80}, 41-52$

Chomczynski P (1993): A reagent for the single-step simultaneous isolation of RNA, DNA and proteins from cell and tissue samples. BioTechniques $\underline{15}, 532-4,536-7$

Chou S, Prince T, Gong J, Calderwood SK, Sherman M (2012): mTOR Is Essential for the Proteotoxic Stress Response, HSF1 Activation and Heat Shock Protein Synthesis. PLoS ONE $\underline{7}$, e39679

Conroy H, Mawhinney L, Donnelly SC (2010): Inflammation and cancer: macrophage migration inhibitory factor (MIF)--the potential missing link. QJM $\underline{103}$, 831836

Dai C, Whitesell L, Rogers AB, Lindquist S (2007): Heat shock factor 1 is a powerful multifaceted modifier of carcinogenesis. Cell $\underline{130}, 1005-1018$ 
Di Fiore P, Pierce J, Kraus M, Segatto O, King C, Aaronson S (1987): erbB-2 is a potent oncogene when overexpressed in NIH/3T3 cells. Science 237, 178-182

Eccles SA (2011): The epidermal growth factor receptor/Erb-B/HER family in normal and malignant breast biology. Int J Dev Biol 55, 685-696

Europäische Arzeneimittelagentur: Herceptin EPAR - Product Information 2012

Feng B, Xu JJ, Bi Y, Mireles R, Davidson R, Duignan DB, Campbell S, Kostrubsky VE, Dunn MC, Smith AR et al. (2009): Role of Hepatic Transporters in the Disposition and Hepatotoxicity of a HER2 Tyrosine Kinase Inhibitor CP-724,714. Tox Sci $\underline{108}, 492-500$

Gabai VL, Meng L, Kim G, Mills TA, Benjamin IJ, Sherman MY (2012): Heat Shock Transcription Factor Hsf1 Is Involved in Tumor Progression via Regulation of Hypoxia-Inducible Factor 1 and RNA-Binding Protein HuR. Mol Cell Biol 32, 929-940

Goldhirsch A, Wood WC, Gelber RD, Coates AS, Thurlimann B, Senn H (2007): Progress and promise: highlights of the international expert consensus on the primary therapy of early breast cancer 2007 . Ann Oncol $\underline{18}, 1133-1144$

Guettouche T, Boellmann F, Lane WS, Voellmy R (2005): Analysis of phosphorylation of human heat shock factor 1 in cells experiencing a stress. BMC Biochem $\underline{6}, 4$ Hudis CA (2007): Trastuzumab - Mechanism of Action and Use in Clinical Practice. N Engl J Med 357, 39-51

Isaacs JS (2002): Hsp90 Regulates a von Hippel Lindau-independent Hypoxiainducible Factor-1alpha -degradative Pathway. J Biol Chem 277, 29936-29944

Jani JP, Finn RS, Campbell M, Coleman KG, Connell RD, Currier N, Emerson EO, Floyd E, Harriman S, Kath JC et al. (2007): Discovery and Pharmacologic Characterization of CP-724,714, a Selective ErbB2 Tyrosine Kinase Inhibitor. Canc Res $\underline{67}$, 9887-9893

Kaatsch P, Spix C, Katalinic A, Hentschel S, Krebsinformationsdienst M, Baras N, Barnes B, Bertz J, Dahm S, Haberland J et al.: Krebs in Deutschland 2007/2008: Eine gemeinsame Veröffentlichung des Robert Koch-Instituts und der Gesellschaft der epidemiologischen Krebsregister in Deutschland e. V. Broschüre, 8. Auflage 2012

Kamal A, Thao L, Sensintaffar J, Zhang L, Boehm MF, Fritz LC, Burrows FJ (2003): A high-affinity conformation of Hsp90 confers tumour selectivity on Hsp90 inhibitors. Nature $\underline{425}, 407-410$ 
LAEMMLI UK (1970): Cleavage of Structural Proteins during the Assembly of the Head of Bacteriophage T4. Nature 227, 680-685

Larson DF, Horak K (2006): Macrophage migration inhibitory factor: controller of systemic inflammation. Crit Care $\underline{10}, 138$

Li D, Marchenko ND, Moll UM (2011): SAHA shows preferential cytotoxicity in mutant p53 cancer cells by destabilizing mutant p53 through inhibition of the HDAC6Hsp90 chaperone axis. Cell Death Differ 18, 1904-1913

Lindquist S (1986): The heat-shock response. Annu Rev Biochem 55, 1151-1191

Liu J, Smith CL, DeRyckere D, DeAngelis K, Martin GS, Berger JM (2000): Structure and function of Cdc6/Cdc18: implications for origin recognition and checkpoint control. Mol Cell $\underline{6}, 637-648$

Lue H, Kapurniotu A, Fingerle-Rowson G, Roger T, Leng L, Thiele M, Calandra T, Bucala R, Bernhagen J (2006): Rapid and transient activation of the ERK MAPK signalling pathway by macrophage migration inhibitory factor (MIF) and dependence on JAB1/CSN5 and Src kinase activity. Cell Signal $\underline{18}, 688-703$

Lue H, Thiele M, Franz J, Dahl E, Speckgens S, Leng L, Fingerle-Rowson G, Bucala R, Lüscher B, Bernhagen J (2007): Macrophage migration inhibitory factor (MIF) promotes cell survival by activation of the Akt pathway and role for CSN5/JAB1 in the control of autocrine MIF activity. Oncogene 26, 5046-5059

Maio A, Santoro MG, Tanguay RM, Hightower LE (2012): Ferruccio Ritossa's scientific legacy 50 years after his discovery of the heat shock response: a new view of biology, a new society, and a new journal. Cell Stress Chaperon 17, 139-143

Mariani G (2005): Breast cancer: New developments in the treatment of metastatic breast cancer: from chemotherapy to biological therapy. Ann Oncol 16, ii191

McMillan DR (1998): Targeted Disruption of Heat Shock Transcription Factor 1 Abolishes Thermotolerance and Protection against Heat-inducible Apoptosis. J Biol Chem 273, 7523-7528

Mendillo ML, Santagata S, Koeva M, Bell GW, Hu R, Tamimi RM, Fraenkel E, Ince TA, Whitesell L, Lindquist S (2012): HSF1 Drives a Transcriptional Program Distinct from Heat Shock to Support Highly Malignant Human Cancers. Cell 150, 549-562

Meng L, Gabai VL, Sherman MY (2010): Heat-shock transcription factor HSF1 has a critical role in human epidermal growth factor receptor-2-induced cellular transformation and tumorigenesis. Oncogene $\underline{29}, 5204-5213$ 
Modi S, Stopeck A, Linden H, Solit D, Chandarlapaty S, Rosen N, D'Andrea G, Dickler M, Moynahan ME, Sugarman S et al. (2011): HSP90 Inhibition Is Effective in Breast Cancer: A Phase II Trial of Tanespimycin (17-AAG) Plus Trastuzumab in Patients with HER2-Positive Metastatic Breast Cancer Progressing on Trastuzumab. Clin Cancer Res 17, 5132-5139

Moon RT, McMahon AP (1990): Generation of diversity in nonerythroid spectrins. Multiple polypeptides are predicted by sequence analysis of cDNAs encompassing the coding region of human nonerythroid alpha-spectrin. J Biol Chem $\underline{265}$, 44274433

Münster PN, Marchion DC, Basso AD, Rosen N (2002): Degradation of HER2 by ansamycins induces growth arrest and apoptosis in cells with HER2 overexpression via a HER3, phosphatidylinositol 3'-kinase-AKT-dependent pathway. Cancer Res $\underline{62}, 3132-3137$

Nahta R, Yu D, Hung M, Hortobagyi GN, Esteva FJ (2006): Mechanisms of Disease: understanding resistance to HER2-targeted therapy in human breast cancer. Nat Clin Prac Oncol $\underline{3}, 269-280$

Picard (2013): HSP90 interactors.

http://www.picard.ch/downloads/Hsp90interactors.pdf

Ravandi-Kashani F, Hayes TG (1998): Male breast cancer: a review of the literature. Eur J Cancer $\underline{34}, 1341-1347$

Reddy JC, Reimann JD, Anderson SM, Klein PM (2006): Concordance between central and local laboratory HER2 testing from a community-based clinical study. Clin Breast Cancer $\underline{7}, 153-157$

Rendon BE, Willer SS, Zundel W, Mitchell RA (2009): Mechanisms of macrophage migration inhibitory factor (MIF)-dependent tumor microenvironmental adaptation. Exp Mol Pathol $\underline{86}, 180-185$

Santagata S, Hu R, Lin NU, Mendillo ML, Collins LC, Hankinson SE, Schnitt SJ, Whitesell L, Tamimi RM, Lindquist $S$ et al. (2011): High levels of nuclear heat-shock factor 1 (HSF1) are associated with poor prognosis in breast cancer. Proc Natl Acad Sci USA $\underline{108}, 18378-18383$

Sarge KD, Murphy SP, Morimoto RI (1993): Activation of heat shock gene transcription by heat shock factor 1 involves oligomerization, acquisition of DNA-binding activity, and nuclear localization and can occur in the absence of stress. Mol Cell Biol $\underline{13}, 1392-1407$ 
Schulz R, Marchenko ND, Holembowski L, Fingerle-Rowson G, Pesic M, Zender L, Dobbelstein M, Moll UM (2012): Inhibiting the HSP90 chaperone destabilizes macrophage migration inhibitory factor and thereby inhibits breast tumor progression. $\mathrm{J}$ Exp Med 209, 275-289

Schulz R, Streller F, Scheel AH, Rüschoff J, Reinert M, Dobbelstein M, Marchenko ND, Moll UM (2014): HER2/ErbB2 activates HSF1 and thereby controls HSP90 clients including MIF in HER2-overexpressing breast cancer. Cell Death Dis $\underline{5}$, e980

Slamon D, Clark G, Wong S, Levin W, Ullrich A, McGuire W (1987): Human breast cancer: correlation of relapse and survival with amplification of the HER-2/neu oncogene. Science $\underline{235}, 177-182$

Slamon DJ, Leyland-Jones B, Shak S, Fuchs H, Paton V, Bajamonde A, Fleming T, Eiermann W, Wolter J, Pegram M et al. (2001): Use of Chemotherapy plus a Monoclonal Antibody against HER2 for Metastatic Breast Cancer That Overexpresses HER2. N Engl J Med 344, 783-792

Sobin LH, Gospodarowicz MK, Wittekind C: TNM classification of malignant tumours, 7th ed; Wiley-Blackwell, Chichester, West Sussex, UK, Hoboken, NJ 2010

Taipale M, Jarosz DF, Lindquist S (2010): HSP90 at the hub of protein homeostasis: emerging mechanistic insights. Nat Rev Mol Cell Biol 11, 515-528

Tavaria M, Gabriele T, Kola I, Anderson RL (1996): A hitchhiker's guide to the human Hsp70 family. Cell Stress Chaperon $\underline{1}, 23-28$

Trepel J, Mollapour M, Giaccone G, Neckers L (2010): Targeting the dynamic HSP90 complex in cancer. Nat Rev Cancer 10, 537-549

Vu T, Claret FX (2012): Trastuzumab: Updated Mechanisms of Action and Resistance in Breast Cancer. Front Oncol $\underline{2}$

Whitesell L, Lindquist S (2009): Inhibiting the transcription factor HSF1 as an anticancer strategy. Expert Opin Ther Targets $\underline{13}$, 469-478

Whitesell L, Lindquist SL (2005): HSP90 and the chaperoning of cancer. Nat Rev Cancer $\underline{5}, 761-772$

Witkowski A, Rangan VS, Randhawa ZI, Amy CM, Smith S (1991): Structural organization of the multifunctional animal fatty-acid synthase. Eur J Biochem $\underline{198}, 571-$ 579

Wolff AC, Hammond MEH, Schwartz JN, Hagerty KL, Allred DC, Cote RJ, Dowsett M, Fitzgibbons PL, Hanna WM, Langer A et al. (2006): American Society of Clinical Oncology/College of American Pathologists Guideline Recommendations for Human 
Epidermal Growth Factor Receptor 2 Testing in Breast Cancer. J Clin Oncol 25, 118-145

Xi C, Hu Y, Buckhaults P, Moskophidis D, Mivechi NF (2012): Heat Shock Factor Hsf1 Cooperates with ErbB2 (Her2/Neu) Protein to Promote Mammary Tumorigenesis and Metastasis. J Biol Chem 287, 35646-35657

Xia W, Mullin RJ, Keith BR, Liu L, Ma H, Rusnak DW, Owens G, Alligood KJ, Spector NL (2002): Anti-tumor activity of GW572016: a dual tyrosine kinase inhibitor blocks EGF activation of EGFR/erbB2 and downstream Erk1/2 and AKT pathways. Oncogene 21, 6255-6263

Xu X, Wang B, Ye C, Yao C, Lin Y, Huang X, Zhang Y, Wang S (2008): Overexpression of macrophage migration inhibitory factor induces angiogenesis in human breast cancer. Cancer Lett $\underline{261}, 147-157$

Yarden Y, Pines G (2012): The ERBB network: at last, cancer therapy meets systems biology. Nat Rev Cancer $\underline{12}, 553-563$

Ye Q, Worman HJ (1996): Interaction between an integral protein of the nuclear envelope inner membrane and human chromodomain proteins homologous to Drosophila HP1. J Biol Chem 271, 14653-14656

Zhao Y, Liu H, Liu Z, Ding Y, LeDoux SP, Wilson GL, Voellmy R, Lin Y, Lin W, Nahta $R$ et al. (2011): Overcoming Trastuzumab Resistance in Breast Cancer by Targeting Dysregulated Glucose Metabolism. Cancer Res $\underline{71}$, 4585-4597 


\section{Danksagung}

Mein Dank gilt in erster Linie Dr. Ramona Schulz, für die exzellente Betreuung während meiner Zeit im Labor und auch danach, bei der Anfertigung dieser Dissertation. Ebenso möchte ich meinem Doktorvater, Prof. Dr. Matthias Dobbelstein, für die Möglichkeit danken, in seiner Abteilung dieses interessante Projekt bearbeiten zu dürfen. Außerdem für die vielen Gespräche, in denen er mir zielführende Denkanstöße geben konnte.

Ich möchte allen Teammitgliedern der Molekularen Onkologie für die Wärme danken, mit der ich dort empfangen und integriert wurde.

Ferner danke ich für die Förderung durch die Universitätsmedizin Göttingen (UMG) im Rahmen des Jacob-Henle-Programms - ohne diese wäre diese Dissertation nicht zustande gekommen. 


\section{Lebenslauf}

Mein Name ist Felix Streller und ich wohne im Albrecht-Thaer-Weg 24 h 01 in 37075 Göttingen. Ich wurde am 30.04.1989 in Berlin-Steglitz als Sohn der Ärzte Dr. Angelika Pape-Streller und Dr. Andreas Streller geboren.

1995 wurde ich in der Grundschule am Harrl in Bückeburg eingeschult und besuchte dort die erste bis vierte Klasse. Anschließend besuchte ich die Orientierungsstufe Bückeburg und nach vorzeitiger Versetzung in die siebte Klasse schließlich das Gymnasium Adolfinum in Bückeburg. Dort erlangte ich im Jahr 2007 die Allgemeine Hochschulreife mit einer Durchschnittsnote von 1,5.

Zunächst begann ich im September 2007 ein Physikstudium an der Technischen Universität München, welches ich jedoch bereits nach 3 Monaten abbrach. Bis zur Aufnahme meines Medizinstudiums an der Georg-August-Universität Göttingen im April 2008 leistete ich ein dreimonatiges Krankenpflegepraktikum in der Allgemeinchirurgischen Abteilung des Krankenhaus Bethel in Bückeburg ab. Den Ersten Abschnitt der Ärztlichen Prüfung schloss ich 2010 erfolgreich mit der Note 2,0 (89,0 $\%$ ) ab. Es folgten eine Famulatur wieder in der Viszeralchirurgie in Bückeburg sowie in einer psychiatrischen Klinik (Burghofklinik) in Rinteln.

Im September 2011 wurde ich als Stipendiat im Jacob-Henle-Programm für experimentelle Medizin der Universitätsmedizin Göttingen (UMG) aufgenommen und unterbrach das Medizinstudium für zwei Semester. Im Rahmen dieses Programms nahm ich auch meine Arbeit an einer Dissertation in der Abteilung für Molekulare Onkologie auf.

Im Verlauf des Medizinstudiums konnte ich im Rahmen von weiteren Famulaturen im Jahr 2013 neue Einblicke in die Bereiche Allgemeinmedizin (Dr. Streller, Bückeburg), Anästhesie (Krankenhaus Bethel, Bückeburg; Dagkirurgisk senter, Førde, Norwegen) und Kinder- und Jugendpsychiatrie (UMG) erlangen. Den Zweiten Abschnitt der Ärztlichen Prüfung schloss ich im April 2014 mit der Note 2,0 (89,6\%) ebenfalls erfolgreich ab.

Am 16.08.2014 heiratete ich Frau Berit Hesjedal, jetzt Hesjedal-Streller, auf dem Standesamt in Nörten-Hardenberg.

Nach Absolvieren des Praktischen Jahres mit Wahltertial Allgemeinmedizin (Praxis Lang, Göttingen) sowie Abschluss des Dritten Abschnitts der Ärztlichen Prüfung, voraussichtlich Mitte 2015, visiere ich eine Weiterbildung zum Facharzt der Allgemeinmedizin an. 